\title{
Drug Discovery Targeting Amino Acid Racemases
}

Paola Conti, ${ }^{,}$Lucia Tamborini, ${ }^{a}$ Andrea Pinto, ${ }^{a}$ Arnaud Blondel,,${ }^{b}$ Paola Minoprio,

Andrea Mozzarelli and Carlo De Michelia

'Dipartimento di Scienze Farmaceutiche 'P. Pratesi', via Mangiagalli 25, 20133 Milano, Italy;

Unité de Bioinformatique Structurale, CNRS-URA 2185, Département de Biologie Structurale et Chimie, 25 rue du Dr. Roux, 75724 Paris, France.

Institut Pasteur, Laboratoire des Processus Infectieux à Trypanosoma; Départment d'Infection and Epidémiologie; 25 rue du Dr. Roux, 75724 Paris, France

¿Dipartimento di Biochimica e Biologia Molecolare, via G. P. Usberti 23/A, 43100 Parma, Italy

and

Istituto di Biostrutture e Biosistemi, viale Medaglie d'oro, Rome, Italy. RECEIVED DATE

Corresponding Author: Prof. Carlo De Micheli, Dipartimento di Scienze Farmaceutiche 'P. Pratesi', via Mangiagalli 25, 20133 Milano (Italy); tel. +39 02 50319330; FAX +39 02 50319326; e-mail: carlo.demicheli@unimi.it 


\section{TABLE OF CONTENTS}

1. Introduction

2. Classification and Catalytic Mechanisms of Racemases

2.1. PLP-dependent Amino Acid Racemases

2.2. PLP-independent Amino Acid Racemases

3. Amino Acid Racemases as Drug Targets.

3.1 PLP-dependent Racemases

3.1.1 Alanine Racemase

3.1.1.1 Localization, structure and function

3.1.1.2 Inhibitors and Drug perspectives

3.1.2 Serine Racemase

3.1.2.1 Localization, structure and function

3.1.2.2 Inhibitors and Drug perspectives

3.1.3 Arginine Racemase

3.1.3.1 Localization, structure and function

3.1.4 Aspartate Racemase

3.1.4.1 Localization, structure and function

3.2 PLP-independent Racemases

3.2.1 Proline Racemase

3.2.1.1 Localization, structure and function 


\subsubsection{Inhibitors and drug perspectives}

\subsubsection{Glutamate Racemase}

\subsubsection{Localization, structure and function}

\subsubsection{Inhibitors and drug perspectives}

\subsubsection{Aspartate Racemase}

\subsubsection{Localization, structure and function.}

\subsubsection{Diaminopimelate epimerase}

\subsubsection{Localization, structure and function.}

\subsubsection{Inhibitors and drug perpectives}

\section{Conclusions and Future Perspectives}

\section{Acronyms}

D-aspartate: D -Asp; L-aspartate: L-Asp; D-alanine: D-Ala; L-alanine: L-Ala; D-glutamate: D-Glu; Lglutamate: L-Glu; L-proline: L-Pro; D-proline: D-Pro; D-serine: D-Ser; L-serine: L-Ser; D-phenylalanine: D-Phe; L-phenylalanine: L-Phe; D-arginine: D-Arg; D-methionine: D-Met; D-tyrosine: D -Tyr

aspartate racemase: AspR; alanine racemase: AlaR; glutamate racemase: GluR; proline racemase: ProR; serine racemase: SerR; arginine racemase: ArgR; diaminopimelate epimerase: DAPE; aspartate transcarbamylase: ATC; D-amino acid oxidase: DAAO; Superoxide Dismutase 1: SOD 1; protein kinase $\mathrm{C}$ : PKC; phospholipase C: PLC; protein interacting with $\mathrm{C}$ kinase 1: PICK1; glutamate receptor interacting protein: GRIP; growth hormone: GH; luteinizing hormone: LH; luteinizing hormonereleasing hormone: $\mathrm{LHRH} ; \alpha$-melanocyte-stimulating hormone: $\alpha-\mathrm{MSH}$

(L)-1-aminoethylphosphonic acid: L-Ala-P; (1-aminomethy1)boronic acid: L-Ala-B; (L,L)-2,6diaminopimelic acid: DAP; pyrrole-2-carboxylic acid: PYC; $N$-methyl-D-aspartate: NMDA; 2-amino-3(5-methyl-3-oxo-1,2-oxazol-4-yl)propanoic acid: AMPA; pyridoxal-5'-phosphate: PLP; phosphatidylinositol-(4,5)-bisphosphate: PIP2; adenosine-5'-triphosphate: ATP; adenosine diphosphate: ADP; guanosine diphosphate: GDP; isothermal titration calorimetry: ITC

Trypanosoma cruzi: Tc; Clostridium sticklandii (Cs); Amyotrophic Lateral Sclerosis: ALS

\section{Introduction}


Amino acids are among the most important molecules in nature since they play central roles both as building blocks of proteins and as intermediates in metabolism. The amino acid sequence dictates protein folding, the native three dimensional structure, and protein stability. Furthermore, the peculiar chemical properties of the amino acids forming the active site and their interplay determine protein function and regulation.

All amino acids found in proteins, except glycine, possess a stereogenic center at the $\alpha$-carbon atom. Millions of years of evolution have resulted in the virtually complete homochirality of such a stereogenic center, i.e. the L-enantiomer, in mammals.' This selection of the L-amino acids by nature is generally considered to be a result of chance.

Since the cornerstone of the protein-ligand recognition is the multi-point attachment theory, it turns out that the configuration of the $\alpha$-carbon atom of amino acids strongly affects the protein-ligand interaction.

Nevertheless, during the last half of the twentieth century, various studies evidenced the presence of Damino acids in some plants and bacteria., These compounds were either found in a free state or in peptides and proteins. Most bacteria produce significant amounts of D-alanine (D-Ala) and D-glutamate (D-Glu), which are incorporated into peptidoglycan.s Peptidoglycan is a strong and elastic polymer of the bacterial wall, which is capable to counteract the osmotic pressure of the cell, maintaining cell shape and anchoring components of the cell envelope. ${ }^{6}$ The number of D-amino acids present in the structure of peptidoglycan seems to constitute a measure of protection against peptidase and protease attacks. So far, no peptidase capable of hydrolyzing a peptide bond characterized by the sequence D-D or D-L amino acids has been isolated in mammals. In addition, several antibiotics produced by prokaryotes (e.g. bacitracin, actinomycin D) contain D-amino acids (Figure 1). It has been recently demonstrated that bacteria synthesize a pool of different D-amino acids, including D-methionine (D-Met) and D-leucine (DLeu) in Vibrio cholerae and D-tyrosine (D-Tyr) and D-phenylalanine (D-Phe) in Bacillus subtilis. By selectively incorporating them in the peptidoglycan cell wall, bacteria cope to different environmental stresses.? 
The first reports on D-amino acids in animal tissues were restricted to amphibians and invertebrates. As a matter of fact, dermorphin (Figure 1) was the first D-amino acid-containing peptide isolated from the skin of a frog; it is provided with an analgesic activity a thousand times greater than that of morphine. ${ }^{.}$Worth noting, the replacement of D-Ala by its mirror image causes a sharp drop in activity indicating that D-Ala, located at position 2 of the amino acid sequence, is essential for its activity. Subsequently, D-amino acids have been detected in a variety of peptides synthesized by animal cells, including opioids (deltorphins) (Figure 1), neuropeptides (achatin and fulicin) (Figure 1) and a family of antimicrobial peptides named bombinins H. For example, a tetrapeptide, termed achatin I (Figure 1), containing a D-phenylalanine (D-Phe) at position 2, was isolated from the ganglia and atrium of the African giant snail Achatina fulica..$^{10}$ Also in this case the excitatory activity on the heart or other muscles is lost by replacing D-Phe with L-phenylalanine (L-Phe). 
<smiles>CC(NC(=O)[C@H](N)Cc1ccc(O)cc1)C(=O)N[C@@H](Cc1ccccc1)C(=O)NCC(=O)N[C@@H](Cc1ccc(O)cc1)C(=O)N1CCC[C@H]1C(=O)N[C@@H](CO)C(N)=O</smiles>

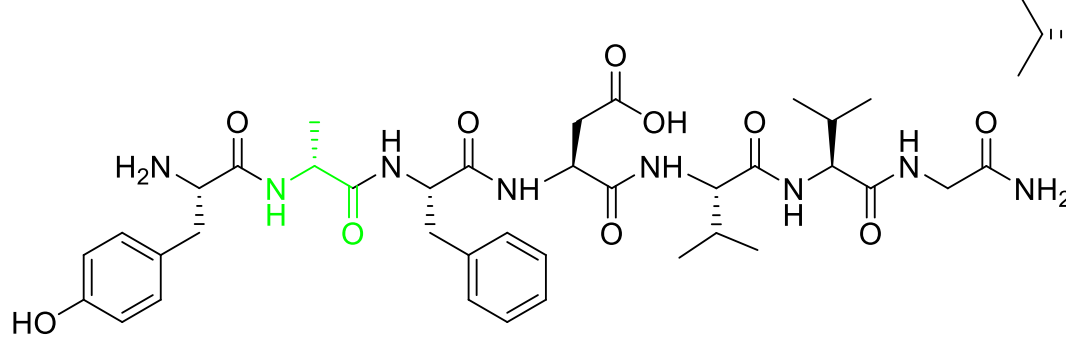

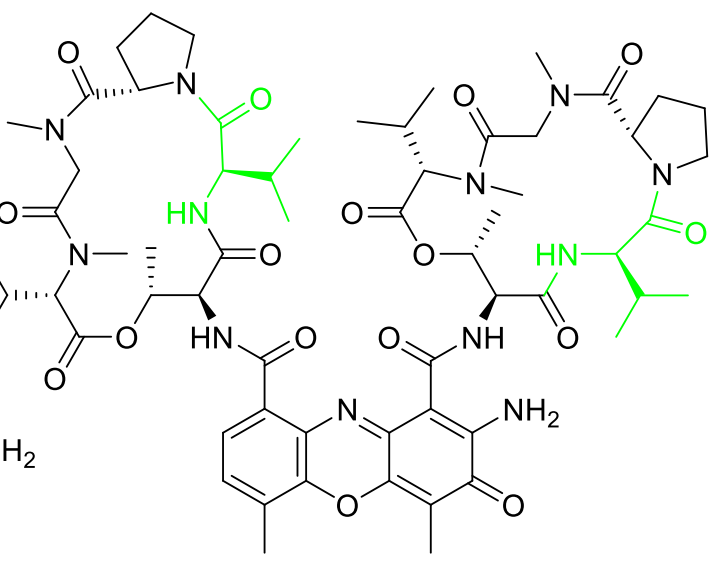

Deltorphin I

Actinomycin D<smiles>C[C@H](NC(=O)[C@H](Cc1ccccc1)NC(=O)CN)C(=O)N[C@@H](CC(=O)O)C(=O)O</smiles>

Achatin I<smiles>CC(C)[C@H](NC(=O)[C@H](Cc1ccccc1)NC(=O)[C@H](CCC(=O)O)NC(=O)[C@H](CC(N)=O)NC(=O)[C@H](N)Cc1ccccc1)C(N)=O</smiles>

Fulicin<smiles>CCC(N)=O</smiles><smiles>CCCNC(=O)[C@H](CC(C)C)NC(=O)C1CSC(C(I)C(C)C)=N1</smiles>
$\mathrm{O} \mathrm{OH}$<smiles>CCC(C)[C@H](NC(C)=O)C(N)=O</smiles><smiles>CCCCC(=O)N[C@@H](CC)C(=O)NC</smiles><smiles>CC[C@H](C)[C@H](NC(=O)CCCCN)C(=O)N[C@@H](Cc1ccccc1)C(=O)N[C@@H](Cc1c[nH]cn1)C(=O)N[C@@H](CC(=O)O)C(N)=O</smiles>

Bacitracin A

Figure 1

Recent developments of highly sensitive chromatographic techniques allowed the detection of low concentrations of free D-amino acids in mammals, including humans. The principal free D-amino acids found in significant amount in animal tissues are D-Ala, D-serine (D-Ser) and D-aspartate (D-Asp). In particular, D-Ser was detected predominantly in the mammalian brain. The specific biological function of these D-amino acids remained unknown for long time, in spite of the fact that in 1935 Krebs discovered the presence of a flavin-containing enzyme in mammals, the D-amino acid oxidase (DAAO), which catalyzes the oxidative deamination of D-amino acids to the corresponding $\alpha$-keto acids with 
high enantiospecificity." DAAO is an ubiquitous enzyme in eukaryotes, with a selective distribution that, in humans, includes kidney and cerebellum. The biological role of DAAO remained uncertain for a number of years. Since the presence of D-amino acids in mammalian tissues was initially attributed to the action of endogenous microbial flora, to ingestion with the diet or to spontaneous racemization of Lamino acids incorporated in polypeptides during aging, ${ }^{12}$ it was suggested that such an enzyme acts as a detoxifying agent to remove D-amino acids. The subsequent detection of substantial amounts of Damino acids in various human tissues and in the brain suggested the involvement of DAAO in modulating the level of D-amino acids. Moreover, it has been shown that the human brain contains endogenous D-Ser and D-Asp, which are likely to act as modulators of neurotransmission. ${ }^{13.14}$ Consequently, it has been hypothesized that DAAO may play a role in controlling the level of these neurotransmitters.

At present, the physiological significance of D-amino acids, i.e. D-Ser and D-Asp, is well-established. As a consequence, it is conceivable to admit the presence in the human body of a pathway, which involves specific enzymes, for the synthesis of such D-amino acids. These enzymes have been discovered, structurally characterized and termed racemases. The different racemases, which have been discovered in mammals and in bacteria, may differ considerably with respect to substrate specificity. For example, arginine racemase (ArgR) is mostly active with lysine, arginine and ornithine, and merely weakly active with alanine, whereas alanine racemase (AlaR) acts on alanine only.

In the following chapters we will discuss the classification of racemases, their diffusion, function, localization, structural features and the state of the art in the discovery of novel drugs targeting such enzymes for the treatment of different pathologies.

\section{Classification and Catalytic Mechanisms of Racemases}

The array of racemases can be divided in two classes on the basis of their mode of action: 1) pyridoxal 5'-phosphate-dependent amino acid racemases and 2) pyridoxal 5'-phosphate-independent racemases.

The first group of racemases depends on pyridoxal 5'-phosphate (PLP), the coenzyme representing the biologically active form of vitamin B6. Its members are exemplified by eukaryotic enzymes such as serine racemase (SerR), AlaR, and aspartate racemase (DR-), and by bacterial enzymes such as AlaR, 
SerR and ArgR (Table 1). The second group of racemases, which are cofactor-independent, includes aspartate racemase (AspR), glutamate racemase (GluR), proline racemase (ProR) as well as diaminopimelate epimerase (DAPE) (Table 2). These enzymes occur in bacteria and archaea, except for ProR that was found in eukaryotic Trypanosoma spp.

Table 1. PLP-dependent Amino Acid Racemases

\begin{tabular}{|c|c|c|}
\hline & Localization/function & Substrates \\
\hline $\begin{array}{l}\text { Alanine } \\
\text { Racemase }\end{array}$ & $\begin{array}{l}\text { Bacteria (peptidoglycan } \\
\text { synthesis) } \\
\text { Eukaryotes (biosynthesis of } \\
\text { D-aa containing peptides) }\end{array}$ & Ala \\
\hline $\begin{array}{l}\text { Serine } \\
\text { Racemase }\end{array}$ & $\begin{array}{l}\text { Bacteria (vancomycin } \\
\text { resistance) } \\
\text { Mammalian } \\
\text { (CNS/biosynthesis of the } \\
\text { neuromodulator D-Ser) }\end{array}$ & Ser \\
\hline $\begin{array}{l}\text { Arginine } \\
\text { Racemase }\end{array}$ & $\begin{array}{l}\text { Bacteria (catabolism of D- } \\
\text { Arg and D-Lys) }\end{array}$ & $\begin{array}{l}\text { Arg, Lys, } \\
\text { ornithine, } \\
\text { other basic } \\
\text { amino } \\
\text { acids }\end{array}$ \\
\hline $\begin{array}{l}\text { Aspartate } \\
\text { Racemase }\end{array}$ & $\begin{array}{l}\text { Ark shell (storage of D-Asp } \\
\text { as an energy source under } \\
\text { anaerobic condition). } \\
\text { Mammalian } \\
\text { biosynthesis of the } \\
\text { neurotransmitter D-Asp) }\end{array}$ & Asp \\
\hline
\end{tabular}

Table 2. PLP-independent Amino Acid Racemases 


\begin{tabular}{|c|c|c|}
\hline & Localization/function & Substrates \\
\hline $\begin{array}{l}\text { Proline } \\
\text { Racemase }\end{array}$ & $\begin{array}{l}\text { Bacteria (proline and } \\
\text { arginine metabolism) } \\
\text { Eukariotes (T.cruzi/T. } \\
\text { vivax, proline metabolism } \\
\text { and catabolism, B-cell } \\
\text { mitogen, parasite evasion } \\
\text { mechanisms) }\end{array}$ & Pro \\
\hline $\begin{array}{l}\text { Glutamat } \\
\text { e } \\
\text { Racemase }\end{array}$ & $\begin{array}{ll}\text { Bacteria } & \text { (peptidoglycan } \\
\text { synthesis) } & \end{array}$ & Glu \\
\hline $\begin{array}{l}\text { Aspartate } \\
\text { Racemase }\end{array}$ & $\begin{array}{ll}\text { Bacteria } & \text { (peptidoglycan } \\
\text { synthesis) } & \end{array}$ & Asp \\
\hline $\begin{array}{l}\text { Diamino- } \\
\text { pimelate } \\
\text { Epimeras } \\
\text { e }\end{array}$ & $\begin{array}{l}\text { Bacteria and Plants } \\
\text { (biosynthesis of L-Lys) }\end{array}$ & L,L-DAP \\
\hline
\end{tabular}

In both cases, the racemases catalyze the abstraction of the $\mathrm{C} \alpha$-hydrogen of an amino acid as a proton to form a planar carboanionic transition state, followed by the return of the proton to the same carbon from either the same or the opposite side (Scheme 1). The stereochemical inversion of an amino acid works in both directions, i.e. $\mathrm{L} \rightarrow \mathrm{D}$ and $\mathrm{D} \rightarrow \mathrm{L}$.

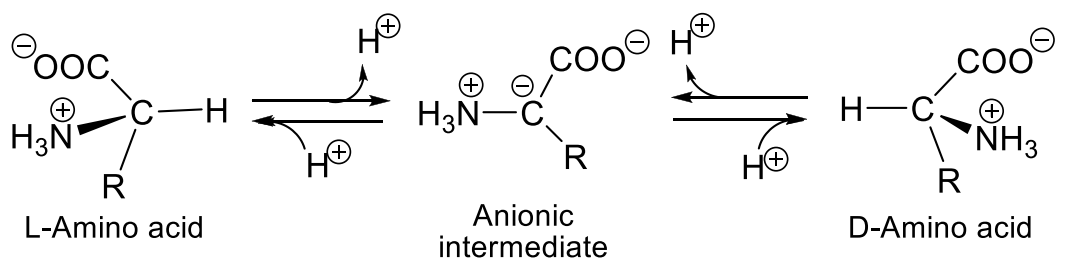

Scheme 1

\subsection{PLP-dependent Amino Acid Racemases}


Since the $\mathrm{pKa}$ value of the amino acidic C $\alpha$-hydrogen usually spans the range of $21-34,,^{15}$ several enzymes evolved to employ the PLP coenzyme in order to increase the acidity of such a hydrogen ${ }^{16-19} \mathrm{All}$ known PLP-dependent enzymes exist in their native state as an internal aldimine (Schiff base) (Scheme 2) with the $\varepsilon$-amino group of a lysine residue present in the catalytic site. The amino moiety of the amino acidic substrate displaces the lysine from the internal aldimine to form a new aldimine, termed external aldimine, which is characterized by a sizable acidity of the C $\alpha$-hydrogen of the substrate (Scheme 2). Typically, the formation of such an external aldimine brings about a sharp drop in the $\mathrm{pKa}$ value of the substrate from 21-34 to 6-17.20.21 This huge reduction in the $\mathrm{pKa}$ value is due to the delocalization of the negative charge of the anionic intermediate by resonance through the conjugated $\pi$ system extending on the PLP ring. The scissile bond of the external aldimine must be oriented perpendicularly to the coenzyme planar $\pi$-bonding system to maximize the $\sigma-\pi$ orbital overlap in the transition state, ${ }^{22}$ as recognized by crystallographic studies carried out on PLP-dependent enzymes. ${ }^{2325}$ The process of racemization takes place because the $\alpha$-hydrogen of the external aldimine, due to its substantial acidity, can be easily abstracted as a proton to form an anionic planar intermediate which, subsequently, undergoes a re-protonation on either the re- or si-faces of the substrate-cofactor complex. The mechanism of racemization of the PLP-dependent enzymes as well as the three most significant resonance forms of the anionic intermediate are depicted in Scheme 2. The quinonoid resonance structure is commonly considered the major species responsible for the catalytic power of PLP, in which the electrons from $\mathrm{C} \alpha$ are neutralized by the positively charged pyridine nitrogen. 
<smiles></smiles>

Internal aldimine

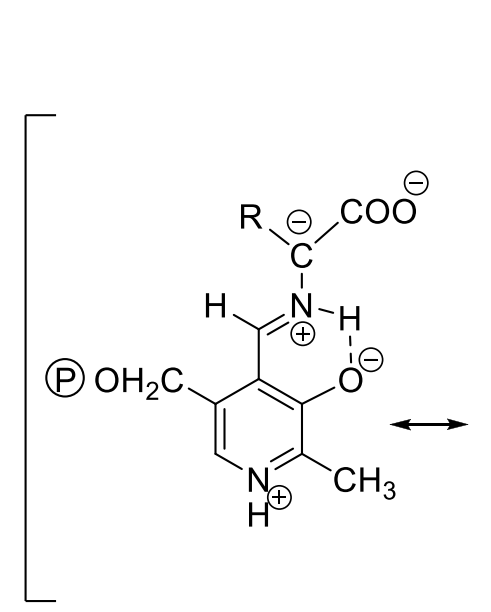

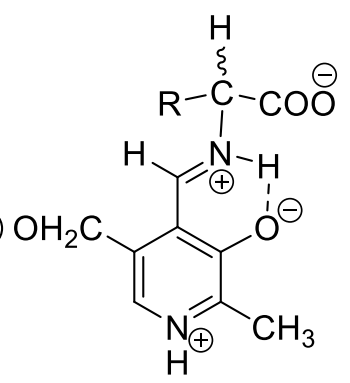

External aldimine

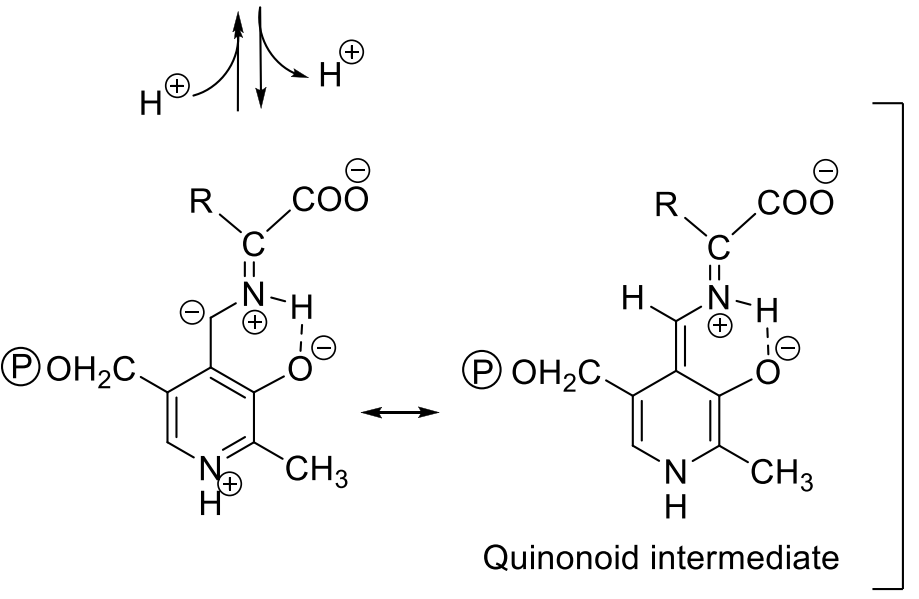

\section{Scheme 2}

The PLP-dependent enzymes have been classified, on the basis of their tertiary structures, into five groups, namely fold type $\mathrm{I}-\mathrm{V}^{2627}$ and they probably evolved from at least three different ancestral proteins.

The fold type $\mathrm{I}$ is the most common and best known structure, and is found in a variety of aminotransferases and decarboxylases, as well as in enzymes that catalyse an $\alpha$-, $\beta$ - or $\gamma$-elimination reaction. The prototype of the fold type I enzyme is aspartate aminotransferase. This family includes enzymes that are catalytically active as homodimers, but some of them assemble into larger complexes. Each subunit folds into two domains: a large domain, in which the central feature is a seven stranded $\beta$ sheet, and a small domain, which folds into a three- or four-stranded $\beta$ sheet covered with helices on one side. The active site is located in a cleft between the two domains, at the interface between the two subunits of the dimer. All enzymes belonging to this fold type show an aspartate interacting with the pyridine nitrogen. In turn, the enzymes belonging to the fold type I can be divided into eight subtypes. ${ }^{28}$ 
The fold type II is found mainly in enzymes that catalyse $\beta$-replacement and $\beta$-elimination reactions. The prototype of the fold type II enzyme is tryptophan synthase. SerR ${ }^{29.31}$ belongs to this fold type. Each subunit consists of two domains: an N-terminal domain containing a four-stranded sheet surrounded by helices, and a C-terminal domain built up by a six-stranded sheet with flanking helices. The active site is located in a cleft between the C-terminal ends of the two $\beta$ sheets. At variance with fold type I enzymes, a serine residue interacts with the pyridine nitrogen, rather than an aspartate.

The Fold type III family includes AlaR, ArgR and a subset of amino acid decarboxylases. The subunit is characterized by an eight-stranded $\alpha / \beta$ barrel and a domain mainly comprising $\beta$ strands. The side chain of an arginine residue forms a hydrogen bond with the pyridine nitrogen, indicating that protonation of the pyridine nitrogen is not crucial for the catalytic activity.

The Fold-type IV subset comprises D-Ala aminotransferase and a few other enzymes. The fold consists of a two-domain structure with the active site located at the domain interface. Two identical subunits form a catalytical dimer. However, branched chain aminotransferase further assembles into a hexamer. The smaller N-terminal domain contains a six-stranded antiparallel $\beta$ sheets with two $\alpha$ helices on one side. In the larger C-terminal domain, two four-stranded $\beta$ sheets form a pseudo- $\beta$-barrel that is surrounded by a few helices.

Finally, the fold-type V group includes glycogen and starch phosphorylases. The C-terminal domain has a dinucleotide-binding fold and binds the cofactor PLP. In these enzymes, the catalytic role of PLP is via its phosphate moiety, thus diverging from the coenzyme action in the enzymes belonging to the other four fold types.

In all the five types, a covalent Schiff-base linkage with lysine, present in the active site, is used to anchor the cofactor to the enzyme in the resting state and the phosphate group is bound to the $\mathrm{N}$ terminus of an $\alpha$ helix. In four of the five folds, the catalytic lysine residue is located in the connection between a $\beta$ strand and the following $\alpha$ helix. In contrast to the classical binding mode of, for example, $\mathrm{NAD}(\mathrm{P}) \mathrm{H}$ or thiamine diphosphate to open $\alpha / \beta$ structures, cross-over connections to adjacent parallel strands in the sheet are, with the exception of fold type II, not utilized for PLP binding. 


\subsection{PLP-independent Amino Acid Racemases}

The members of this second class of enzymes, which includes proline, aspartate, and glutamate racemases as well as diaminopimelate epimerase operates through a "two-base" mechanism in a cofactor-independent manner, as first proposed by pioneering work on ProR from Abeles' group ${ }^{32,33}$ (Scheme 3).

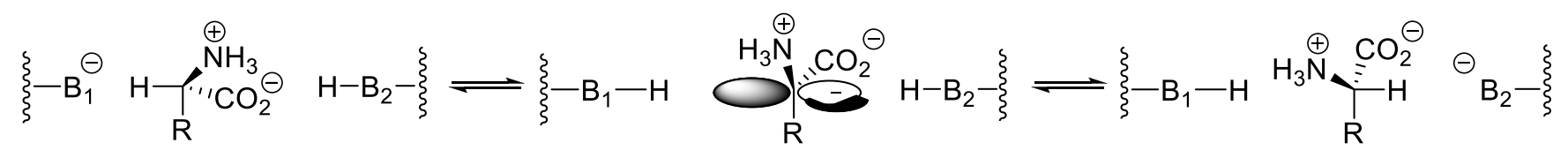

\section{Scheme 3}

All these enzymes are members of the class of proteins that contain both $\alpha$ and $\beta$ secondary structural elements. In particular, AspR and GluR belong to the aspartate transcarbamylase (ATC)-like fold, while ProR and DAPE belong to the diaminopimelate epimerase-like fold. The former fold consists of two similar domains related by a pseudodyad axis, whereas the latter fold consists of mixed beta-sheet folds into a barrel around the central helix.

ProR has been considered the prototype of PLP-independent racemases, as it interchanges L and D enantiomers without the aid of any cofactor. A partially purified preparation of ProR from the Grampositive bacterium Clostridium sticklandii was first described by Stadtman and Elliot in 1957.34 The Authors also established the sulfhydryl nature of the enzyme and they speculated that PLP was not involved in the racemization of Pro. It was only ten years later that Cardinale and Abeles published, for the first time, the isolation of ProR in a highly purified form and described a conceivable mechanism of catalysis. ${ }^{32}$ The reported studies on isotope incorporation and enzyme kinetics in $\mathrm{D}_{2} \mathrm{O}$ demonstrated a 'two-base' mechanism in which one base of the enzyme removes the substrate $\alpha$-hydrogen as a proton while the conjugate acid of the second base delivers a proton to the opposite side of the $\alpha$-carbon. The Authors also observed that deuterium can not be exchanged while the active site is occupied, indicating that the two bases of the catalytic site are monoprotic. In 1975, the same group hypothesized that the active site of ProR is located at the interface of two identical, or nearly identical, subunits..$^{33}$ Each of these two subunits supplies one base, which were then identified as the thiol group of two cysteines. 
Moreover, at saturating substrate levels, the initial rate of the enzyme-catalyzed release of ${ }^{3} \mathrm{H}$ from L-[2$\left.{ }^{3} \mathrm{H}\right]$-proline into the solvent is independent of the initial L-proline (L-Pro) concentration, whereas the initial rate of the enzyme-catalyzed release of ${ }^{3} \mathrm{H}$ from $( \pm)-\left[2-{ }^{3} \mathrm{H}\right]$-proline decreases by increasing the ( \pm )-Pro concentration. On the basis of these observations, the Authors speculated that there are two forms of the enzyme, one which is able to bind L-Pro while the other recognizes solely the D enantiomer.

Fundamental studies by Knowles and coworkers on ProR ${ }^{35}$ further clarified the mode of action of this enzyme deepening the energetics and mechanism of ProR. Subsequently, the same authors extended their work to GluR, ${ }^{36}$ confirming the same "two-base" catalytic mechanism of racemization, in which one cysteine residue behave as a base abstracting the $\mathrm{C}-\alpha$ proton to generate a carbanion intermediate, which is then protonated by the second Cys residue, behaving as a conjugated acid. Such a catalytic mechanism is also shared by $\mathrm{AspR}^{37}$ and DAPE ${ }^{38}$ Although they all operate through a similar acid/base mechanism, involving two Cys residues, it is possible to separate the PLP-independent racemases into two subgroups on the basis of sequence and structural similarity: GluR and AspR constitute one homologous family of enzymes, whereas ProR and DAPE form the other one.

\section{Amino Acid Racemases as Drug Targets.}

\subsection{PLP-dependent Racemases}

\subsubsection{Alanine Racemase}

\subsubsection{Localization, structure and function}

AlaR (EC 5.1.1.1), one of the PLP-dependent racemases, is ubiquitous in bacteria and only a few similar enzymes have been found in eukaryotes, such as aquatic animals,,$^{39}$ fungi, ${ }^{40,41}$ fission yeast ${ }^{42}$ and plants. ${ }^{43}$ The enzyme produced by pathogenic fungi such as Tolypocladium niveum and Cochliobolus carbonum are responsible for the synthesis of D-Ala in cyclosporin A, an immunosuppressant drug widely used in post-allogeneic organ transplant, as well as in HC-toxin, a cyclic peptide isolated from varieties of maize (Zea mays L.) infected by C. carbonum. 
Bacterial AlaR is one of the best-studied amino acid racemases. In fact, D-Ala, produced by the action of AlaR on L-Alanine (L-Ala), is important to both Gram-positive and Gram-negative bacteria, since it is required for the synthesis of the peptidoglycan in the cell wall. Because peptidoglycan is ubiquitously distributed in bacteria, but not in mammals, AlaR can be considered a target for new antimicrobial drugs. Several bacteria, such as Salmonella typhimurium, Escherichia coli and Bacillus subtilis contain two independent AlaR genes, DadB and Alr, ${ }_{44}$ belonging to the fold-type III. The expression of DadB is induced when cells are grown in high concentration of L- or D-Ala and is probably responsible for the catabolism of D-Ala. ${ }^{45}$ By contrast, Alr is constitutively expressed and is probably involved in the synthesis of D-Ala. Moreover, recent studies have indicated that AlaR, which is accessible in the exosporium, plays a key role in the inhibition of germination in Bacillus spores. ${ }^{46}$ As a matter of fact, while L-Ala is an effective germination-promoting compound, its mirror image (D-Ala) is a potent inhibitor of L-Ala-induced germination. ${ }^{47}$ Therefore, a compound capable to inhibit the AlaR activity could trigger a premature germination leading to the death of Bacillum spores in suboptimal environments..$^{48,49}$ Bacillus anthracis, a spore-forming Gram-positive bacterium, is the causative agent of the zoonotic disease anthrax. Although the disease is most common in wild and domestic mammals, it can also occur in humans when exposed to infected animals or living spores.$^{50}$ Inhalation of $B$. anthracis spores can lead to the most severe form of the disease, historically associated with a very high mortality rate. ${ }^{5152}$ Triggering the premature germination of $B$. anthracis spores by spraying a solution of an AlaR inhibitor on affected areas may therefore be a strategy to speed decontamination efforts and reduce the risk of infection in humans.The crystal structure of AlaR from Bacillus stearothermophilus and the complexes between AlaR and two inhibitors, namely propionate and 1-aminoethylphosphonic acid, have been reported (Figure 2) ${ }^{53.57}$ The crystal structure revealed that the enzyme is a homodimer of 388 residues. ${ }^{56}$ Each monomer is composed of two folded domains; i) a $N$-terminal domain formed by the portion 1-240 and ii) a C-terminal domain which involves the remaining portion of the monomer (241388). The $N$-terminal domain is made up of an eight-stranded $\alpha / \beta$-barrel while the $\mathrm{C}$-terminal domain contains mainly $\beta$-strands. A water molecule was identified in both active sites of the AlaR homodimer. ${ }^{57}$ This water molecule plays an important role and should be taken into account for the design of specific AlaR inhibitors either by utilizing it as a bridging group or by displacing it by a suitable moiety appended to the inhibitor. 
An interesting feature of AlaR is that the pyridine ring of PLP is not protonated due to the contiguity with Arg219, ${ }^{58}$ which possesses a pKa value in water of about 13. The X-ray crystal structure evidenced this structural feature where Arg219 interacts with the PLP pyridine nitrogen through a hydrogen bond, preventing the formation of the cationic pyridinium ion (Figure 2B). ${ }^{56}$ Therefore, the main catalytic effect of PLP in AlaR may be ascribed to solvation. ${ }^{50.61}$ It has been assumed that in such an enzyme the non-protonated form generates an intermediate with a limited lifetime which aids the enzyme in avoiding side reactions. ${ }^{2}$ Quantum mechanical and molecular dynamics simulations were recently carried out on the wild type and Arg219Glu mutant..$^{59,63}$ Results suggest that in the wild type the stabilization of the quinonoid intermediate is due to solvent effects whereas in the mutant also Glu219 contributes to catalysis. 


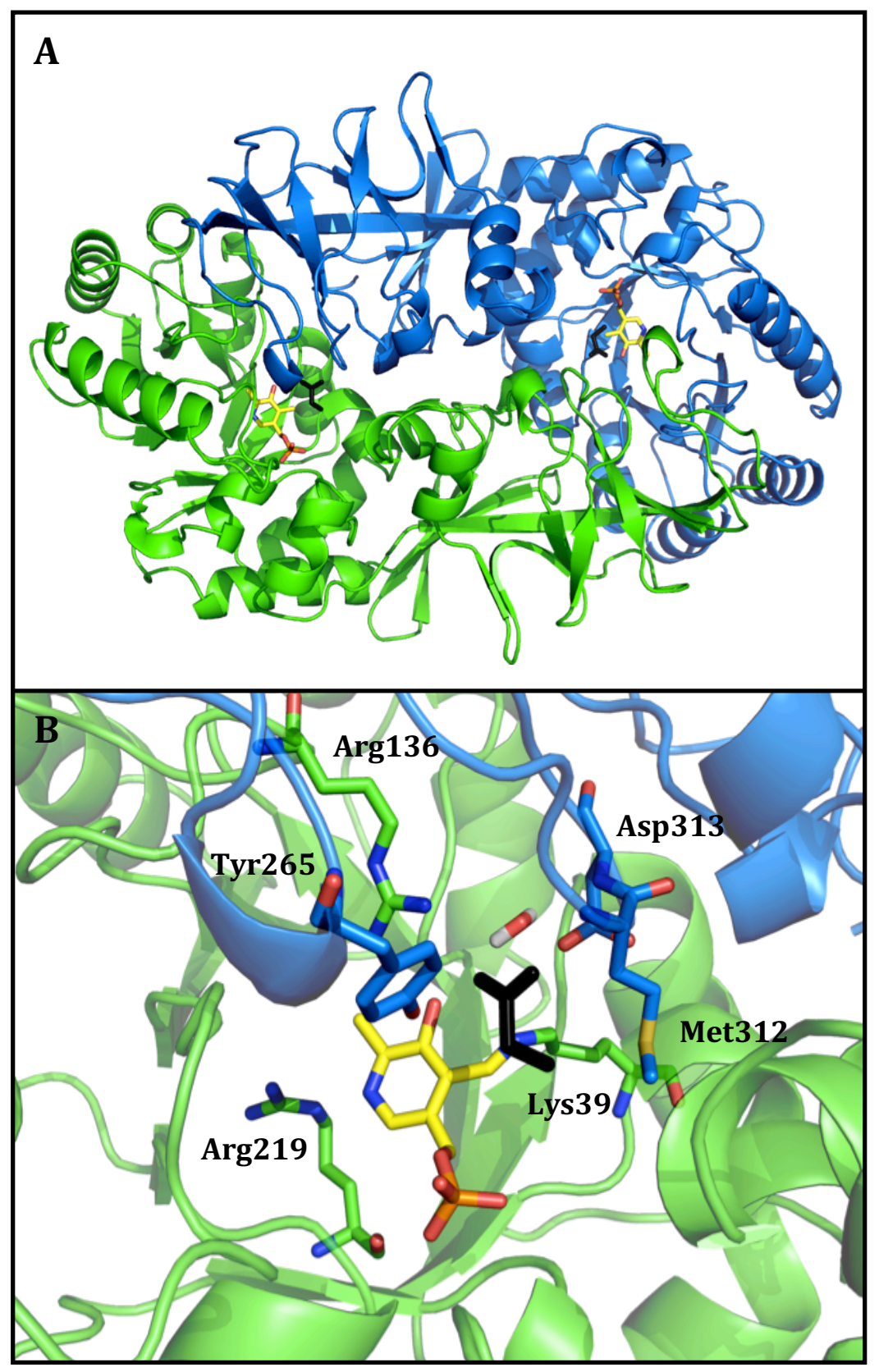

An alternative mechanism of action involving two bases, i.e. lysine (Lys39) and tyrosine (Tyr265'), has also been proposed. The lysine residue, connected to the PLP cofactor, acts as a base for the conversion of D-Ala into L-Ala, while a nearby tyrosine localized on the other monomer performs as a base to abstract the C $\alpha$-hydrogen from L-Ala.6466 The role of Tyr265' was supported by the theoretical model published by Ondrechen et al. ${ }^{\urcorner 7}$ Due to the low $\mathrm{pKa}$ value, the phenolic group of Tyr265' is predicted to be in the anionic form in the $\mathrm{pH}$ range $(\mathrm{pH} 7-9)$ where the racemase is most active. It was also reported that a small fraction of Lys39 is non-protonated in the same pH range. Therefore, Lys39 can be available as a neutral amine and can behave as the catalytic base for the conversion of D-Ala into L-Ala. 
Moreover, AlaR has been shown to be capable to catalyze a transamination reaction. ${ }^{26,68}$ The enzyme catalyzes one or the other transformation at different $\mathrm{pH}$ values. While the racemization process has its optimum $\mathrm{pH}$ in the range $7-10$, the rate of the transamination reaches its peak value around $\mathrm{pH} 6.5 .^{68}$

\subsubsection{Inhibitors and Drug perspectives}

Two well known natural inhibitors of AlaR are D-cycloserine and $O$-carbamoyl- D-serine (Figure 3). ${ }^{69}$ These compounds inhibit AlaR of many bacteria, e.g. S. aureus,$^{70}$ E. coli, ${ }^{71}$ and $B$. subtilis.$^{72}$ D-cycloserine is transported across the cell wall via the D-Ala/glycine transport system forming a covalent adduct with the PLP cofactor of the protein. ${ }^{33}$ Both L- and D- enantiomers act as irreversible suicide inhibitors of $\mathrm{AlaR}^{71,74}$ and, thus, can be used as antimicrobial agents. Moreover, cycloserine has been shown to inhibit D-Ala- D-Ala ligase in vitro. ${ }^{75}$

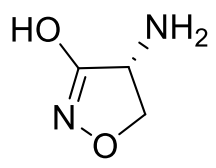<smiles>NC(=O)OC[C@H](N)C(=O)O</smiles>

D-cycloserine

O-carbamoyl-D-serine

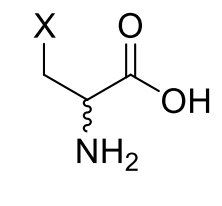

$$
\mathrm{X}=\mathrm{Cl}, \mathrm{F}
$$

$\beta$-haloalanine
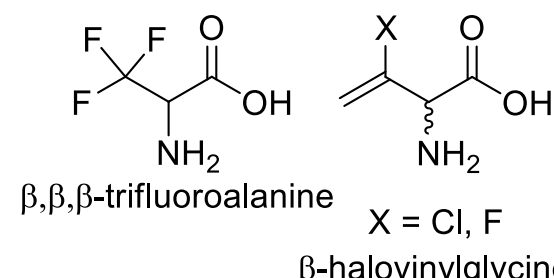

$\beta$-halovinylglycine

\section{Figure 3}

D-Cycloserine is an effective second-line drug against Mycobacterium avium and Mycobacterium tuberculosis and has been commercialized as Seromycin, which is indicated in the treatment of active pulmonary and extrapulmonary tuberculosis, when the treatment with the primary medications (streptomycin, isoniazid, rifampin, and ethambutol) proved to be inadequate. Moreover, the drug is used for treating acute urinary tract infections caused by susceptible strains of Gram-positive and Gramnegative bacteria, especially Enterobacter spp. and E. coli. Unfortunately, cycloserine can provoke toxic side effects, in particular on central nervous system (CNS), such as seizures, psychosis, confusion, tremor, vertigo, hyperreflexia or dysarthria. ${ }^{76}$ The toxicity of Seromycin is closely related to excessive 
blood levels (above $30 \mu \mathrm{g} / \mathrm{mL}$ ) due to a high dosage or to an inadequate renal clearance. The cause of these neuronal disorders is probably connected to the activity of D-cycloserine as partial agonist of the glycine site of $N$-methyl-D-aspartate (NMDA) receptors ${ }^{77}$ and as an inhibitor of PLP-dependent enzymes involved in the biosynthesis and metabolism of the neurotransmitter $\gamma$-aminobutyric acid $(\mathrm{GABA}){ }^{{ }^{88}}$ Moreover, resistance has been observed in many clinical situations..$^{79}$ Since cycloserine is not a specific inhibitor of AlaR but can inhibit several PLP-dependent enzymes, ${ }^{80}$ the existence of more than one mechanism leading to cycloserine resistance is likely. Cycloserine may enter the bacterial cell by either diffusion or uptake via a specific transporter. ${ }^{73}$ Mutations in the transporter gene which cause a reduced cycloserine binding or eliminating the transporter from the cell surface affect the drug uptake and increase the resistance. Analogously, a mutation in a gene coding for an efflux pump may lead to a higher affinity for cycloserine increasing the efficiency of the drug expulsion. Alternatively, it is possible that a mutational change could increase the affinity or the levels of a drug-detoxifying enzyme which would derivatize or hydrolyze cycloserine. The overproduction of a protein target could lead to increased resistance due to the sequestration or removal of the drug by the excess target protein. To this end, it was shown that a natural mechanism of resistance to the drug is the overproduction of the AlaR due to a promoter-up mutation. ${ }^{81}$

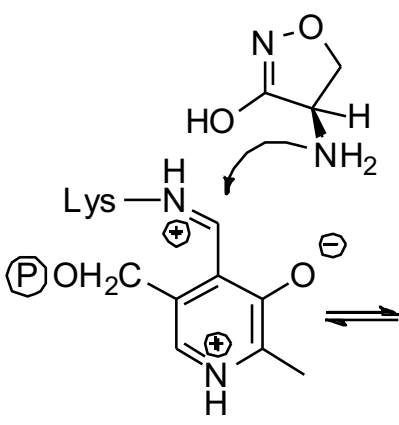

internal aldimine

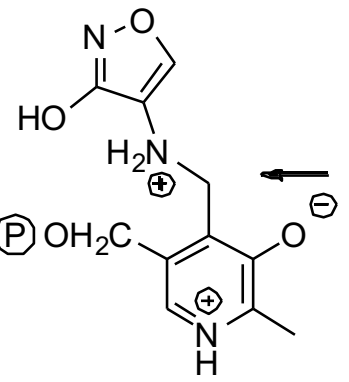

hydroxy-isoxazole/PLP derivative

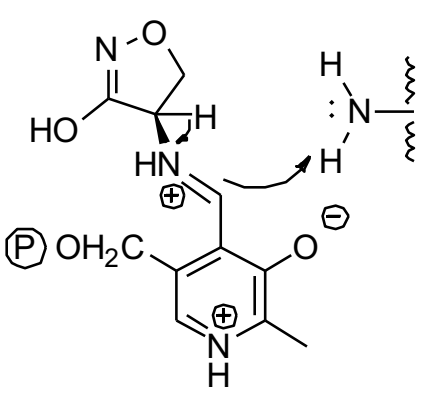

external aldimine

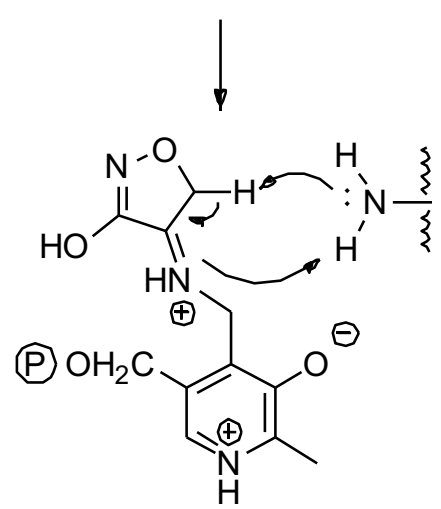

exocyclic-ketimine 


\section{Scheme 4}

NMR and IR spectra indicate that cycloserine exists in solution primarily in the lactim form. Recent studies suggest a mechanism of inactivation that results in aromatization of cycloserine (Scheme 4)..$^{82}$ This mechanism requires an initial transamination step to form an external aldimine which subsequently undergoes a proton shift to yield an exocyclic ketimine. Such an exocyclic ketimine, which is no more conjugated with the pyridine ring, proceeds through a second prototropic shift to form the stable covalent adduct hydroxy-isoxazole/PLP..$^{73}$

Cycloserine can be considered a model compound for the development of similar derivatives capable to inactivate PLP-dependent enzymes. The goal is focused on the discovery of drug candidates characterized by a high selectivity for AlaR.

The most successful approach to design inhibitors of PLP-dependent enzymes consists in incorporating olefinic, acetylenic, or halogen functional groups in the substrates of the target enzymes. In fact, many D-Ala analogues have shown to exhibit a remarkable inhibitory activity if they bears a halogen in a position suitable for a nucleophilic attack, i.e. $\beta$-chloroalanine, $\beta$-fluoroalanine, ${ }^{83.84} \beta, \beta, \beta-$ trifluoroalanine, ${ }^{85} \beta$-halovinylglycine (Figure 3 ). ${ }^{86}$ The inactivation of AlaR by $\beta$-haloalanines and trifluoroalanine proceeds via two different mechanisms. ${ }^{85}$ In both cases, the first step is invariably the formation of the cross-conjugated enamino-PLP species through the nucleophilic attack of the nascent aminoacrylate on the PLP-lysine aldimine (Scheme 5). ${ }^{87}$ Such an intermediate can undergo a bifurcated route: $i)$ if the $\beta$-carbon atom bears a single halogen ( $\beta$-haloalanines), the electrophilicity at the olefinic terminus is insufficient to trap the nearby nucleophile, i.e. the $\varepsilon-\mathrm{NH}_{2}$ of the active-site Lys38, and the nucleophilic attack occurs at the aldimine carbon atom or ii) if the $\beta$-carbon atom bears more halogens, i.e. trifluoroalanine, the amino group of Lys38 acts as a nucleophile and attacks the highly electron deficient difluoroenamino moiety. In both cases the enzyme is irreversibly inhibited but, whereas in the 
first route the inactivation is caused by the alkylation of the PLP-cofactor, in the second route the inhibition of the enzyme is due to the formation of a covalent bond between the $\varepsilon-\mathrm{NH}_{2}$ of $\mathrm{Lys} 38$ and the $\beta$ position of the fluoro-aminoacrylate. An important indicator of potency of irreversible inhibitors is the number of turnovers per inactivation event, termed partition ratio. This parameter measures the frequency (for turnover to inactivation) with which an alkylation of the active site occurs causing the inactivation of the enzyme before the electrophilic species uncovered in turnover can be deactivated chemically or physically (e.g., product release) at the active site. With a lower partition ratio, the amount of drug required to fully inhibit a given amount of enzyme is reduced. Consequently, the release of activated metabolites, which could interact with other cellular constituents, is diminished with an amelioration of the pharmacological profile. In the case of $\beta$-haloalanines, a side reaction that leads to the formation of pyruvate and ammonia without inactivation of the enzyme can take place (Scheme 5) ${ }^{88}$ 


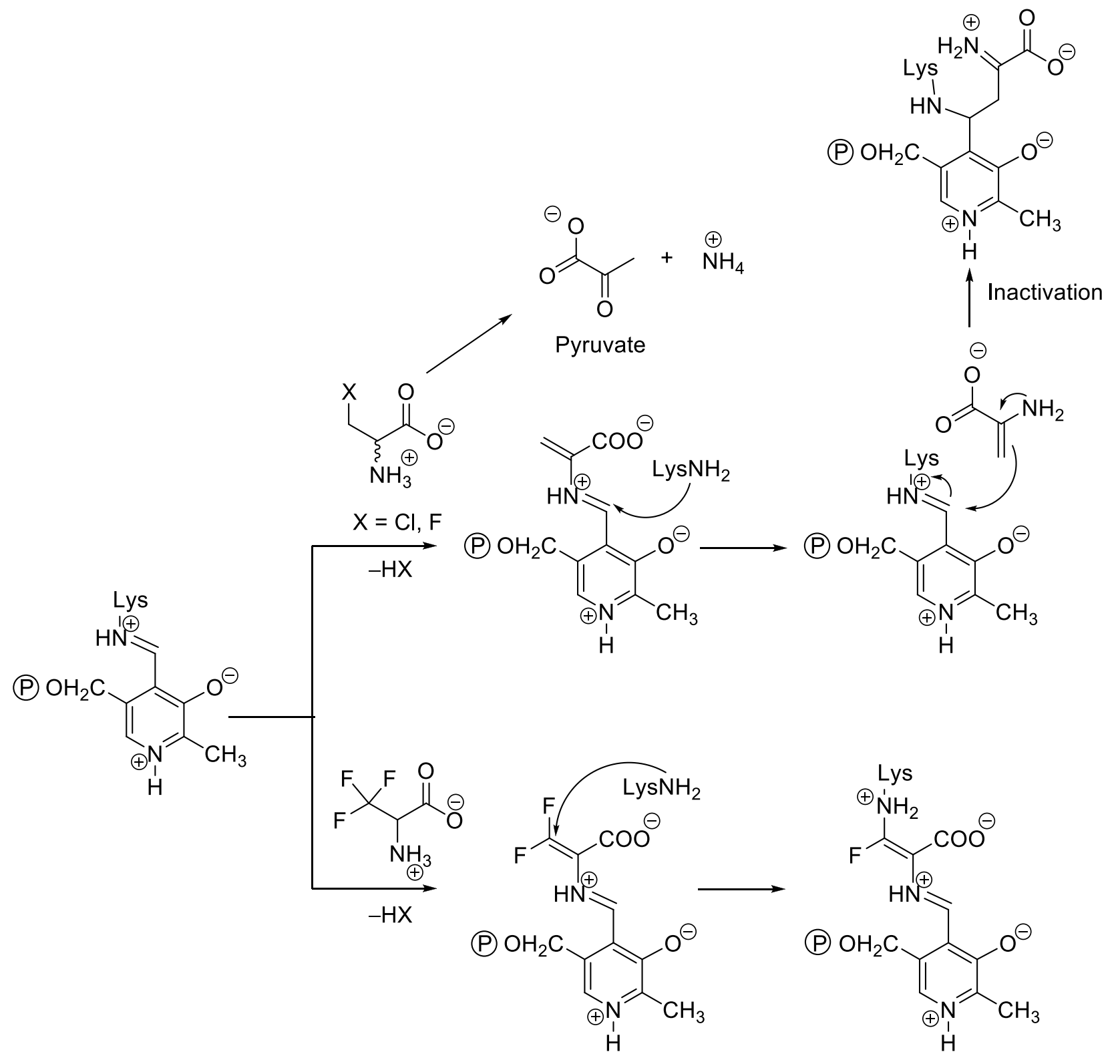

Scheme 5

Racemic $\beta$-fluoroalanine was the first drug candidate prepared at Merck by Kollonitsch and colleagues; the D isomer was successfully validated as a potent, wide-spectrum and orally active antibiotic (partition ratio $\sim 800)^{.339980}$ Unfortunately, safety issues unrelated to its mechanism of action have hindered its development for clinical applications.

Halovinylglycines represent a class of potent AlaR inhibitors. At variance with haloalanines, in which the loss of HX leads to the formation of a nucleophile (aminoacrylate), the removal of the halide from halovinylglycines generates 2-amino-2,3-dienoic acid 1, an allene characterized by a highly 
electrophilic reactivity (Scheme 6). Allene 1 can undergo the following three different transformations:

i) $57 \%$ of the reactive intermediate $\mathbf{1}$ is hydrolyzed to vinylglyoxylate $\mathbf{2}$, a reactive Michael acceptor; ii) $12 \%$ of the same intermediate reacts with the amino group of a lysine to yield paraquinoid $\mathbf{3}$ or its tautomer $\mathbf{4}$, then the lysine-enamine linkage is hydrolyzed to $\alpha$-aminoacetone $\mathbf{5}$ restoring the active form of the enzyme; iii) the remaining $31 \%$ of allene 1 reacts with the same lysine residue to yield heterodiene $\mathbf{6}$ which subsequently O-alkylates a tyrosine residue to give 7 and inactivating the enzyme in an irreversible manner. ${ }^{91}$ Fluorovinylglycines are much less reactive than chlorovinylglycines due to the higher stability of the $\mathrm{C}-\mathrm{F}$ bond in comparison to the corresponding $\mathrm{C}-\mathrm{Cl}$ bond. Furthermore, chlorovinylglycine is much more reactive than D-fluoroalanine, with a partition ratio of $2.2 \pm 0.2$, a value 450 -fold lower than that of the reference compound (partition ratio $\sim 800$ ).

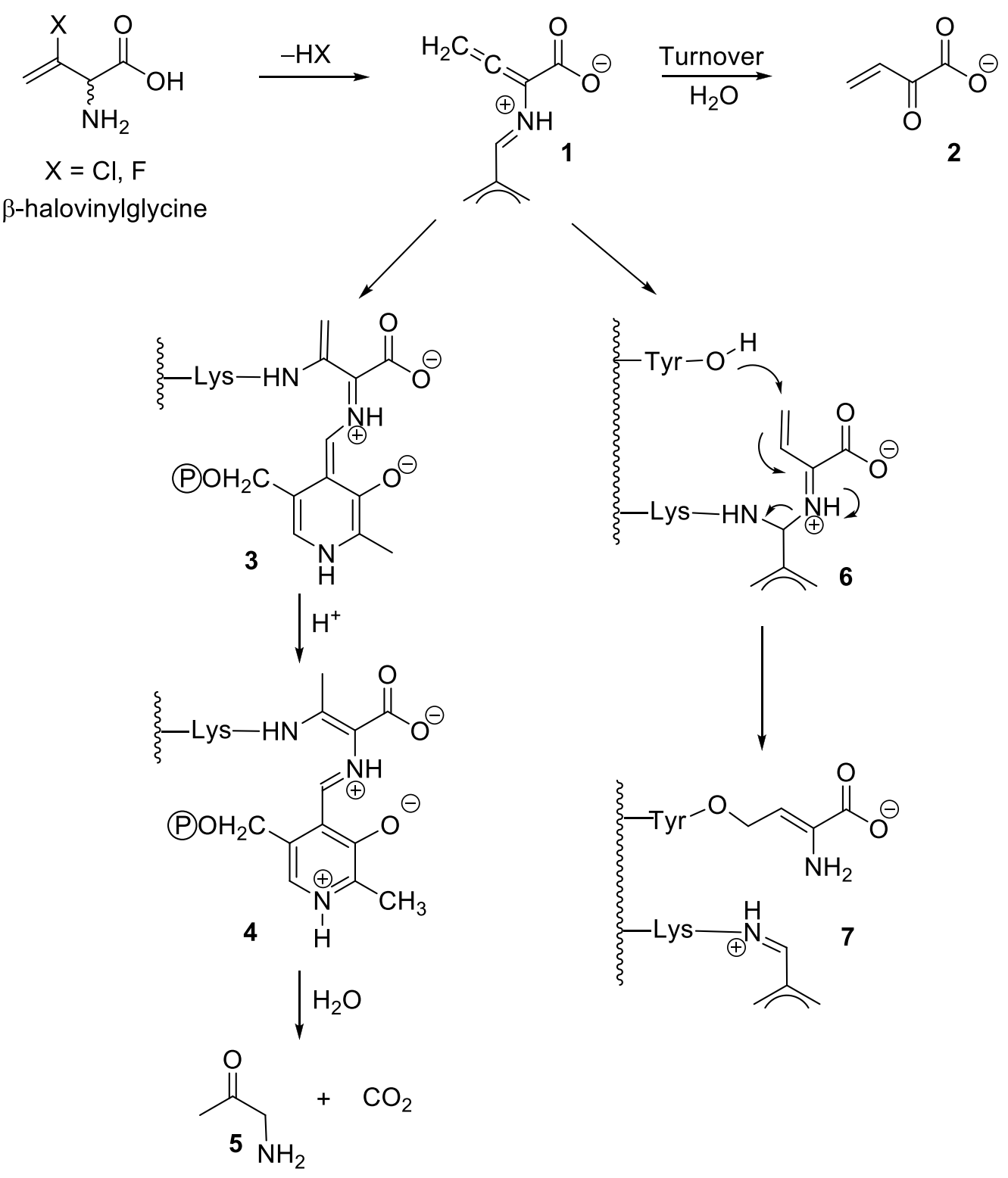




\section{Scheme 6}

Unfortunately, their potency as antibiotics in vivo is not commensurate to their efficiency as inactivators of AlaR in vitro, probably because these inhibitors are not well recognized by the amino acid transport systems of the bacteria.

An interesting compound that selectively inhibits the biosynthesis of the bacterial cell wall is Alaphosphin (L-alanyl-L-1-aminoethylphosphonic acid, Figure 4). Alaphosphin is representative of a series of antibacterial phosphonopeptides which were designed to mimic the terminal dipeptide moiety (D-Ala- D-Ala) of the bacterial cell wall peptidoglycan. Alaphosphin efficiently crosses the bacterial cell wall and is hydrolyzed to L-Ala and (L)-1-aminoethylphosphonic acid (L-Ala-P) by intracellular aminopeptidases. The $(\mathrm{L}, \mathrm{L})$ stereochemistry of Alaphosphin is necessary for its recognition by the transporters and to cross the cell wall. Its bactericidal activity arises from the inhibition activity of AlaR brought about by L-Ala-P. It is well documented that L-Ala-P is a competitive inhibitor of AlaR present in crude extracts of Gram-negative bacteria (E. coli and $S$. typhimurium). ${ }^{7192 \cdot 94}$ It is also a time-dependent and irreversible inhibitor of AlaR isolated from Gram-positive bacterial sources (Streptomyces aureus and Streptococcus faecalis) $.^{92} \mathrm{~L}-\mathrm{Ala}-\mathrm{P}$ is characterized by a slow binding and a slow release process, ${ }^{9596}$ with an extremely slow off rate $\left(t_{1 / 2} \sim 25\right.$ days). The dianionic form of the phosphonate moiety may mimic a potential transition-state intermediate of the reaction and the two negative charges are crucial for the observed inhibitory activity of L-Ala-P. In 1998, Stamper et al. published the crystal structure of the complex of L-Ala-P with AlaR; this was the first report on the X-ray structure of an external aldimine involving this enzyme..$^{54}$

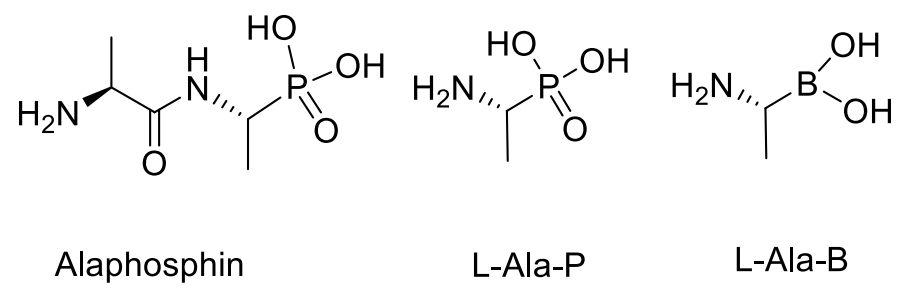

Figure 4

The replacement of the carboxylic group of L-Ala with the boronic moiety leads to (1aminomethy1)boronic acid (L-Ala-B, Figure 4), which is a powerful slow binding and time-dependent 
inhibitor of both AlaR from B. stearothermophilus and D-Ala- D-Ala ligase from S. typhimurium $.^{97} \mathrm{~L}-$ Ala-B is less potent than L-Ala-P in terms of both $K_{i}$ and lifetime of the enzyme-inhibitor complex, probably, the two bioisosteres differently interacting with the enzyme active site.

In a perspective of developing more specific inhibitors for AlaR via a structure-based drug design, crystallographic structures from three species (B. stearothermophilus, Pseudomonas aeruginosa and M. tuberculosis) have been solved and compared in detail.98 The identity levels of the amino acid sequence between $M$. tuberculosis AlaR (MtbAlaR) and the two other published AlaR structures, i.e. P.aeruginosa (PaoAlaR) ${ }^{53}$ and G. stearothermophilus (BstAlaR), ,56 32 and 34\%, respectively. The secondary structure and overall fold of $M t b$ AlaR are very similar to those observed in PaoAlaR and BstAlaR, confirming a strong architectural resemblance between prokaryotic AlaRs. The $\beta$-structure of the C-terminal domain and the geometry of the active site of MtbAlaR closely match that of PaoAlaR and BstAlaR (Figure 5). At the N-terminal domain, structural differences between MtbAlaR, PaoAlaR and BstAlaR occur near the N-terminus and in some helices and loops located in the periphery of the $\alpha / \beta$-barrel (Figure 5). Concerning the active site, the levels of sequence identity between the residues of MtbAlaR and those of PaoAlaR and BstAlaR are 44 and 50\%, respectively. From the active site cavity containing the PLP moiety it is possible to access a second cavity on the opposite side. In BstAlaR, this accessory cavity contains four water molecules, whereas in PaoAlaR, it contains three solvent molecules. In $M t b A l a R$, the presence in this cavity of tryptophan (Trp88) reduces the free space, and only two water molecules can be accommodated. Moreover, it was shown the presence of a constriction, created by two amino acid residues (Tyr271' and Tyr364), at the entryway corridor nearby the PLP. This corridor is roughly conical with its base oriented toward the outside of the enzyme. The corridor to the active site of AlaR can be ideally divided into three layers: outer, middle, and inner, with the inner layer terminating at the PLP moiety. In the inner and middle layers, all four residues of MtbAlaR, PaoAlaR and BstAlaR are identical and they are located similarly around the corridor. Residues in the outer layer near the surface of the enzyme are not conserved. Consequently, the design of novel inhibitors selective for one of the above mentioned enzymes should be based on an extended pharmacophore model which takes into account interactions with amino acid residues located in the outer layer of the corridor. 
Given the key role of AlaR in the formation of the bacterial wall, it is not surprising that activities aimed at developing efficient enzyme inhibitors are covering more than two decades. In spite of many unsuccessful strategies, new avenues are opened by the recent determinations of the crystal structures of AlaR from Bacillus anthracis in the presence and absence of L-Ala-P,9 AlaR from Streptococcus pneumonia. ${ }^{100}$ AlaR from Enterococcus faecalis,${ }^{101}$ AlaR from Escherichia coli in the absence and in the presence of cycloserine and four mutants of the active site residues Pro219 and Glu221, ${ }^{102}$ the characterization and preliminary crystallographic studies on AlaR from Bacillus pseudofirmus OF4. ${ }^{103,104}$ These recent structural studies indicate that the entryway of the active site is very narrow, conserved residues are present in the active site as well as a string of water molecules, and dimer formation is a critical step for AlaR activity Thus, it has been proposed ${ }^{100}$ that strategies for AlaR inhbitors should be aimed at a high throughput screening (HTS) and structure-based methods for the identification of compounds that i) occupy and block the entryway of the active site, ii) interfere with active site assembly by preventing dimer formation, ${ }^{105}$ iii) enter in the active site with a specific conformation and by interacting with active site residue change conformations, eventually displacing water molecules

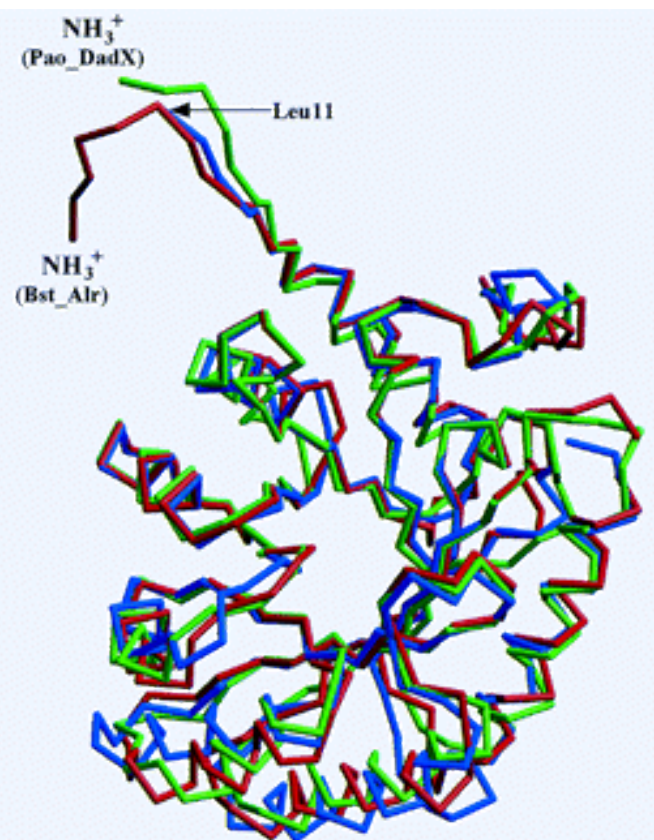

a

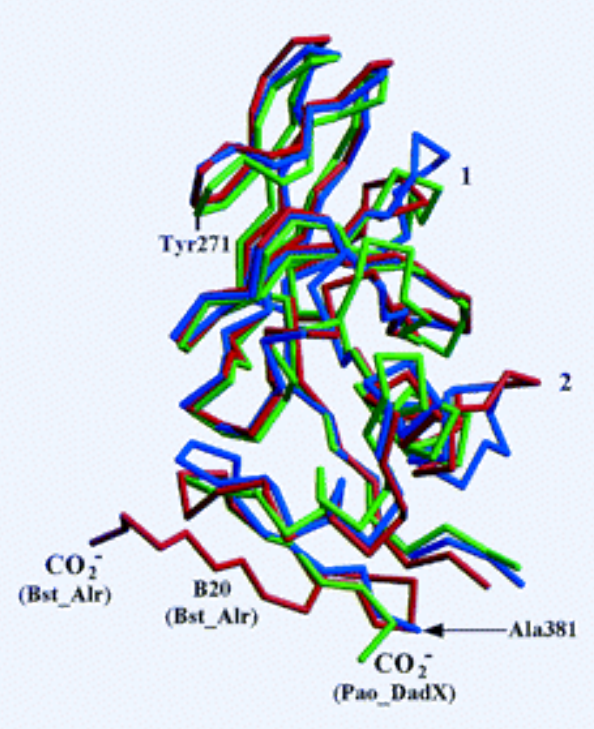

b 


\section{Figure 5}

Recently, modified forms of AlaR have been used as catalysts for chemical transformation. In 2003 Hilvert and co-workers showed that AlaR from Geobacillus stearothermophilus can be converted into a retro-aldolase enzyme by a single point mutation. ${ }^{106}$ As a matter of fact, replacement of Tyr265, one of the catalytic bases, with alanine (alrY265A) decreased the original epimerase activity by more than three orders of magnitude..$^{107}$ In a following paper from the same group ${ }^{108}$ the alrY265A enzyme was used for the semi-preparative production of $\beta$-hydroxy- $\alpha$-amino acids. In fact, the mutant racemase promotes the PLP-dependent aldol condensation of glycine with a range of aromatic aldehydes, working similarly to natural D-threonine aldolases when substrate specificity and stereoselectivity are taken into account.

\subsubsection{Serine Racemase}

\subsubsection{Localization, structure and function}

SerR (EC 5.1.1.18), another PLP-dependent racemase, was first discovered in 1998 in pupae of the silkworm Bombyx mori ${ }^{109}$ while the first purification of brain mammalian SerR was performed by Wolosker and co-workers. ${ }^{110,11}$ SerR is the enzyme involved both in the reversible conversion of L- to DSer and serine catabolism by $\alpha, \beta$-elimination of water, thereby regulating D-Ser levels.

In their pioneering work, Wolosker et al..$^{10}$ showed that SerR is abundant in the glial cells of young rats. Recent immunohistochemical and in situ hybridization studies revealed the localization of the enzyme ${ }^{12}$ and its mRNA ${ }^{113}$ in neurons and glia. Expression of SerR has also been shown in the peripheral tissues including retinal ganglion cells, ${ }^{114}$ Schwann cells, ${ }^{115}$ and chondrocytes. ${ }^{116}$

The existence of free D-Ser in the mammalian brain of both rats and humans was first reported by two Japanese laboratories. ${ }^{117-119}$ Sizable amounts of D-Ser are released by astrocytes, a type of glia cells, where SerR was later detected. ${ }^{10} \mathrm{D}$-Ser behaves as a 'neuromodulator' acting as an agonist at the glycine site of NMDA receptors in the mammalian nervous system. ${ }^{120}$ L-glutamate (L-Glu) is the main excitatory neurotransmitter in the CNS, where it is involved in the modulation of many physiological processes such as learning, memory, and synaptic plasticity. ${ }^{121}$ However, a massive influx of L-Glu into the synapses can lead to acute and chronic neurodegenerative diseases (for example, cerebral ischemia, traumatic brain injury, stroke, spinal injury, epilepsy, and Parkinson's, Alzheimer's and Huntington's 
diseases)..$^{122}$ Memantine, a non competitive antagonist of the NMDA receptors, is the only glutamatergic drug currently approved for the treatment of moderate to severe Alzheimer's disease. Due to its low affinity for the NMDA receptors and capability to block the channel in the open state, memantine does not substantially accumulate in the channel to interfere with the normal synaptic transmission. ${ }^{123}$ An alternative approach to reduce glutamatergic hyperactivity is the use of blockers of the glycine site of the NMDA receptors. Unfortunately, the development of drugs with such a mode of action was discontinued since clinical trials evidenced the appearance of heavy adverse effects, such as hallucinations. ${ }^{124}$ These side effects were attributed to an excessive blockage of the NMDA receptors and alteration of the normal neurotransmission. In this context, inhibition of SerR may provide an alternative therapeutic approach, ${ }^{125}$ since inhibitors of SerR could offer a more gentle and indirect way to decrease NMDA receptor function, with less unwanted side effects.

A few years ago, Sasabe et al..$^{26}$ demostrated that elevated levels of D-Ser in the glia may enhance Glu toxicity in Amyotrophic Lateral Sclerosis (ALS). Although the discovery of mutations in the gene encoding superoxide dismutase 1 (SOD 1) resulted in a considerable number of studies, the reason of the selective motoneuronal death is still unclear. An inefficient GluA2 RNA editing has been proposed as a cause of the death of motoneurons in sporadic ALS patients. ${ }^{127}$ In addition, based on the experimental evidences that elevated level of Glu remained unchanged during the progression of the disease at variance with D-Ser whose level increases progressively along with the course of the pathology, Sasabe et al. speculated that the amount of D-Ser can be used to test the progress of ALS. ${ }^{26}$ Consequently, the reduction of the concentration of D-Ser could be set forth to slow down or to halt the progression of ALS.

The increased glial production of D-Ser seems to be caused by pro-inflammatory stimuli that induce release of D-Ser from microglia by elevating the transcription of SerR. ${ }^{28}$ At the same time, the excessive amounts of L-Glu in the spinal cord of ALS patients can improve the enzymatic activity of SerR in astrocytes, determining an increased level of D-Ser. A further cause of increased levels of D-Ser in ALS patients could be a failure in the D-Ser metabolic pathway, caused by the inactivation of DAAO, the degradation enzyme, and/or a decrease in the glial uptake. Thus, decreasing the D-Ser levels by 
inhibiting the enzymatic activity of SerR or by stimulating the activity of DAAO may represent a new therapeutic strategy to treat patients affected by ALS. ${ }^{26}$

An altered level of D-Ser seems to be involved also in schizophrenia. ${ }^{129}$ In this severely debilitating psychiatric disorder reduced levels of D-Ser have been observed in the cerebrospinal fluid and serum, with a corresponding increase in its precursor, L-Ser..$^{130.131}$ This finding points out the need to deepen the investigation on the involvement of D-Ser modulation in schizophrenia. Some recent studies indicated the misfunctioning of enzymes such as SerR, DAAO and G72, a putative activator of DAAO, as risk factors for the appearance of schizophrenia. ${ }^{132,133}$ SerR knockout mice have been used for determining the biological role of SerR and D-Ser. A recent review has summarized the phenotypes of the presently available three SerR-KO mice and discusses the role of SerR and D-Ser in vivo. ${ }^{134}$

The initial isolation of SerR from mammalian brains ${ }^{110}$ also allowed the establishment of its molecular weight $(37 \mathrm{kDa})$, optimum operational $\mathrm{pH}$ and $K_{\mathrm{m}}$ value. Subsequent studies from the same group ${ }^{13}$ led to the identification of Lys56 as the residue involved in the formation of the internal Schiff base with the PLP moiety. The crystal structure of a homolog of mammalian SerR from Schizosaccharomyces pombe was determined in the absence and presence of serine and in the absence and presence of an adenosine5'-triphosphate (ATP) analogue. ${ }^{135}$ More recently, the first crystal structure of mammalian SerR, both in the presence and absence of the inhibitor malonate, was determined (Figure 6)..$^{136}$ A conformational change affecting the small domain and the active site was detected upon ligand binding with the volume of the active site significantly decreasing in the transition from the open to the closed state. Moreover, Ser84 was identified as the residue that plays a critical role in the catalytic racemization of serine, providing the C- $\alpha$ proton (Figure 6B). The X-ray data show that human and rat SerRs are $90 \%$ identical in sequence and are structurally almost indistinguishable confirming the dimeric structure of the enzyme.

SerR, like AlaR, is a bifunctional enzyme since, in addition to the racemization of serine, it is able to catalyze the dehydration of serine to produce pyruvate and ammonia. The physiological relevance of this dual activity has been investigated. ${ }^{137}$ By generating a SerR mutant (Q155D) with impaired elimination activity, it was demonstrated that the levels of D-Ser were several fold higher both in vitro and in vivo. This finding suggests that the irreversible elimination reaction, coupled to the reversible 
racemization controls the physiological level of D-Ser especially in the brain tissues lacking DAAO. Random mutagenesis studies on human SerR provided further evidence on the role of Ser84 in the enzyme activity and Cys217 and Lys221 in $\mathrm{Mg}^{2+}$ binding and protein stability. ${ }^{138}$

A peculiar feature of SerR is the multiple catalytic regulatory mechanisms, involving the interaction with i) divalent cations, ii) nucleotides, iii) specific proteins, and iv) NO.

i) Divalent cations, i.e. calcium, magnesium and manganese were shown to bind to the enzyme at a cation-binding site (Fig. 6) through a hexavalent coordination composed by two carboxylate anions of amino acid residues, a carbonyl oxygen of the main-chain and three well-ordered water molecules. ${ }^{139}$ In human SerR, the residues directly involved in the coordination of calcium are: Glu210, Asp216 and Ala214. Divalent cations at physiological concentrations activate 5 to 10 fold the racemization and elimination reactions ${ }^{140}$ with EDTA favouring racemization over elimination. Since the cation binding site is relatively far from the active site, the cation effect is likely associated to a conformational change more than a direct involvement in the catalytic reaction. This behaviour resembles the scenario previously observed in tryptophan synthase where monovalent cations bind to a site distinct from the active site affecting catalytic rates and intermediate equilibrium distribution..$^{141,142}$

ii) Nucleotides, such as ATP, adenosine diphosphate (ADP) and guanosine diphosphate (GDP), bind at a site localized at the subunit interface, although with different affinities (Fig. 6A), increasing 5 to 10 fold the racemase and elimination activity. Since ATP is not hydrolized during the catalytic cycle, ATP acts as an allosteric effector. 


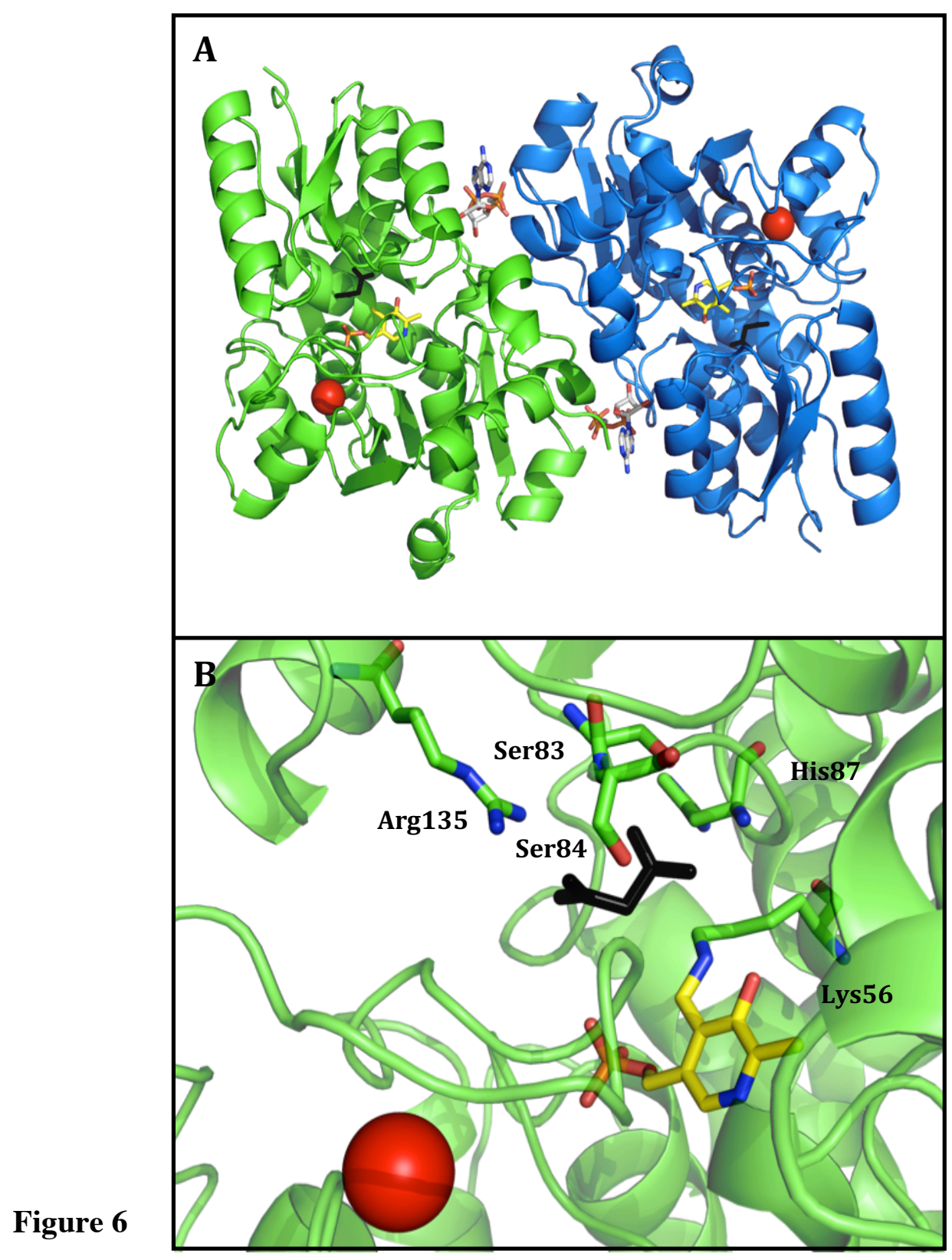

iii) By means of the yeast two-hybrid approach, three proteins have been shown to interact with brain SerR: glutamate receptor interacting protein (GRIP), ${ }^{143.144}$ protein interacting with C kinase 1 (PICK1) ${ }^{145}$ and Golga3 ${ }^{146}$ Both GRIP and PICK1 bind to the four amino acids of SerR C-terminal (-Ser-Val-SerVal-COOH in the human enzyme and -Thr-Val-Ser-Val-COOH in the mouse enzyme), whereas Golga3 binds to the N-terminal 66 amino acids of brain SerR generating a conformational change of the enzyme which gives rise to an increased synthesis of D-Ser. PICK1 is known to direct protein kinase C (PKC) to its targets in cells. It has been recently found that PKC phosphorylating SerR at serine residues, decreases SerR activity, thus, regulating D-Ser availability in the brain. ${ }^{147}$ The level of SerR is 
dynamically regulated by glutamate. In fact, activation of metabotropic glutamate receptors leads to the cleavage of phosphatidylinositol (4,5)-bisphosphate (PIP2) by phospholipase C (PLC); the reduced concentration of PIP2 diminishes its inhibition effect on SerR..$^{148}$ On the other hand, GRIP, which is normally bound to 2-amino-3-(5-methyl-3-oxo-1,2-oxazol-4-yl)propanoic acid (AMPA) receptors, dissociates from them upon neuronal depolarization to induce SerR activation as a consequence of its association with the enzyme. ${ }^{49}$ The activation of NMDA receptors by L-Glu (the agonist) and D-Ser (the co-agonist) leads to the formation of nitric oxide which, by binding to SerR, inactivates the enzyme; this mechanism is a feedback homeostatic regulation of SerR. ${ }^{149}$

iv) SerR is selectively nitrosylated at Cys113, ${ }^{149}$ that is localized near the ATP binding site. The Cys-133 nitrosylation inhibits the enzyme activity likely by decreasing the stimulatory effect brought about by ATP. It was found that such a nitrosylation interferes with ATP binding causing a 40 -fold increase in $\mathrm{K}_{\mathrm{m}}$ for ATP without affecting $\mathrm{V}_{\max }$. The S-nitrosylation does not affect $\mathrm{K}_{\mathrm{m}}$ for L-Ser but causes a 2-fold decrease in $\mathrm{V}_{\max }$. Because NMDA receptors stimulate NO synthase, the SerR nitrosylation seems to act as a negative feedback in regulating the level of D-Ser.

In bacteria, SerR has been implicated in vancomycin resistance..$^{150}$ Vancomycin is a glycopeptide antibiotic that inhibits peptidoglycan synthesis by formation of a complex with the D-Ala- D-Ala residue of the peptidoglycan precursors. Resistance to vancomycin is acquired by modification of the D-Ala- DAla residue. Depending on the phenotype, the second D-Ala residue can be mutated in D-lactate or in DSer, in turn produced by the action of SerR (VanT)..$^{150}$

\subsubsection{Inhibitors and drug perspectives}

Very few potent and specific inhibitors of SerR have been identified to date; the two most potent competitive inhibitors, malonic acid and L-erythro-3-hydroxyaspartic acid, ${ }_{151}$ (Figure 7) possess inhibitory constants in the micromolar range $\left(K_{i}=77 \mu \mathrm{M}\right.$ and $49 \mu \mathrm{M}$, respectively). Recently, a series of hydroxamic and dihydroxamic acids (Figure 7) with potent inhibitory activity was identified by Hoffman et al..$^{152}$ In this series, succinodihydroxamic acid $\mathbf{9}$ appears to be the most potent competitive SerR inhibitor identified to date $\left(K_{i}=3.6 \pm 0.6 \mu \mathrm{M}\right)$. Unfortunately, although some dihydroxamic acids are effective SerR inhibitors (e.g compounds $\mathbf{8}$ and 9), their lack of specificity renders them unattractive 
candidates for further drug development. Their potent inhibition activity was initially attributed to their capacity to chelate $\mathrm{Mg}^{2+}$, a potent SerR activator present in the screening assay. Subsequently, this hypothesis was discarded by the experimental evidence that the hydroxamic acid derivatives maintained their activity even in the presence of a large molar excess of $\mathrm{Mg}^{2+}$, indicating that the capacity of the substrate to chelate $\mathrm{Mg}^{2+}$ plays a marginal role in SerR inhibition. Probably, the inhibition is due to a modification of the cofactor, which forms a catalytically inactive aldoxime species. Among the hydroxamic acid inhibitors, compound 10 (Figure 7) exhibits a moderate selectivity for mouse and human SerR. Compound $\mathbf{1 0}\left(K_{i}=98 \mu \mathrm{M}\right)$ is an L-aspartic acid (L-Asp) analogue and is 20-fold more potent as an inhibitor of mouse SerR than L-Asp $\left(K_{i}=1900 \mu \mathrm{M}\right)$. For these reasons, compound 10 could serve as a lead compound for the development of the next generation of SerR inhibitors.<smiles>O=C(O)CC(=O)O</smiles>

Malonic acid<smiles>N[C@@H](C(=O)O)[C@H](O)C(=O)O</smiles>

L-erythro-3-hydroxyaspartic acid<smiles>O=C(CC(=O)NO)NO</smiles>

8<smiles>O=C(CCC(=O)NO)NO</smiles><smiles>N[C@@H](CC(=O)NO)C(=O)O</smiles>

10

\section{Figure 7}

The very recent determination of the structure of SerR in the absence and presence of ligands has triggered a few studies aimed at the development of SerR inhibitors. In this quest an added difficulty is represented by the need for such compounds to cross the blood-brain barrier.

The comparison of the structures of SerR in the absence and presence of malonate ${ }^{135.136}$ indicates that the enzyme undergoes an open to closed transition upon inhibitor binding. A similar conformational change is likely to occur upon L-Ser binding. Ligand-induced open-closed transitions are common in PLPdependent enzymes and usually involve the reorientation of the small and large domains that form a 
subunit. As a result the volume of the active site is significantly reduced and active site residues are relocated. This molecular event might hamper or make more difficult the identification of high affinity ligands. In fact, if a virtual screening is carried using the open conformation, less specific compounds might be identified, whereas if the screening is carried out using the closed conformation, the reduced space may lead to the identification of ligands with reduced size and affinity. In an effort to overcome these limitations and to include SerR conformational flexibility in virtual screening investigations, targeted molecular dynamics of SerR was combined with conformational sampling and docking studies. ${ }^{153}$ Results suggest that a virtual screenings of SerR carried out sampling a defined number of protein conformations along the open-to-closed state pathway might lead to the identification of selective and high affinity enzyme inhibibitors.

An ongoing investigation is carrying out an in silico screening exploiting the the open structure of human SerR and the searching engine FLAP. ${ }^{154}$ Selected hits were docked in the active site using GOLD $^{155}$ and the free energy of binding was evaluated by HINT.156-158 Compounds that exhibit dissociation constants in the low micromolar range were identified.159 A similar approach was applied to the identification of PLP-dependent enzyme inhibitors of $O$-acetylserine sulfhydrylase. ${ }^{160}$

Finally, SerR activation by ATP and inhibition by Cys133 nitrosylation suggest an alternative route for the modulation of the D-Ser level in the brain. Compounds that target the ATP allosteric site displacing ATP or capable to cause selective nitrosylation of Cys 133 are predicted to inhibit SerR activity.

\subsubsection{Arginine Racemase}

\subsubsection{Localization, structure and function}

ArgR (EC 5.1.1.9) is an example of a PLP-dependent racemase with broad substrate specificity because it catalyzes the racemization of arginine, lysine, ornithine and various other amino acids, including ethionine and citrulline. However, ArgR is unable to recognize and transform hydrophobic, acidic or aromatic amino acids.. The enzyme was first isolated from Pseudomonas graveolens as early as 1971..$^{61}$ It was shown that four moles of the cofactor are bound to one mole of ArgR. In 2009, Matsui et al. ${ }^{162}$ established that in both Pseudomonas taetrolens and Escherichia coli, ArgR resided almost exclusively in the periplasm, a feature so far unknown for any other amino acid racemase. The experiments 
performed with $P$. taetrolens on the utilization of D- and L- amino acids as a carbon source demonstrated that ArgR is a catabolic enzyme necessary for the efficient utilization of the two basic amino acids D-Lys, and D-arginine (D-Arg). ArgR from P. taetrolens was found to contain a disulfide bridge. However, enzyme activity and stability were unaffected by either removal of the disulfide bond through a reduction process or by mutating the involved cysteines. ${ }^{163}$

The existence of an ArgR in Pseudomonas aeruginosa, an opportunistic human pathogen with an enormous catabolic capability, was suggested by Jann et al in 1988..$^{164}$ Generalized inflammation and sepsis are the symptoms of infections by $P$. aeruginosa. If colonization occurs in organs such as lungs, urinary tract, and kidneys, the result can be fatal. P. aeruginosa is capable of growing on D-Arg as the sole source of carbon and nitrogen. ${ }^{165}$

\subsubsection{Inhibitors and drug perspectives}

The observed broad substrate specificity of ArgR suggests the presence in the active site of only a few well defined anchor points. This feature and the lack of three-dimensional structure of ArgR has so far prevented studies aimed at the identification of enzyme inhibitors. Towards this goal, protein expression, careful biochemical investigations and crystallization trials are the pre-requisites. A possible short-cut might be a homology modelling study using as a parent structure the PLP-dependent enzyme that more closely matches ArgR sequence.

\subsubsection{Aspartate Racemase}

\subsubsection{Localization, structure and function}

D-Asp has been detected in the brain and neuroendocrine tissues. ${ }^{1631655168}$ This finding triggered a genomic sequence analysis that led to the identification and cloning of a PLP-dependent enzyme..$^{14}$ The recombinant enzyme exhibits a $\mathrm{K}_{\mathrm{m}}$ value for L-Asp of $3.1 \mathrm{mM}$ and a $V_{\max }$ of $0.46 \mathrm{mmol} / \mathrm{mg} / \mathrm{min}$ at the optimum $\mathrm{pH}$ and temperature of 7.5 and $37^{\circ} \mathrm{C}$, respectively. Based on in vivo experiments in which the enzyme was depleted, it was proposed that D-Asp may function as a modulator of adult neurogenesis..$^{14}$ Furthermore, biochemical investigations, coupled to tissue immunostaining, suggest that D-Asp is a novel endogenous neurotransmitter, ${ }^{169}$ thus indicating that AspR is a potential target for neuropathological disorders. 


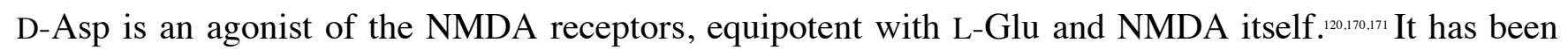
demonstrated that in human brain very high levels of D-Asp occur transiently during the last stage of embryonic life or in the early postnatal life. ${ }^{117}$ In human fetal cortex, the concentration of D-Asp exceeded that of L-Asp, but diminished rapidly to trace levels after birth. D-Asp is crucial for neurotransmission and neurosecretion in the CNS, as well as for the biosynthesis and/or secretion of hormones in endocrine glands. ${ }^{172-174} \mathrm{D}$-Asp is present in some neuronal populations of the brain and of neuroendocrine tissues, such as the catecholaminergic cells of the adrenal medulla, the anterior and posterior lobes of pituitary gland, the pineal gland, and the testes. $.^{120.167} \mathrm{D}-$ Asp is highly concentrated in the supraoptic and paraventricular hypothalamic nuclei, whose axons terminate in the posterior pituitary. ${ }^{175}$ D-Asp occurs also in a high concentration in the pineal gland, ${ }^{176}$ where it modulates melatonin synthesis in rat pinealocytes. ${ }^{177}$ Its localization in different areas of the hypothalamic-pituitary axis suggested that D-Asp might have a role in neuroendocrine modulation. In fact, D-Asp has been shown to increase serum growth hormone $(\mathrm{GH})$, luteinizing hormone $(\mathrm{LH})$ and prolactin levels, through modulation of the release of some of the neuropeptides and neurotransmitters involved in their regulation, such as luteinizing hormone-releasing hormone (LHRH), $\alpha$-melanocyte-stimulating hormone ( $\alpha-\mathrm{MSH}), \mathrm{GABA}$ and dopamine..$^{170.178}$ The high concentrations of D-Asp in the cortical plate, subventricular zone, and discrete portions of the hippocampal formation, during early neonatal stages, imply an important role during the developmental phase. ${ }^{179}$ In adult hippocampus, D-Asp persists in dentate gyrus where new neurons are generated ${ }^{180,18}$ and integrated into existing neural circuitries which are involved in process of learning and memory formation. If D-Asp is physiologically formed by AspR, the enzyme should have similar localizations. ${ }^{14.182 .183}$ It was demonstrated that AspR plays an important role in neuronal development, consistent with the high levels of D-Asp in early neonatal stages. ${ }^{14}$

Although many studies on the physiological relevance of D-Asp have been published, at present, there are no reports dealing with the connection of altered levels of D-Asp with any pathological state. Yamada and his co-workers also reported the occurrence of a PLP-dependent AspR in an ark shell, Scapharca broughtonii. ${ }^{184}$ A peculiar characteristic of AspR from S. broughtonii, is that it is markedly affected by AMP, which maximally enhances its activity up to seven-fold. By contrast, ATP lowers the activity to less than $7 \% .{ }^{185}$ 


\subsubsection{Inhibitors and drug perspectives}

The interest in AspR as a potential drug target for neurological disorders is very recent. ${ }^{14}$ So far, no high yield expression system for AspR has been reported, thus preventing detailed enzyme characterization, biochemical assays and extensive crystallization campaign for the determination of enzyme structure. Given the AspR role in modulating NMDA-associated signals, intensive activities should be first focussed on a deep understanding of enzyme structure-function relationships.

\subsection{PLP-independent Racemases}

\subsubsection{Proline Racemase}

\subsubsection{Localization, structure and function}

A partially purified preparation of ProR from the Gram-positive bacterium Clostridium sticklandii (Cs) was first described by Stadtman and Elliot in 1957. ${ }^{34}$ The first eukaryotic ProR was identified in 2000 by Minoprio et al. in the human parasite Trypanosoma cruzi $(T c),{ }^{186}$ the etiological agent of Chagas disease. ${ }^{187}$ Investigating the in vitro-induced differentiated metacyclic trypomastigotes of $T c$, Reina San Martin et al. ${ }^{188}$ were able to isolate a $45 \mathrm{kDa}$ protein $(T c 45)$ which is involved in the non-specific polyclonal activation of B lymphocytes. Subsequently, it was hypothesized the existence of two homologous of the $T c 45$ genes $(T c 45-A$ and $T c 45-B),{ }^{186}$ where the $T c 45-A$ gene copy shares a high sequence homology with $C$ s ProR, the only ProR then described in the literature. Worthnoting, since the active site of $C s \operatorname{ProR}^{33,186}$ is fully conserved in the $T c 45$ protein, both proteins catalyze the racemization of L- and D-proline (D-Pro) without the aid of any cofactor while leaving unaffected the stereochemistry of the other amino acids. Furthermore, specific or non-specific inhibitors, such as pyrrole-2-carboxylate (PYC), iodoacetamide, and iodoacetate, abolish or severely compromise both the mitogenic activity of $T c$ ProR45 and its enzymatic activity. ${ }^{186}$ Through a site-directed mutagenesis investigation, the Cys330 residue was identified as the key amino acid, since its replacement completely abolished the ProR activity; ${ }^{189}$ the catalytic mechanism was further deepened in $2006 .{ }^{190}$ The crystal structure of the TcProR$A$ was obtained with its competitive inhibitor PYC and showed that the enzyme is in fact a homo-dimer, with each monomer folded in two equally sized $\alpha / \beta$ domains separated by a deep crevice. The refined 
model revealed the presence of two molecules of the inhibitor, each one occupying the central hydrophobic cavity of the monomer (see Figure 8). Each of the active site cavities found in the interdomain crevices, includes two cysteines (Cys130 and Cys300 in TcProR-B; Cys160 and Cys330 in TcProR-A) which are suitably located to perform the acid-base catalysis of L/D-Pro (Scheme 7), according to the general mechanism proposed for PLP-independent racemases.
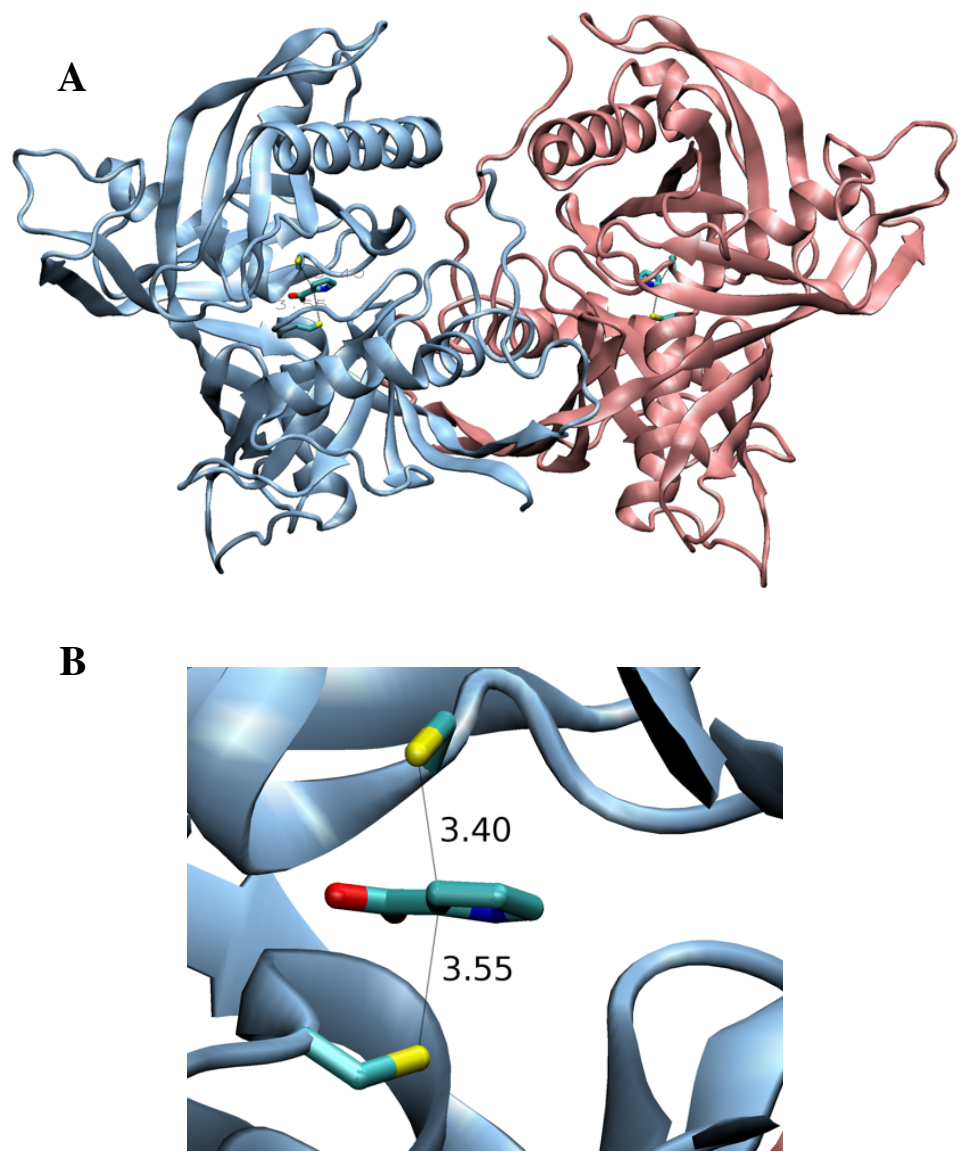

Figure 8

Since the $\mathrm{pKa}$ value of the Cys sulfhydryl group in aqueous solution is 8.4 , it should be almost completely protonated at physiological $\mathrm{pH}$ and therefore unable to remove the $\alpha$-proton of Pro. However, it has been suggested that the electrostatic field inside the enzyme could highly perturb its aqueous $\mathrm{p} K \mathrm{a}$ value, generating the anionic species needed for the catalytic process. 


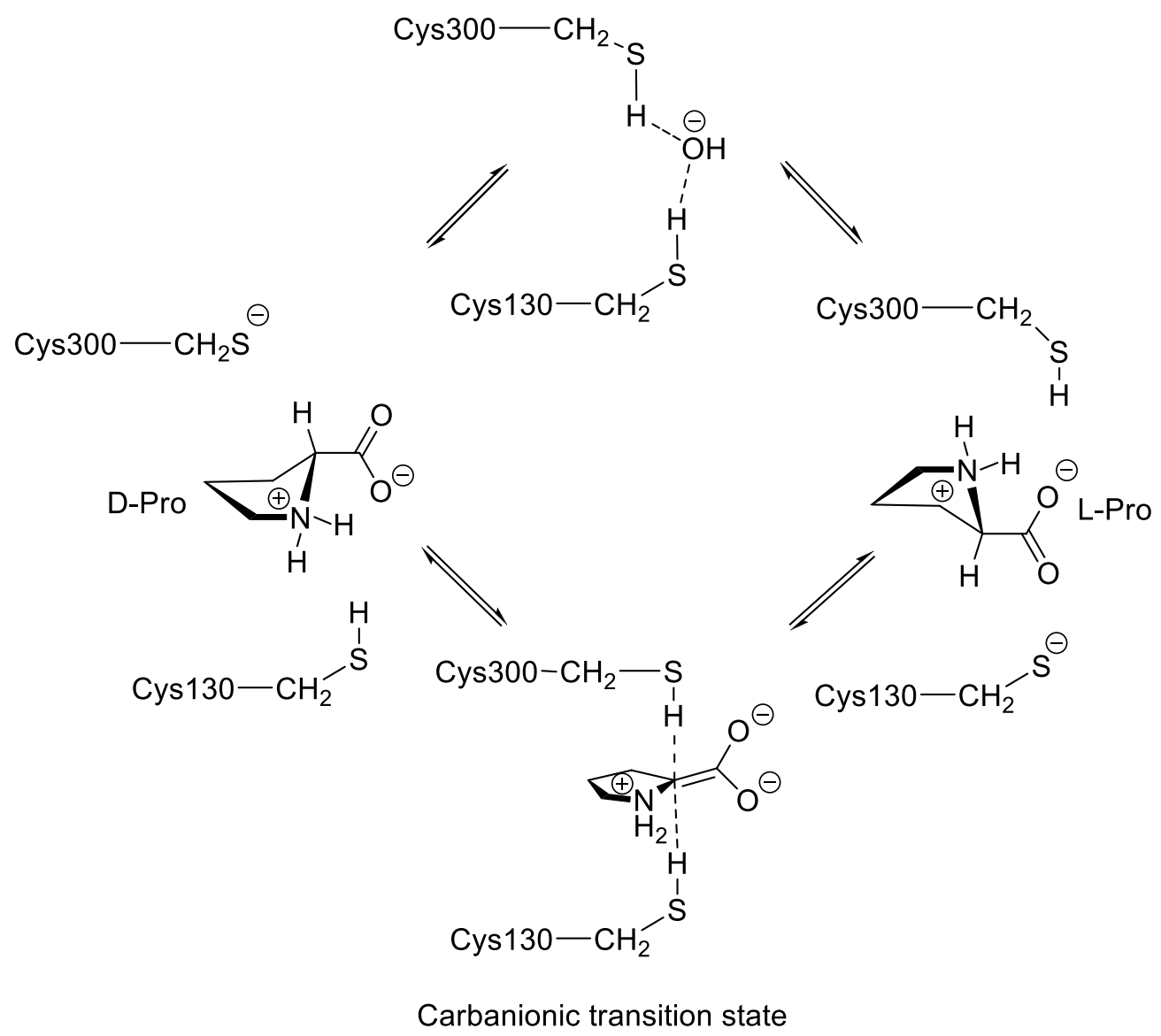

Scheme 7

In the crystal structure of the complex of ProR with PYC, an inhibitor representing a transition state analogue, the $\mathrm{C} 2$ atom of PYC is in close contact with the two sulfhydryl groups of residues Cys130 and Cys300 from equivalent $\alpha$-helices in each structural domain (Figure 9). ${ }^{100}$ This experimental evidence strongly supports the 'two-base' mechanism. PYC is firmly fixed in place through H-bonding interactions of its carboxylate group with five amino acidic residues of the enzyme; additionally, the Pro quaternary amine group is involved in hydrogen bonding interactions with His132 and Asp296. The $\mathrm{pKa}$ of proline inside the ProR active side may be estimated to be about 23.4, reflecting a reduction of more than $7 \mathrm{pKa}$ units when compared to the calculated value of 30.9 in aqueous solution. This relatively high $\mathrm{pKa}$ of Pro in the active site raises the question of why $\mathrm{C} \alpha$-deprotonation occurs and not deprotonation of the ammonium group of the zwitterionic Pro ( $\mathrm{pKa} \approx 9.6$ ). Probably the answer is the tight interactions with His132 and Asp296, which prevent Pro from reorienting in a position enabling ammonium deprotonation. ${ }^{61.90}$ 


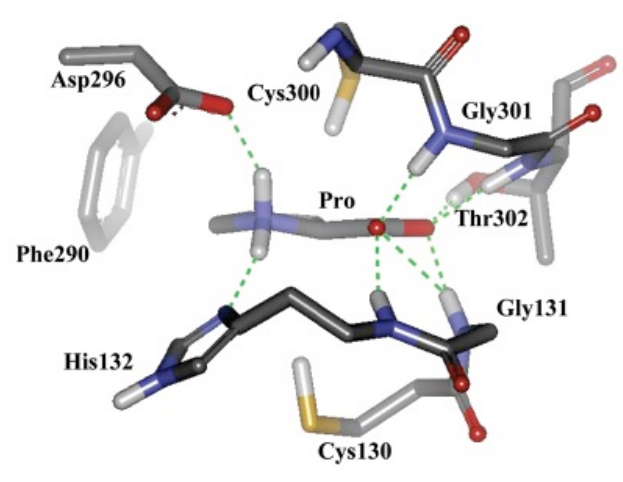

Figure 9

As in other PLP independent amino acid racemases, the two domains of each monomer in the dimeric TcProR-A are structurally equivalent. The symmetric properties correlating both subunit domains stand on a dyad axis crossing the reaction center granting to the enzyme the ability to react with both enantiomeric forms of proline. A complete thermodynamic characterization of TcProR-A association with its inhibitor was obtained by isothermal titration calorimetry (ITC) using temperatures between 15 ${ }^{\circ} \mathrm{C}$ and $35{ }^{\circ} \mathrm{C}$. The binding isotherm was best fitted to a model with two interacting sites with the enzyme expressed in terms of protein-dimer concentration. This data confirmed that TcProR-A binds with high affinity $\left(\mathrm{K} 1=4.6 \times 10^{\circ} \mathrm{M}^{-1}, \mathrm{~K} 2=3.0 \times 10^{5} \mathrm{M}^{-1}\right)$ two molecules of PYC as a dimer in solution. The ITC also supported the negative cooperativity and a differential packing constraint among the subunits. Thus, the binding of the first ligand molecule triggers conformational changes of one of the monomers resulting in a $c a .15$ times lower affinity to bind the second inhibitor molecule. This property may explain the initial conclusions of Rudnick and Abeles on one active site per dimer by quantifying the binding stoichiometry of the inhibitor at equilibrium. ${ }^{33}$

Recently, the corresponding TvProR gene and functional enzyme have been found also in Tripanosoma vivax (Tv), a livestock trypanosome cyclically and mechanically transmitted between domestic and wild ruminants by tsetse flies, tabanids and other varieties of biting flies. ${ }^{191}$

The human parasite $T c$ as well as the livestock-infective $T v$ take advance of the presence of ProR in their genome as a way to escape the host immune responses. It has been hypothesised that $T c$ ProR is also involved in the machinery of the parasite differentiation by regulating intracellular proline metabolic pathways through the conversion of free L-Pro, internalised from the vector digestive tract, into D-Pro, that would be integrated into expressed peptides or stocked in reservosomes. ${ }^{191.192}$ The 
replacement of the L-Pro moiety with its mirror image, i.e. D-Pro, into a peptide sequence increases its half-life, stability and resistance to host proteases. Furthermore, the presence of D-Pro would make the peptide less immunogenic than the corresponding one made up exclusively by L-amino acids..$^{193,194}$

In addition to the above mentioned enzymatic properties, ProR of both $T c$ and $T v$ possesses a T-cellindependent B-cell mitogenic activity.

Attempts to better explore the direct or indirect association between TcProR mitogenic and enzymatic activities have demonstrated that they are dissociated ${ }^{186,189}$ It is believed that the structure of $T c P r o R$ active site may expose protein conformational motifs that bind to B-cell expressed molecules, thus triggering lymphocyte activation. Indeed, modification of key catalytic site residues of the enzyme aiming at abolishing catalysis without altering TcProR conformational structure, produced TcProR mutants in which the mitogenic activity was preserved. On the other hand, B cell proliferation assays showed that TcProR inactivated by PYC was unable to trigger B-cell proliferative activity. These data confirmed that conformational changes of TcProR takes place upon inhibitor binding preventing its direct interaction with B-cell expressed ligand(s) and that polyclonal B-cell activation observed with TcProR is unambigously dependent on conformational epitopes displayed by the active protein.

\subsubsection{Inhibitors and drug perspectives}

In the previous section we have discussed how the first eukaryotic ProR was identified in $T c$. This intracellular protozoan causes Chagas disease, one of the most neglected diseases. Endemic in several regions of Latin America, this disease persists as the major infectious heart disease in the world..$^{195.196}$ It is estimated that 13 million people are currently infected in Central and South America and that the global incidence of the disease is 300,000 new cases per year. ${ }^{197}$ Natural transmission of the disease occurs through faeces of the vector (a haematophagous bug belonging to the subfamily Triatominae, family Reduviidae) deposited near a skin lesion or mucosa (80-90\%) or via organ transplantation/blood transfusion (5-20\%) or congenital transmission (0.5-8\%). The majority of infections occur during early childhood, and around 30\% infected people develop chronic cardiac involvement, usually after decades of asymptomatic infection. 
The available therapeutic options for Chagas disease are very limited. At the moment, there are only two drugs, nifurtimox and benznidazole (Figure 10), which may be helpful in the acute stages of the infection. Both of these drugs cure around $80 \%$ of the acute form of the disease and $20 \%$ of the chronic one. Patients require 60 days of treatment, with 2-3 doses per day. The drugs are of difficult access for patients in non endemic areas, and the distribution of benznidazole is restricted to specialised clinics that require medical monitoring during the course of treatment. Moreover, both medications have serious side effects limiting their use. Benznidazole is contraindicated to treat pregnant women and, more generally triggers liver and kidney failure. Nifurtimox has been gradually discontinued and particularly contraindicated to patients previously diagnosed with psychiatric and neurological disorders. Furthermore, some strains of $T c$ are resistant to the treatment. ${ }^{198}$ Therefore, it is clear that it is of utmost importance to find out new therapeutic targets and novel drugs for the treatment of Chagas disease, particularly for late stages of the disease.

ProR is an essential enzyme in the parasite metabolism and in the interactions of the parasite with the host immune defences. Chamond and colleagues constructed transgenic parasites for TcProR genes and analyzed the ability of mutants to pursue differentiation into infective forms and to interact with host cells. ${ }^{192}$ The data determined that over expression, but not reduction, of $T c$ ProR in non-infective forms leads to an increase in parasite differentiation to metacyclic infective forms and enhance parasite infectivity to host cells. The existence of proline transport systems in $T c$ has added importance to the role of $T c$ ProR to parasite bioenergetics, ${ }^{199}$ since L-Pro is known as the most important carbon source in trypanosomatids.$^{200}$ Consequently, inhibitors of ProR could represent a new therapeutic approach for the treatment of Chagas disease. Unfortunately, at the moment only few molecules capable to inhibit ProR have been reported.

ProR of Clostridium sticklanclii and of Tc is inhibited by PYC (Figure 10). Modifications of the heterocyclic ring lead to a reduction of the inhibitory activity. In fact, the thiophene analogue is less effective while the furan analogue is almost inactive. The high affinity for the enzyme of PYC could be due to the planar arrangement of its key substituents, which mimic the transition state of the proline racemization process represented by 4,5-dihydro-3H-pyrrole-2-carboxylic acid, which turned out to be a good inhibitor of ProR. 


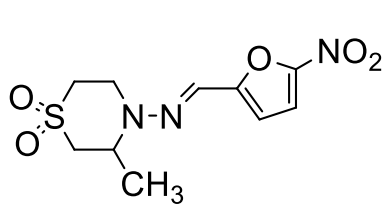

Nifurtimox

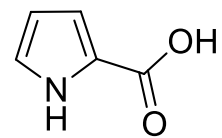

PYC

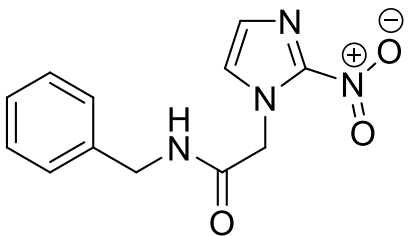

Benznidazole<smiles>O=C(O)C1=NCCC1</smiles>

4,5-dihydro-3H-pyrrole-2-carboxylic acid

\section{Figure 10}

Crystallographic data have shown that incubation of $T c$ ProR in the presence of PYC promotes considerable alteration of the enzyme structure, thus interfering with its binding to B-cell expressed ligands. ${ }^{190}$ Furthermore, studies of $T c$ ProR localization showed that the enzyme localizes in the cytoplasm of intracellular dividing parasites (tissue amastigotes) and nearby the flagellar pocket, the principal site of excretion/secretion of trypanosomes. Interestingly, the addition of PYC to $T c$-infected cultures results in a dose-dependent decrease of the conversion of amastigotes to circulating trypomastigotes, suggesting that the enzyme, which is up-regulated in actively multiplying parasites, may be related to the parasite differentiation triggering steps. ${ }^{201}$ The addition of PYC during the initial steps of the parasite-host cell interaction led to a significant initial reduction of Tc invasion in vitro. The inhibition of the enzyme has a direct or an indirect influence on the parasite metabolism, differentiation and virulence. Unfortunately, PYC has a very poor solubility in water and this problem limits its further development as a drug. Minoprio's and Blondel's groups and collaborators had dedicated lots of efforts to produce by medicinal chemistry more soluble PYC variants and to design pharmocophoric models based on the catalytic site of $T c$ ProR to be further used in virtual screening of compound libraries. However, at present, those attempts have not yet yielded better inhibitors with a higher affinity for the enzyme than PYC. ${ }^{202}$ The active site of $T c$ ProR in its complexed form defines a small pocket of $100 \AA^{3}$ presenting a very specific set of oriented functional groups. Hence, the design of active inhibitors for this enzyme by the classical strategies of drug design represents a particular challenge. Therefore, a more aggressive and less traditional approach has been conceived. It takes advantage of the conformational changes observed in the $T c$ ProR upon ligand binding. In effect, ongoing innovative approaches and modeling technologies making use of Molecular dynamics and transition path 
calculations $^{203}$ can be used to build new docking models for enzymes, either in the catalytic site or by identifying previously unknown allosteric sites. This approach, based on a new powerful transition Path Optimization and Exploration method (POE), has proved to allow a drastic expansion of virtual screening strategies and, thus, of the chemical space accessible through computational aided drug design, as successfully validated in other systems..$^{204}$

A different approach was first reported by Minoprio's group, which tried to use TcProR45 as a 'vaccine'. ${ }^{205}$ The aim was to induce specific responses against TcProR45 and neutralise its mitogenic activity. They developed two protocols. In the first one, intramuscular DNA 'vaccination' containing the $T c$ ProR45 gene was used. It turned out that 'immunoprotection' is possible, since an $85 \%$ decrease in the levels of parasitaemia, after a challenge with infective forms of the parasite, was obtained. Moreover, even higher levels of parasitaemia control have been observed when sub-mitogenic doses of the protein were injected. In the second protocol, an i.p. injection of low doses of recombinant protein (rTcProR45) was used. The outcome was a decrease up to $95 \%$ of the mice parasitaemia, after challenge with a lethal inoculum of $T c$. Therefore, both protocols of immunization were able to trigger specific B cells and consequently high levels of antibodies anti-rTcProR45 were detected in sera.

In 2010, Bryan et al showed that TcProR may contribute to delay host immune effector mechanisms by non-specifically activating B cells, especially marginal zone B cells, causing hypergammaglobulinemia and inducing production of interleukin-10, a cytokine known to increase host susceptibility to $T c .^{206}$ While $T c$ ProR45 is apparently non-antigenic during experimental T. cruzi infection, it can be delivered as a potent antigen via genetic immunization. Genetic immunization with $T c$ ProR did not lead to detectable systemic B-cell expansion and did not interfere with the immune response to a different test of immunogenity. Moreover, genetic vaccination with $T c$ ProR induces the triggering of memory B cells, underlying the usefulness of $T c$ ProR as a target to the development of new therapies against trypanosomiasis.

Finally, it is also possible to suppose that the parasite uses the racemization process to synthesise and/or express new peptides containing D-Pro to avoid or reduce the host-induced proteolysis. The identities of the parasite proteins bearing D-Pro should be discovered and investigated since they may become 
attractive targets involved in parasite evasion..$^{193}$ These last studies offer the basis for further development of novel strategies to treat Chagas and other infectious diseases.

\subsubsection{Glutamate Racemase}

\subsubsection{Localization, structure and function}

GluR (EC 5.1.1.3) is another PLP-independent racemase that occurs in prokaryotes. The first evidence of GluR from Lactobacillus arabinosus dates back to 1952, but its biochemical function was not clarified..$^{20208}$ In early nineties, it was demonstrated that, like ProR, GluR uses a 'two-base' mechanism in which the sulfhydryl groups of two cysteines serve as the general base/acid catalysts. ${ }^{36}$ The involvement of the two Cys residues was demonstrated with the enzyme from Lactobacillus fermenti, since their replacement, one at a time, with an alanine completely abolished the racemase activity ${ }_{.09}^{209}$ Similar results were obtained by replacing the Cys residues with Thr/Ala in the enzyme from E. coli. ${ }^{210.211}$ It was also suggested that Cys73 is responsible for the deprotonation of D-Glu, while Cys184 is responsible for the deprotonation of L-Glu. Moreover, it was shown that neighboring residues, i.e. Asp10 for the conversion of D into L and His186 for the reverse conversion, assist the catalytic thiol groups in acting as bases. ${ }^{212}$

The structure determination of GluR from Aquifex pyrophilus in the absence and presence of Dglutamine, a weak inhibitor, provided the first structural elucidation of the architecture of the active site. ${ }^{213}$ However, no strong interactions between D-glutamine and the amino acid residues present in the active site were noticed. In 2005 it was reported the crystal structure of the GluR from L. fermenti, ${ }^{214}$ which shares approximately $32 \%$ sequence identity with A. pyrophilus GluR. It represents the first three dimensional structure of a cofactor-independent racemase from a Gram-positive bacterium.

NMR studies carried out on B. anthracis $\mathrm{GluR}^{215}$ and on monomeric H. pylori GluR, ${ }^{216}$ allowed the establishment that the enzyme is quite flexible, adopting multiple conformations. The enzyme active site is rather small, therefore substrate and product can access it exploiting the enzyme flexibility.

GluR is essential to the bacterial cell wall biosynthesis pathway, since the incorporation of D-Glu as the second residue of the pentapeptide is strictly conserved across the bacterial kingdom. ${ }^{6}$ GluR has been implicated in the production and maintenance of sufficient D-Glu pool levels required for growth. 
Peptidoglycan biosynthesis is classified into three distinct phases based on the cellular location of the synthetic pathway. Most of the active drugs act through inhibition of the Phase III segment, which involves the extracellular cross-linking and final maturation of the cellular envelope. Even if the discovery of improved agents that target this phase remains a dominant area of research and development, the onset of resistance limits the therapeutic utility of this class of compounds. Moreover, the emergence of multi-drug-resistant (MDR) bacteria, such as methicillin-resistant Staphylococcus aureus, MDR-Pseudomonas aeruginosa and MDR-Acinetobacter baumannii, has resulted in significantly increased mortality rates with limited or no options for therapeutic intervention. ${ }^{217}$ This crisis has resulted in a call for the discovery of drugs that have a novel mode of action. ${ }^{218}$ Therefore, targeting GluR, which is involved in phase I of peptidoglycan biosynthesis, represents a novel strategy in the search for new antibacterial agents.

\subsubsection{Inhibitors and drug perspectives}

Although the officially recognized importance of GluR as a target for antibacterial drugs, until 1997 only two GluR inhibitors have been reported, L-serine- $O$-sulfate (L-SOS) ${ }^{219}$ and aziridino glutamate (Figure 11).20 Both drugs are irreversible inhibitors and, in addition, suffer either from an inefficiency of the process or an instability.

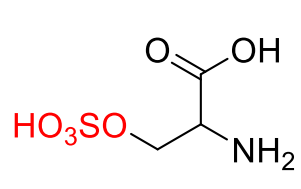

L-SOS<smiles>O=C(O)CCC1(C(=O)O)CN1</smiles>

Aziridino glutamate<smiles>N[C@H](CCC(=O)O)C(=O)O</smiles>

D-N-hydroxyglutamate<smiles>[R][Te][C]([X])C(=O)O</smiles>

11<smiles>N[C@@H](CC(Cc1cccc2ccccc12)C(=O)O)C(=O)O</smiles>

12 


\section{Figure 11}

In the subsequent years, an increased number of GluR inhibitors have been published. Most of the first generation inhibitors are characterized by the presence of an amino acidic chain in their structure. D- $N$ hydroxyglutamate (Figure 11$)$ belongs to this class; it is a good competitive inhibitor $\left(K_{i}=56 \sim \mu \mathrm{M}\right)$ of GluR from Lactobacillus fermenti. ${ }^{221} N$-hydroxyglutamate undergoes an enzyme-catalyzed elimination reaction, that leads to the formation of an imine intermediate (Scheme 8) which is responsible for the strong inhibition. Such an imine could mimic the normal carbanionic intermediate and thus be strongly bound by the racemase. Moreover, hydration of the imine and subsequent elimination of ammonia produces $\alpha$-ketoglutarate as depicted in Scheme 8 .
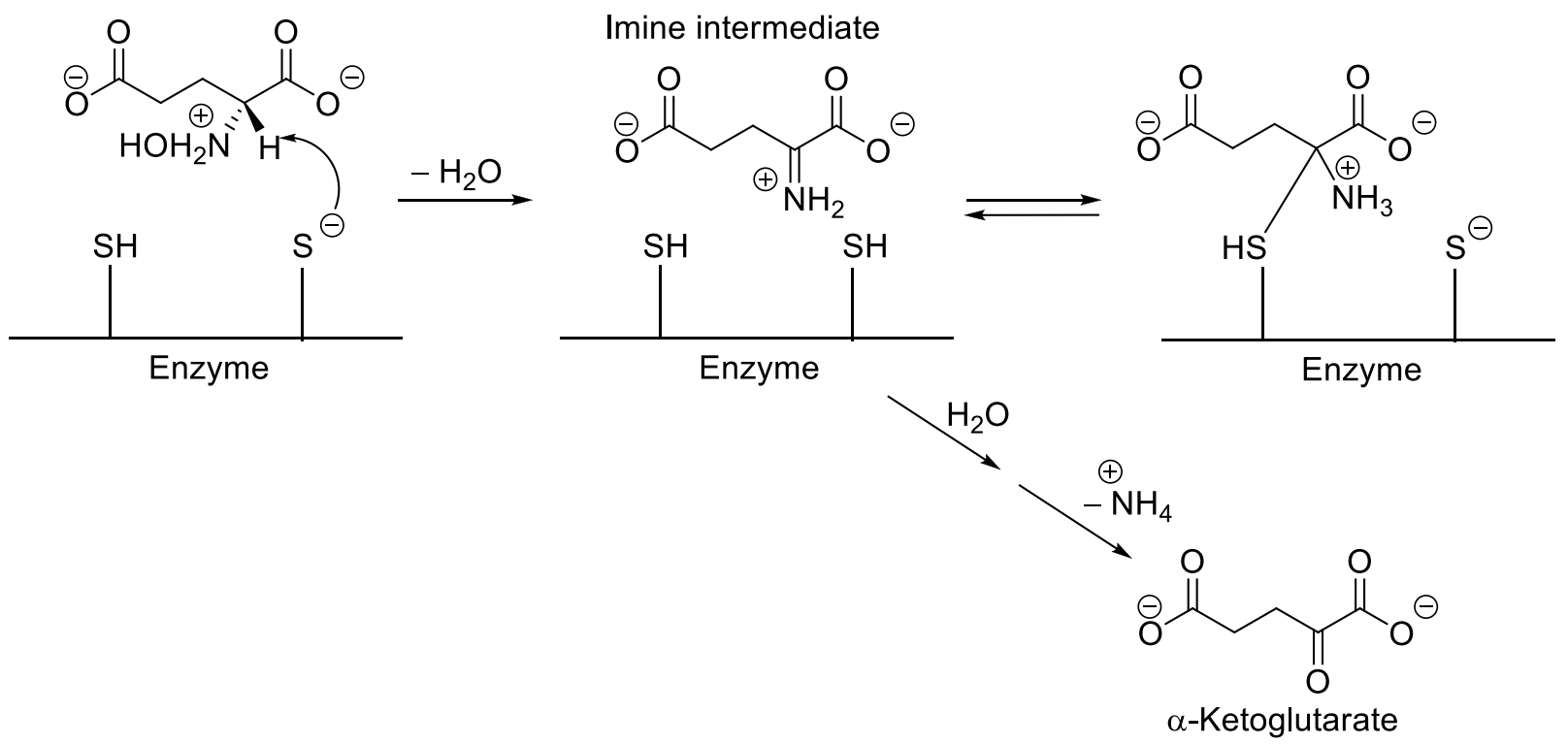

Scheme 8

In 2002 , the discovery of a new class of $(2 R, 4 S)-4$-substituted D-Glu analogues (Figure 11, general structure 11) was reported by Lilly researchers; ${ }^{222}$ this class of compounds showed a promising activity against $S$. pneumoniae, one of the most frequent cause of bacterial respiratory infection and meningitis. One of the most potent compound of this series is the 2-naphthyl derivative (Figure 11, compound 12), with a $K_{i}$ of $16 \mathrm{nM}$. A further increasing in activity was achieved by replacing the naphthyl moiety with a heteroaromatic bicyclic groups, i.e. 2-benzothienyl, 2-(3-Cl-benzothienyl) and 3-(2'-furyl) groups; these new derivatives exhibited inhibition of bacterial infection in an in vivo murine model. 
In the last few years, the research was focused mostly on non amino acidic scaffolds. In this contest, high-throughput screening of the AstraZeneca collection compounds identified a number of hits including 9-benzyl purines that showed good activity against Enterococcus faecalis and Enterococcus faecium GluR. Despite a number of efforts to improve the pharmacological profile of the lead compound through strategies based on an iterative structure-based drug design, only modest improvements in potency was observed for the Enterococcus spp and no activity was detected against the S. aureus enzyme. Furthermore, many members of the series exhibited relatively poor solubility and only moderate antibacterial activity. In 2008, researchers from the same company reported a successful 'scaffold-hopping' endeavor from the 9-benzyl purines to the 8-benzyl pteridinediones and a hit-to-lead work on this series (Figure 12). Among the tested compounds, 2-benzylthio 8-benzyl pteridinedione showed activity against the $S$. aureus enzyme as well as E. faecalis and E. faecium. ${ }^{223}$ Moreover, by decorating the scaffold with different substituents at the 2-, 4- and 8-positions emerged some derivatives provided with a relevant inhibition potency and improved physical properties. The broad spectrum of action exhibited by some derivatives of this series represents a breakthrough in the development of small molecule inhibitors. Unfortunately, this series of compounds generally exhibits a poor solubility. Attempts to improve their physical properties by incorporating polar substituents gave a moderate success.

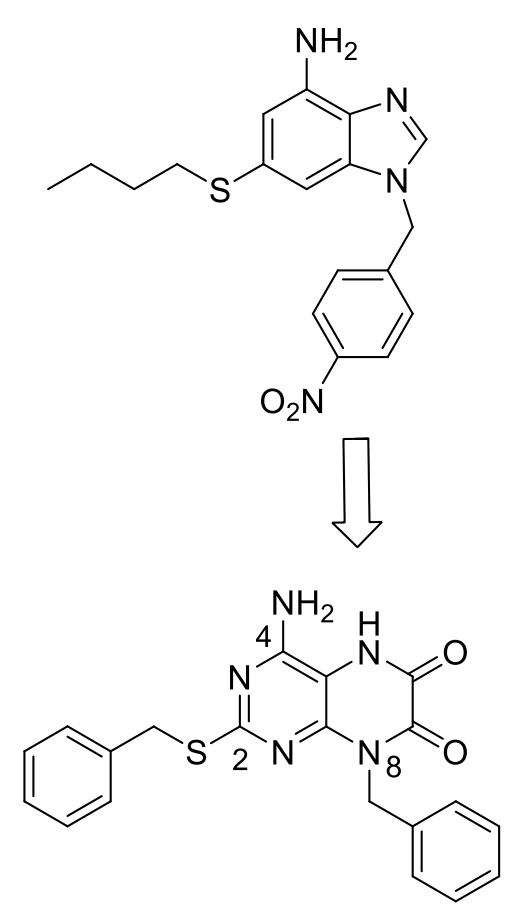




\section{Figure 12}

Recently, a very interesting research plan focused on the design and synthesis of selective $H$. Pylori GluR inhibitors has been published..$^{24} H$. pylori erodes the stomach mucosa and causes gastritis and peptic ulcers. ${ }^{225}$ Moreover, a relationship between infection by such a bacterium and an increased incidence of a gastric cancer has been proposed. ${ }^{262627}$ Current therapies, based on the combined administration of two antibiotics with a proton pump inhibitor (Triple Therapy), gave rise to numerous drawbacks, such as stomach upset, diarrhea, headache, a metallic taste and sensitivity to the sun, that consequently involve a poor patient compliance. ${ }^{228}$ Additionally, the appearance of $H$. pylori strains resistant to the drugs diminished the effectiveness of the multiple therapies. In this contest, researchers at AstraZeneca focused their attention on the design of new H. pylori GluR inhibitors. An initial highthroughput screening of the AstraZeneca compound collection and a subsequent lead optimization

process allowed the identification of pyrazolopyrimidinedione 13 (Figure 13). Such a compound possesses a low nanomolar inhibitory activity at $\operatorname{GluR}\left(\mathrm{IC}_{50}=26 \mathrm{nM}\right)$ but, due to its low aqueous solubility and bioavailability, it is not suitable for oral administration. With the aim to improve its bioavailability, a series of analogues bearing polar functionalities onto the fused pyrimidinedione scaffold were prepared and tested. 

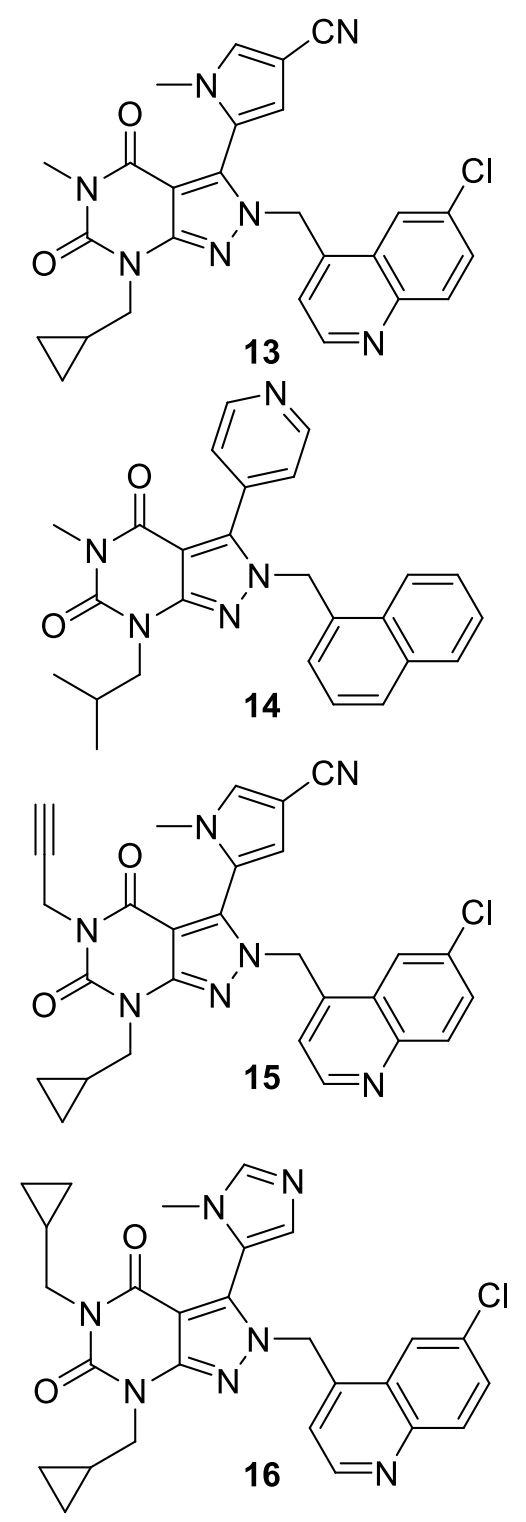

\section{Figure 13}

In Figure 13 are reported the structures of some derivatives characterized by a high inhibitory activity against H. pylori GluR. These inhibitors are time-independent, fully reversible and insensitive to changes in enzyme or detergent concentration. Remarkably, studies of kinetic inhibition on compound 14 indicated that it does not compete with glutamate and, quite interesting, glutamate binding was required for inhibition. H. pylori GluR was co-crystallized with both a substrate (D-Glu) (Figure 14A, B) and an inhibitor (compound 14) (Figure 14C) and the structure of the complexes were solved at high-resolution..$^{29}$ The major feature of the crystalline structure is the presence of a cryptic pocket, formed by a dislocation of the C-terminal helix, capable to accommodate the inhibitor and located $\sim 9 \AA$ 
away from the catalytic centre. The inhibitor binding pocket is formed by displacement and rotation of the $\operatorname{Trp} 252$ side-chain with the pyrazolopyrimidinedione core of derivative $\mathbf{1 4}$, as well as the other members of the cluster, forming a $\pi$-stacking interaction which involves its naphthyl moiety and the indole ring of Trp252 (Figure 14C). Worth of note, the structure of the active site did not change on binding of the inhibitor. 


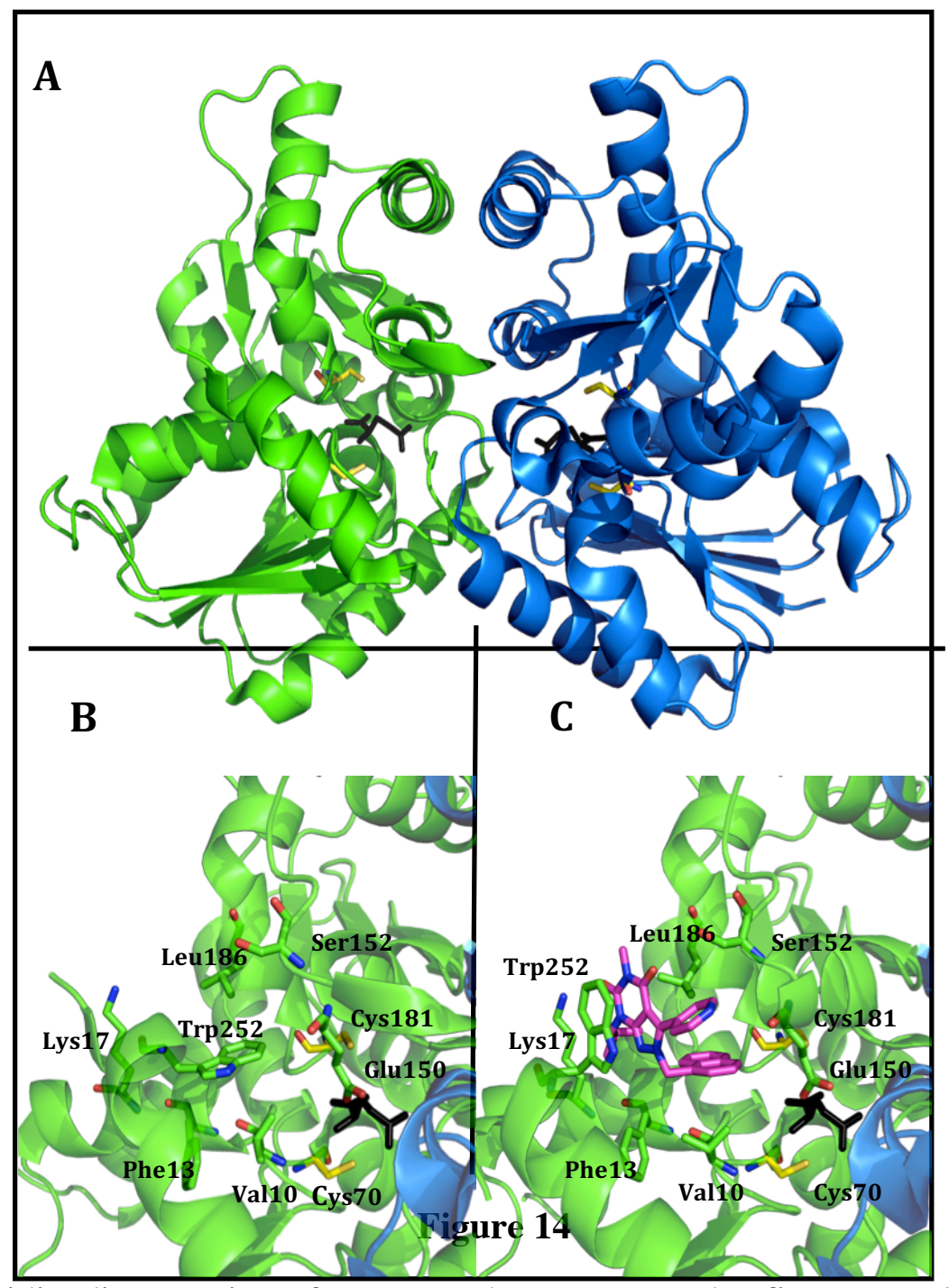

The pyrazolopyrimidinedione series of compounds represents the first example of non-competitive inhibitors of a single-substrate enzyme which fit a cryptic allosteric site. This outcome further highlights the power of a high-throughput screening to search enzyme inhibitors with a novel mode of action. Once again, physico-chemical properties need to be optimized to achieve values of solubility and membrane permeability suitable for oral administration. ${ }^{22}$ Potent analogues, characterized by good in vivo clearance, oral bioavailability and low susceptibility to bacterial efflux pump transport, i.e. derivatives 15, 16, were identified; unfortunately, an improved microbial potency is paralleled by an increase in lipophilicity which enhances the protein binding and lowers the solubility (Figure 13). As a result, the lack of efficacy of the above reported optimized compounds in a murine mouse model of $H$. pylori colonization was attributed to an insufficient plasma concentration of the free drug. Anyway, the 
high degree of selectivity for $H$. pylori GluR showed by these compounds makes them attractive candidates for a novel $H$. pylori-selective therapy.

A second series of allosteric inhibitors targeting the H. pylori GluR enzyme has been reported. ${ }^{230}$ In this series, a novel scaffold represented by the benzodiazepine amine 17 (Figure 15) was discovered by a high-throughput campaign of the former Zeneca compound collection. Also these compounds show selectivity for the H. pylori GluR. X-ray crystallographic studies demonstrated that these inhibitors bind at a site that is clearly distinct from the one that accommodates the pyrazolopyrimidinedione derivatives. This binding site is located along the symmetry axis of the dimer interface. In contrast to the pyrazolopyrimidinedione series, the optimized benzodiazepine analogues generally exhibited improved physico-chemical properties. Physico-chemical parameters such as protein binding, solubility, lipophilicity and molecular weight suitable for oral administration were the hallmarks of the series (e.g. compounds 18 and 19). Despite such an excellent profile, attempts to demonstrate efficacy in a murine H. pylori colonization model turned out to be unsuccessful; the lack of activity was attributed to insufficient concentration levels of the free drug in the plasma of mice caused by a high intrinsic clearance. $^{231}$
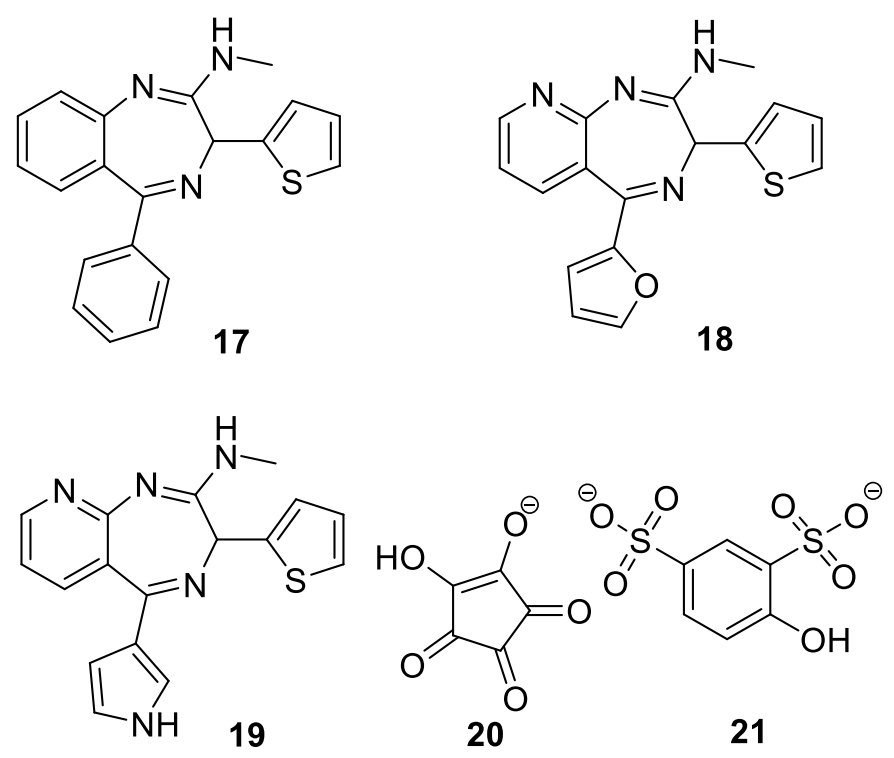

\section{Figure 15}

A recent paper by Whalen et al. ${ }^{232}$ reports a virtual screening using a transition-state conformation of the B. subtilis GluR enzyme. This study resulted in the discovery of several competitive inhibitors, i.e. 20 
and 21 (Figure 15), provided with $\mathrm{IC}_{50}$ values in the micromolar range $\left(K_{i}=42 \mu \mathrm{M}\right.$ for 20 and $59 \mu \mathrm{M}$ for 21). Since the structures of these novel inhibitors are dissimilar from those of current amino acid like inhibitors, they could represent novel scaffolds to be used in the drug discovery process.

Besides these classes of small molecules that inhibit GluR, two reports on large-molecule inhibitors (molecular weight $>650$ ) have been published. The first report identified haemin as a moderately potent inhibitor of the $P$. pentosaceus GluR enzyme. ${ }^{233}$ Haemin was found to be a non-competitive inhibitor $\left(K_{i}\right.$ $=3.7 \mu \mathrm{M})$, hypothesized to bind either to the orthosteric site, or to a distal site inducing a conformational change. The second report, published in 2000 , showed a series of peptides ${ }^{234}$ provided $^{2}$ with a weak inhibitory potency $\left(\mathrm{IC}_{50}=160 \mu \mathrm{M}\right)$ for the $E$. coli GluR enzyme.

\subsubsection{Aspartate Racemase}

\subsubsection{Localization, structure and function.}

The PLP-independent AspR (EC 5.1.1.13) shares with the other members of the AspR group the same 'two-base' mode of action. AspR was discovered in Streptococcus faecalis and partially purified in 1972. ${ }^{235}$ In 1991, Yohda et al. found that AspR occurs exclusively in lactic acid bacteria, such as Streptococcus species and Lactobacillus species, and succeeded to purify the enzyme to homogeneity from Streptococcus thermophilus. ${ }^{236}$ Lactic acid bacteria are characterized by the presence of a D-Asp residue in the peptidoglycan crossbridge, which is produced from L-Asp by the action of AspR. The same Authors were able to clone the AspR gene of $S$. thermophilus and to determine the nucleotide sequence of the gene. ${ }^{237}$

The crystal structure of the Pyrococcus horikoshii OT3 AspR (PhAspR), disclosed in 2002, exhibits a dimeric assembly (Figure 16A) ${ }^{238}$ As expected for a PLP-independent racemase, it showed two strictly conserved Cys residues (Cys82 and Cys194) in its catalytic site (Figure 16B). These two cysteine residues as well as other surrounding amino acid residues, i.e. Asn83, Thr84, Gly193, and Thr195, are highly conserved among all AspR isoforms and some other PLP-independent racemases (Figure 16B). 


\section{Figure 16}

Furthermore, the active site of all known AspRs contains two basic amino acids, i.e. Arg48 and Lys164 (Figure 16B), which are essential to the functionality of the enzyme since they seem to play an 
important role in the substrate recognition and binding. ${ }^{239}$ In particular, the X-ray structure of an inactive mutant of PhAspR complexed with citric acid suggested that Arg48 is responsible for recognizing the carboxylate moieties of the substrate and to stabilize the reaction intermediate, while Lys164 is responsible for stabilizing the closed state structure. ${ }^{240}$

The AspR shows approximately $26 \%$ sequence identity with the GluR from A. pyrophilus. Worth noting, the two enzymes show major differences in the structure of their catalytic site despite the marginal difference among the structure of their natural substrates, namely Asp and Glu, and the similar sequence homology in the core centre..$^{238}$ This reflects into a restricted substrate specificity: in fact GluR exclusively acts on D- and L-Glu, ${ }^{241}$ while both enantiomers of Asp are inactive as substrates, and do not affect Glu racemization. In analogy, AspR is highly specific for Asp. In the crystal structure of both the enzymes, the position of the two regions Cys82-Asn83-Thr84 and Gly193-Cys194-Thr195, as well as of two other threonine residues are highly conserved. These features allow the interaction between two moieties of the enzyme (the sites of Cys, Thr and Asn) with the amino acidic portion of both enantiomers of the substrate. As mentioned above, also the residues Arg48 and Lys164 are strictly conserved in all AspR. Their positively charged guanidinium or ammonium group can form an ion-ion interaction with the negatively charged L-/ D-Asp carboxylate moiety. In addition, Thr84/Thr124 can interact with the amino or the positively charged ammonium group of L-/ D-Asp through a hydrogen bonding.

The Arg and Lys residues of the active site are not conserved in the GluR of A. pyrophilus, which means that the interaction between these residues and the side-chain carboxylate group of glutamate enantiomers may be pointless for their recognition by GluR. The distance between the $\gamma$-sulfur atoms of the two Cys residues present in the active-site of $A$. pyrophilus GluR is $7.6 \AA$, a value definitely lower than that (about $9.6 \AA$ ) found in PhAspR. ${ }^{239}$

\subsubsection{Diaminopimelate epimerase}

\subsubsection{Localization, structure and function.}

DAPE (EC 5.1.1.7) is a member of the PLP-independent amino-acid racemases. It catalyzes the stereoinversion of (L,L)-2,6-diaminopimelate to meso-2,6-diaminopimelate in the lysine-biosynthetic 
pathway in plants and bacteria (Scheme 9). Since lysine biosynthesis does not occur in animals, the members of such a pathway, such as DAPEs, are attractive targets for the rational design of antibiotics..$^{242,243}$

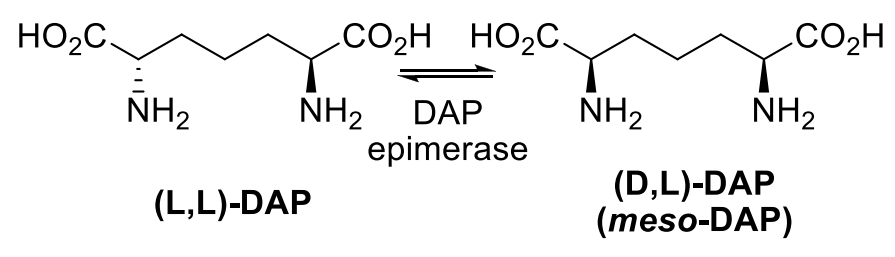

\section{Scheme 9}

DAPE is a unique member of this family of racemases, because its substrates [(L,L)-DAP and (D,L)DAP)] contain two stereocenters but the enzyme recognizes the sole two stereoisomers with the L configuration at the distal site. The DAP epimerase was detected over 50 years ago in E. coli, ${ }^{24}$ but its purification and characterization was made roughly 30 years ago. ${ }^{245}$ Similarly to the other PLPindependent racemases, the catalytic mechanism of DAPE involves two cysteine residues, in a 'twobase' mechanism. ${ }^{38}$ This mechanism was later elucidated by Stenta et al. through QM/MM studies. ${ }^{246}$ The structure of DAPE isoforms from many bacteria ${ }^{247-249}$ and from a plant have been determined recently..$^{250}$ Particular attention has to be paid to the crystal structure of DAPE from Mycobacterium tuberculosis, since it represents a new potential target to overcome the problem of drug resistance in the treatment of tuberculosis. ${ }^{248}$ Differently from Asp and Glu racemases, in which the cysteine residues are assisted in the racemization by a hystidine (His132) and an aspartate (Asp296), it was proposed that the active site of DAPE exists as a thiol-thiolate pair at neutral $\mathrm{pH}$ and does not use any neighboring active-site base to assist the deprotonation process. ${ }^{250}$

DAPE catalyses the interconversion of (L,L)-2,6-diaminopimelic acid (DAP) into meso-DAP. The meso-DAP, a precursor of L-Lys, is a key component of the pentapeptide linker in bacterial peptidoglycan..$^{251}$ Interestingly, mycobacteria incorporate two distinct interpeptide linkages, the common D-Ala/meso-DAP linkage during exponential growth and a meso-DAP/meso-DAP linkage, a penicillinresistant mode of ligation, upon entering the stationary phase. ${ }^{252}$ This unique structural feature could be the cause of the $\beta$-lactam resistance of $M$. tuberculosis. ${ }^{253}$ Tuberculosis is a common and often deadly 
infectious disease among the world's poor and latent infections are estimated to affect one third of the world population..$^{254}$

\subsubsection{Inhibitors and drug perpectives}

In 1986, Girodeau et al. published the synthesis and the biological evaluation of didehydro-DAP analogues as potential inhibitors of DAPE (Figure 17).255 Only one compound of the series, $\gamma$-methyleneDAP 22 (Figure 17), in all its isomeric forms, showed good antibacterial properties against a wide number of bacteria strains.

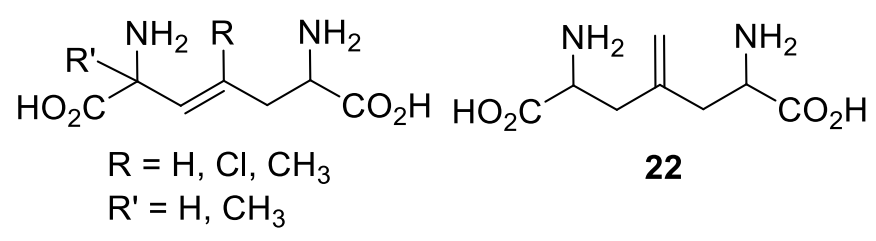

Figure 17

In 1988, it was reported that 3-chloro-DAP (Scheme 10), as a mixture of four possible isomers, is a potent inhibitor of E. coli DAP epimerase in vitro. ${ }^{256}$ In analogy with inhibitors of ProR, which are transition state analogues and bear a sp² hybrid at C-2, it was proposed that the active form of 3-Cl-DAP is the corresponding enamine $\mathbf{2 5}$, resulting from the elimination of $\mathrm{HCl}$. Moreover, it was speculated that compound 25 binds tightly to DAPE and is slowly released from the enzyme; in this respect, 3-ClDAP is a mechanism-based inactivator. It is an innocuous compound by itself but is transformed at the active site of DAPE, becoming a potent competitive inhibitor of the enzyme. After release from the enzyme, 25 could tautomerize to the corresponding imine, which then undergoes a cyclization process to yield tetrahydrodipicolinate (26). It can not be excluded that the predominant epimerase-bound intermediate is the imine tautomer since it has the same planar geometry as enamine $\mathbf{2 5}$.

The 3-fluoro-DAP analogues $\mathbf{2 3}$ and $\mathbf{2 4}$ present the same mechanism of activation, namely the formation of planar enamine 25 by elimination of HF (Scheme 10). All the four stereoisomers are good DAPE inhibitors, with $K_{i}$ values in the range 4-25 $\mu \mathrm{M} .{ }^{257}$ On the contrary, the 3-hydroxy-DAP analogues lack any inhibitory activity since they do not undergo the enzyme-catalyzed elimination of water. 
<smiles>NC(CCC(Cl)C(N)C(=O)O)C(=O)O</smiles>

3-CI-DAP<smiles>N[C@@H](CCC(F)[C@H](N)C(=O)O)C(=O)O</smiles><smiles>NC(=CCCC(N)C(=O)O)C(=O)O</smiles>

$23-: a$

‥11 : b<smiles>CC(C)CCC[C@H](N)C(=O)O</smiles><smiles>CC</smiles>

$24-: a$

‥11 : b

\section{Scheme 10}

In the same years, Lam et al. reported a series of DAP analogues that showed inhibitory activity on DAPE isolated from E. coli. ${ }^{258}$ To this group of compounds belong the meso-lanthionine 27a,b (Figure 18) and its (L,L)-isomer 27c, which are mixed-competitive (allosteric) and competitive inhibitors, respectively $\left(K_{i}=0.18 \mathrm{mM}\right.$ and $0.42 \mathrm{mM}$, respectively), while the (D,D)-isomer $27 \mathbf{d}$ is about 20 times less effective, in accord with the stereochemical requirements of the enzyme for its natural substrates. Oxidation of the sulphur of compounds 27 to the corresponding sulfoxide or sulfone derivatives drastically lowers the affinity for the epimerase active site.

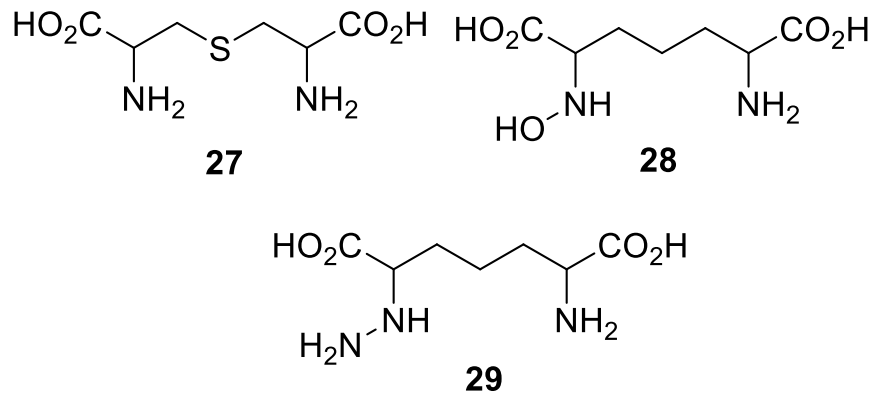
a: $2 \mathrm{R}, 6 \mathrm{~S}$
b: $2 S, 6 R$
c: $2 S, 6 S$
d: $2 \mathrm{R}, 6 \mathrm{R}$

\section{Figure 18}


The most active compound of this series is the $N$-hydroxy analogue $28\left(K_{i}=5.6 \mu \mathrm{M}\right)$. The reason could be the possibility to eliminate water from stereoisomers 28a or 28c (Figure 18) to generate the corresponding $\alpha$-imine as a planar transition state analogue (for details see Scheme 8). This reactive species could be attacked by a nucleophile, such as the Cys thiol group present in the active site, at the $\alpha$-carbon in a reversible fashion. Interestingly, the $N$-amino analogue $\mathbf{2 9}$ is about 500 times less effective than compound $\mathbf{2 8}$ as a competitive inhibitor. This may reflect the inability of the hydrazino group to release ammonia through elimination.

In 1990, the irreversible inactivation of DAPE was reported ${ }^{259260}$ using a crude mixture of all possible diastereomers of 2-(4-amino-4-carboxybutyl)aziridine-2-carboxylic acid (azi-DAP, Figure 19). Enzymatic digestion studies established that Cys73 is alkylated by the aziridino moiety, thereby demonstrating its presence in the active site. The $K_{i}$ values could not be determined due to the extremely fast conversion of the enzyme-inhibitor complex to the inactivated enzyme. Further studies determined that (L,L)-azi-DAP was bound exclusively to Cys73, while (D,L)-azi-DAP was linked solely to Cys $217 ;{ }^{261}$ this result was confirmed by the crystal structure reported by the same group in $2009 . .^{50}$

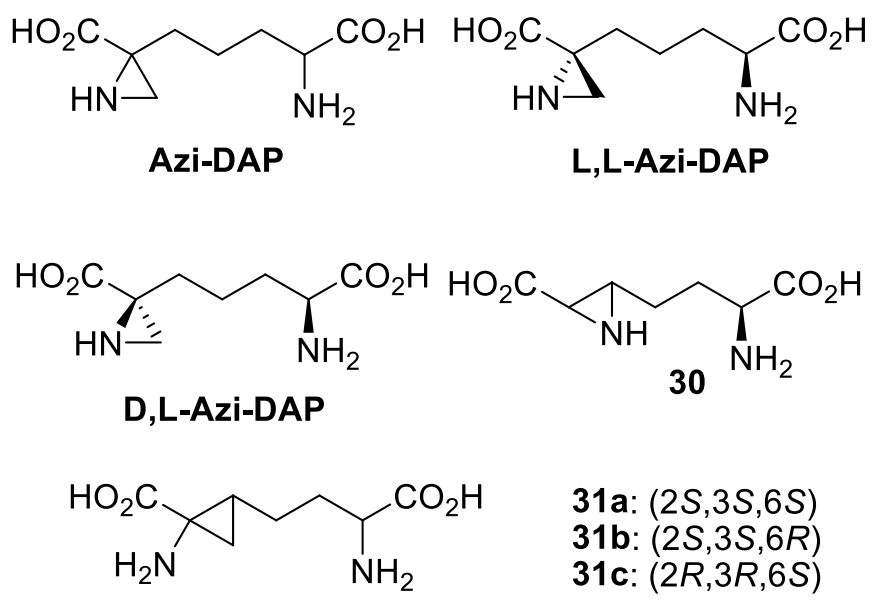

Figure 19

It was also reported that unlike azi-DAP, which rapidly and irreversibly inactivates DAPE, aziridine derivative 30 (Figure 19) is a weak reversible inhibitor of DAPE, with an $\mathrm{IC}_{50}$ value of $2.88 \mathrm{mM} .{ }^{261}$ This different behaviour could be explained by taking into account the different arrangement of the aziridino moiety in the two structures. While azi-DAP can undergo a nucleophilic attack by the thiol group of a 
cysteine at its unhindered methylene position of the aziridine ring, the same reaction occurs on derivative $\mathbf{3 0}$ with the involvement of a tertiary carbon atom which, by definition, is more crowded.

Another class of compounds that have been designed as inhibitors of DAPE is represented by 2,3methano-2,6-diaminopimelic acids (31a-c, Figure 19). These compounds did not exhibit any antibacterial properties; probably they mimic DAP and act as substrates for the enzyme; as a matter of fact, they are incorporated into the cell wall..$^{62}$

\section{Conclusions and Future Perspectives}

L-amino acids are the common building blocks of proteins and are also deeply involved in metabolism to produce energy. They are currently termed "natural amino acids" in contrast to their mirror images, i.e. D-amino acids, which could be tagged as "unnatural amino acids" and, according to a long-standing belief, have been considered inactive substances. Along the years there have been compelling evidences of the presence of D-amino acids in bacterial cell wall, in antibiotics as well as in peptides produced by molluscs and amphibians. These peptides are provided with an array of biological properties spanning from antimicrobial to analgesic activity. Worth noting, the biological activity of the peptides is strictly dependent, not only on the presence of D-amino acids, but also upon the position of such building blocks along the amino acid sequence. Furthermore, free D-amino acids have been detected in mammals, including humans, where they play physiological roles of utmost importance. For example, substantial amounts of D-Asp and D-Ser have been found in the brain of newborn rats and humans, where they perform as neurotransmitter. Their concentration decreases gradually with the development.

The present review deals with the enzymes, termed amino acid racemases, involved in the production of D-amino acids through a racemization process of the L counterparts. We took into account solely the amino acid racemases which are specific for a single amino acid or recognize as a substrate a selected number of amino acids. These enzymes have been classified into two groups according to the mechanism used to interconvert the stereocenter of the amino acids: i) PLP-dependent racemases and ii) PLP-independent racemases.

Among the PLP-dependent racemases, bacterial AlaR is one of the best-studied amino acid racemases. The crystal structure of AlaR from Bacillus stearothermophilus as well as its complexes with two 
inhibitors have been reported and allowed the definition of the active site features. This information is of utmost importance to design new antimicrobial drugs since AlaR, ubiquitously distributed in bacteria and not in mammals, produces D-Ala, which is an essential component of peptidoglycan. D-Cycloserine, an irreversible suicide inhibitor of AlaR, is clinically used as a second-line drug against Mycobacterium avium and Mycobacterium tuberculosis. The major drawbacks associated to the administration of this drug is related to its capacity to cross the blood brain barrier causing side effects probably due to an interaction with the NMDA receptors as well as to its low specificity for AlaR; it is able to inhibit several PLP-dependent enzymes. Novel structural information has opened new avenues for the design of specific and potent AlaR inhibitors. In the future we expect antimicrobial drugs characterized by a higher selectivity for AlaR and with reduced side effects. In this set of enzymes, SerR and AspR will be the targets of novel drugs capable to treat neuropathological disorders. Sizable amount of D-Ser and DAsp have been detected in the mammalian brain of both rats and humans where they perform as neuromodulators of the NMDA receptors.

Within the set of PLP-independent racemases in depth investigations have been carried out both in academia and in industry with the goal to find out new antiparasitic, antibiotic, and antibacterial agents. Most of the antibacterial drugs present in the market act through inhibition of the Phase III segment of the peptidoglycan biosynthetic route. Even if this phase remains the dominant area of research and drug development, the onset of resistance limits the therapeutic utility of this class of compounds. Therefore,

targeting GluR, which is involved in phase I, represents a novel strategy in the search for new antibacterial agents. The major problem associated to the development of drugs targeting the cofactorindependent family is the need to find out potent inhibitors selective for a single species of racemases. In the field of GluR, selective inhibitors of the H. Pylori GluR have been discovered through a highthroughput screening of a large collection of compounds. Quite interesting, the drug candidates are noncompetitive inhibitors, since they fit a cryptic allosteric site. This outcome further highlights the power of a high-throughput screening to search enzyme inhibitors with a novel mode of action. In addition, investigations carried out with the aim to uncover allosteric inhibitors of racemases could be a fruitful way to obtain compounds provided with a selective profile. 


\section{Acknowledgments}

Financial supports from Ministry of Education (MIUR - Rome) and Università degli Studi di Milano (PUR) are gratefully acknowledged. We thank Dr. Francesca Spyrakis for the preparation of figures and the graphic abstract.

\section{References}

(1) Lamzin, V. S.; Dauter, Z.; Wisoln, K. S. Curr. Opin. Struct. Biol. 1995, 5, 830.

(2) Prelog, V. Science 1976, 193, 17.

(3) Corrigan, J. J. Science 1969, 164, 142.

(4) Meister, A. Biochemistry of the amino acids; Meister, A., 2 ${ }^{\text {nd }}$ ed/Academic Press: New York, London, 1965; vol 1, pp 113-139.

(5) Holtje, J. V. Microbiol. Mol. Biol. Rev. 1998, 62, 181.

(6) van Heijenoort, J. Nat. Prod. Rep. 2001, 18, 503.

(7) Lam, H.; Oh, D.C.; Cava, F.; Takacs, C. N.; Clardy, J.; de Pedro, M. A.; Waldor, M. K. Science 2009, 325, 1552.

(8) Broccardo, M.; Erspamer, V.; Falconieri Erspamer, G.; Improta, G.; Linari, G.; Melchiorri, P.; Montecucchi, P. C. Br. J. Pharmacol. 1981, 73, 625.

(9) G. Kreil Annu. Rev. Biochem. 1997. 66, 337.

(10) Kamatani, Y.; Minakata, H.; Kenny, P. T.; Iwashita, T.; Watanabe, K.; Funase, K.; Sun, X. P.; Yongsiri, A.; Kim, K. H.; Novales-Li, P.; Novales, E. T.; Kanapi, C. G.; Takeuchi, H.; Nomoto, K. Biochem. Biophys. Res. Commun. 1989, 160, 1015.

(11) Krebs, H. A. Biochem. J. 1935, 29, 1620.

(12) Helfman, P. M.; Bada, J. L.; Shou, M. Y. Gerontology 1977, 23, 419. 

13409.

(14) Kim, P. M.; Duan, X.; Huang, A. S.; Liu, C. Y.; Ming, G.-1; Song, H.; Snyder, S. H., Proc. Natl. Acad. Sci. U.S.A. 2010, 107, 3175.

(15) Tanner, M. E. Acc. Chem. Res. 2002, 35, 237.

(16) John, R. A. Biochim. Biophys. Acta 1995, 1248, 81.

(17) Eliot, A. C.; Kirsch, J. F. Annu. Rev. Biochem. 2004, 73, 383.

(18) Toney, M. D. Arch. Biochem. Biophys. 2005, 433, 279.

(19) Amadasi, A.; Bertoldi, M.; Contestabile, R.; Bettati, S.; Cellini, B.; di Salvo, M. L.; Borri-Voltattorni, C.; Bossa, F.; Mozzarelli, A. Curr. Med. Chem. 2007, 14, 1291.

(20) Dixon, J. E.; Bruice, T. C. Biochemistry 1973, 12, 4762.

(21) Toth, K.; Richard, J. P. J. Am. Chem. Soc. 2007, 129, 3013.

(22) Dunathan, H. C. Adv. Enzymol. Relat. Areas Mol. Biol. 1971, 35, 79.

(23) Kirsch, J. F.; Eichele, G.; Ford, G. C.; Vincent, M. G.; Jansonius, J. N.; Gehring, H.; Christen, P. J. Mol. Biol. 1984, 174, 497.

(24) Momany, C.; Ernst, S.; Ghosh, R.; Chang, N. L.; Hackert, M. L. Protein Sci. 1995, 4, 84.

(25) Toney, M. D.; Hohenester, S. W.; Cowan, S. W.; Jansonius, J. N. Science 1993, 261, 756.

(26) Grishin, N. V.; Phillips, M.A.; Goldsmith, E. J. Protein Sci. 1995, 4, 1291.

(27) Soda, K.; Yoshimura, T.; Esaki, N. Chem. Rec. 2001, 1, 373.

(28) Schneider, G.; Käck, H.; Lindqvist Y. Structure 2000, 8, R1.

(29) Hyde, C.C.; Ahmed, S. A.; Padlan, E. A.; Miles, E. W.; Davies, D. R. J. Biol. Chem. 1988, 263, 17857. 
Gallagher, D. T.; Gilliland, G. L.; Xiao, G.; Zondlo, J.; Fisher, K. E.; Chinchilla, D.; Eisenstein, E. Structure 1998, 6, 465.

(31) Burkhard, P.; Rao, G. S. J.; Hohenester, E.; Schnackerz, K. D.; Cook, P. F.; Jansonius, J. N. J. Mol. Biol. 1998, 283, 121.

(32) Cardinale, G. J.; Abeles, R. H. Biochemistry 1968, 7, 3970.

(33) Rudnick, G.; Abeles, R. H. Biochemistry 1975, 14, 4515.

(34) Stadtman, T. C.; Elliot, P. J. Biol. Chem. 1957, 228, 983.

(35) Albery, W. J.; Knowles, J. R. Biochemistry 1986, 25, 2572.

(36) Gallo, K. A.; Tanner, M. E.; Knowles, J. R. Biochemistry 1993, 32, 3991.

(37) Yamauchi, T.; Choi, S. Y.; Okada, H.; Yohda, M.; Kumagai, H.; Esaki, N.; Soda, K. J. Biol. Chem. 1992, 267, 18361.

(38) Pillai, B.; Cherney, M. M.; Diaper, C. M.; Sutherland, A.; Blanchard, J. S.; Vederas, J. C.; James, M. N. G. Proc. Natl Acad. Sci. U.S.A. 2006, 103, 8668.

(39) Abe, H.; Yoshikawa, N.; Sarower, M. G.; Okada, S. Biol. Pharm. Bull. 2005, 28, 1571.

(40) Hoffmann, K.; Schneider-Scherzer, E.; Kleinkauf, H.; Zocher, R. J. Biol. Chem. 1994, $269,12710$.

(41) Cheng, Y. Q.; Walton, J. D. J. Biol. Chem. 2000, 275, 4906.

(42) Uo, T.; Yoshimura, T.; Tanaka, N.; Takegawa, K.; Esaki, N. J. Bacteriol. 2001, 183, 2226.

(43) Ono, K.; Yanagida, K.; Oikawa, T.; Ogawa, T.; Soda, K. Phytochemistry 2006, 67, 856.

(44) Walsh, C. T. J. Biol. Chem. 1989, 64, 2393.

(45) McFall, E.; Newman, E. B. Escherichia coli and Salmonella: Cellular and Molecular biology; Neidhart, F. C./Am. Soc. Microbiol.: Washington, D.C., 1996; pp. 358-379. 
Preston, R. A.; Douthit, H. A. J. Gen. Microbiol. 1988, 134, 3001.

Huang, C. M.; Elmets, C. A.; Tang, D. C.; Li, F.; Yusuf, N. Gen. Prot. Bioinfo. 2004, 2, 143.

(49) Chesnokova, O. N.; McPherson, S. A.; Steichen, C. T.; Turnbough, C. L. Jr. J Bacteriol. 2009, 191, 1303.

(50) Dixon, T. C.; Meselson, M.; Guillemin, J.; Hanna, P. C. N. Engl. J. Med. 1999, 341, 815.

(51) Dahlgren, C. M.; Buchanan, L. M.; Decker, H. M.; Freed, S. W.; Phillips, C. R.; Brachman, P. S. Am. J. Hyg. 1960, 72, 24.

(52) Meselson, M.; Guillemin, J.; Hugh-Jones, M.; Langmuir, A.; Popova, I.; Shelokov, A.; Yampolskaya, O. Science 1994, 266, 1202.

(53) Morollo, A. A.; Petsko, G. A.; Ringe, D. Biochemistry 1999, 38, 3293.

(54) Stamper, C. G. F.; Morollo, A. A.; Ringe, D. Biochemistry 1998, 37, 10438.

(55) Watanabe, A.; Yoshimura, T.; Mikami, B.; Hayashi, H.; Kagamiyama, H.; Esaki, N. J. Biol. Chem. 2002, 277, 19166.

(56) Shaw, J. P.; Petsko, G. A.; Ringe, D. Biochemistry 1997, 36, 1329.

(57) Iurcu Mustata, G.; Soares, T. A.; Briggs, J. M. Biopolymers 2003, 70, 186.

(58) Spies, M. A.; Woodward, J. J.; Watnik, M. R.; Toney, M. D. J. Am. Chem. Soc. 2004, $126,7464$.

(59) Rubinstein, A.; Major, D. T. Biochemistry 2010, 49, 3957.

(60) Major, D. T.; Gao, J. J. Am. Chem. Soc. 2006, 128, 16345.

(61) Rubinstein, A.; Major, D. T. J.Am. Chem. Soc. 2009, 131, 8513. 
(63) Lin, Y. L.; Gao, J.; Rubinstein, A.; Major, D. T. Biochim Biophys Acta. 2011, In press

(64) Strych, U.; Davlieva, M.; Longtin, J. P.; Murphy, E. L.; Im, H.; Benedik, M. J.; Krause, K. L. BMC Microbiol. 2007, 7, 40.

(65) Watanabe, A.; Yoshimura, T. Mikami, B.; Esaki, N. J. Biochem. 1999, 125, 987.

(66) Yoshimura, T.; Goto, M. FEBS Journal 2008, 275, 3527.

(67) Ondrechen, M. J.; Briggs, J. M.; McCammon, J. A. J. Am. Chem. Soc. 2001, 123, 2830.

(68) Kurokawa, Y.; Watanabe, A.; Yoshimura, T.; Esaki, N.; Soda, K. J. Biochem. 1998, 124, 1163.

(69) Neuhaus, F. C. Antimicrob. Agents Chemother. 1967, 7, 304.

(70) Roze, U.; Strominger, J. L. Mol. Pharmacol. 1966, 2, 92.

(71) Lambert, M. P.; Neuhaus, F. C. J. Bacteriol. 1972, 110, 978.

(72) Johnston, R. B.; Scholz, J. J.; Diven, W. F.; Shepard, S.: Pyridoxal Catalysis: Enzymes and Model Systems; Snell, E. E.; Braunstein, A. E.; Severin, E. S.; Torchinsky, Y. M./ WileyInterscience: New York, 1968, p 537.

(73) Wargel, R. J.; Shadur, C. A.; Neuhaus, F. C. J. Bacteriol. 1970, 103, 778.

(74) Fenn, T. D.; Stamper, G. F.; Morollo, A. A.; Ringe, D. Biochemistry 2003, 42, 5775.

(75) David, H. L.; Takayama, K.; Goldman, D. S. Am. Rev. Respir. Dis. 1969, 100, 579.

(76) Lee, H. K. Chest 1960, 37, 378.

(77) Pitkanen, M.; Sirvio, J.; MacDonald, E.; Ekonsalo, T.; Riekkinen, P., Sr. J. Neural Transm. 1995, 9, 133.

(78) Wood, J. D.; Peesker, S. J.; Gorecki, D. K. J.; Tsui, D. Can. J. Physiol. Pharmacol. 1978, 52, 62 . 
(80) Neuhaus, F. C.: Antibiotics, vol. 1. Mechanisms of action; Gottlieb, D.; Shaw P. L./Springer-Verlag: Heidelberg, 1967; p 40.

(81) Cáceres, N. E.; Harris, N. B.; Wellehan, J. F.; Feng, Z.; Kapur, V.; Barletta, R. G. J. Bacteriol. 1997, 179, 5046.

(82) Peisach, D.; Chipman, D. M.; Van Ophem, P. W.; Manning, J. M.; Ringe, D. J. Am. Chem. Soc. 1998, 120, 2268.

(83) Kollonitsch, J.; Barash, L.; Kahan, F. H.; Kropp, H. Nature 1973, 243, 346.

(84) Badet, B.; Roise, D.; Walsh, C. T. Biochemistry 1984, 23, 5188.

(85) Faraci, W. S.; Walsh, C. T. Biochemistry 1989, 28, 431.

(86) Thornberry, N. A.; Bull, H. G.; Taub, D.; Greenlee, W. J.; Patchett, A. A.; Cordes E. H. J. Am. Chem. Soc. 1987, 109,1543.

(87) Wang, E.; Walsh, C. T. Biochemistry 1981, 20, 7539.

(88) Kaczorowski, G.; Shaw, L.; Laura, R.; Walsh, C. T. J. Biol. Chem. 1975, 250, 8921.

(89) Wang, E.; Walsh, C. Biochemistry 1978, 17, 1313.

(90) Kollonitsch, J.; Barash, L. J. Am. Chem. Soc. 1976, 98, 5591.

(91) Thornberry, N. A.; Bull, H. G.; Taub, D.; Wilson, K. E.; Giménęz-Gallego, G.; Rosegay, A.; Soderman, D. D.; Patchett, A. A. J. Biol. Chem. 1991, 266, 21657.

(92) Atherton, F. R.; Hall, M. J.; Hassall, C. H.; Lambert, R. W.; Lloyd, W. J.; Ringrose, P. S. Antimicrob. Agents Chemother. 1979, 15, 696.

(93) Adams, E.; Mukherjee, K. L.; Dunathan, H. C. Arch. Biochem. Biophys. 1974, 165, 126.

(94) Atherton, F. R.; Hall, M. J.; Hassall, C. H.; Lambert, R. W.; Ringrose, P. S. Antimicrob. Agents Chemother. 1979, 15, 677. 
(96) Copie, V.; Faraci, W. S.; Walsh, C. T.; Griffin, R. G. Biochemistry 1988, 27, 4966.

(97) Duncan, K.; Faraci, S.; Matteson, D. S.; Walsh, C. T. Biochemistry 1989, 28, 3541.

(98) LeMagueres, P.; Im, H.; Ebalunode, J.; Strych, U.; Benedik, M. J.; Briggs, J. M.; Kohn, H.; Krause, K. L.; Biochemistry 2005, 44, 1471.

(99) Au, K.; Ren, J.; Walter, T. S.; Harlos, K.; Nettleship, J. E.; Owens, R. J.; Stuart, D. I.; Esnouf, R. M. Acta Crystallogr Sect F Struct Biol Cryst Commun. 2008, 64, 327.

(100) Im, H.; Sharpe, M. L.; Strych, U.; Davlieva, M.; Krause, K. L. BMC Microbiol. 2011, 11,116 (online journal).

(101) Priyadarshi, A.; Lee, E. H.; Sung, M. W.; Nam, K. H.; Lee, W. H.; Kim, E. E.; Hwang, K. Y. Biochim Biophys Acta. 2009, 1794, 1030.

(102) Wu, D.; Hu, T.; Zhang, L.; Chen, J.; Du, J.; Ding, J.; Jiang, H.; Shen, X. Protein Sci. 2008, 17, 1066.

(103) Ju, J.; Qi, J.; Xu, S.; Ohnishi, K.; Benedik, M. J.; Xue, Y.; Ma, Y. Acta Crystallogr Sect F Struct Biol Cryst Commun. 2009, 65, 166.

(104) Ju, J.; Xu, S.; Wen, J.; Li, G.; Ohnishi, K.; Xue, Y.; Ma, Y. J Biosci Bioeng. 2009, 107, 225 .

(105) Ju, J.; Xu, S. ; Furukawa, Y.; Zhang, Y.; Misono, H.; Minamino, T.; Namba, K.; Zhao, B.; Ohnishi, K. J Biochem. 2011, 149, 83.

(106) Seebeck, F. P.; Hilvert, D. J. Am. Chem. Soc. 2003, 125, 10158.

(107) Watanabe, A.; Yoshimura, T.; Mikami, B.; Esaki, N. J. Biochem. 1999, 126, 781.

(108) Fesko, K.; Giger, L.; Hilvert, D. Bioorg. Med. Chem. Lett. 2008, 18, 5987. 
(109) Uo, T.; Yoshimura, T.; Shimizu, S.; Esaki, N. Biochem. Biophys. Res. Commun. 1998, 246,31 .

(110) Wolosker, H.; Sheth, K. N.; Takahashi, M.; Mothet, J. P.; Brady, R. O. Jr; Ferris, C. D.; Snyder, S. H. Proc. Natl. Acad. Sci. U.S.A. 1999, 96, 721.

(111) Wolosker, H. Biochim. Biophys. Acta 2011, In Press.

(112) Kartvelishvily, E.; Shleper, M.; Balan, L.; Dumin, E.; Wolosker, H. J. Biol. Chem. 2006, 281,14151 .

(113) Yoshikawa, M.; Takayasu, N.; Hashimoto, A.; Sato, Y.; Tamaki, R.; Tsukamoto, H.; Kobayashi, H.; Noda, S. Arch. Histol. Cytol. 2007, 70, 127.

(114) Stevens, E. R.; Esguerra, M.; Kim, P. M.; Newman, E. A.; Snyder, S. H.; Zahs, K. R.; Miller, R. F. Proc. Natl. Acad. Sci. U.S.A. 2003, 100, 6789.

(115) Wu, S.; Barger, S. W.; Sims, T. J. Brain Res. 2004, 1020, 161.

(116) Takarada, T.; Takahata, Y.; Iemata, M.; Hinoi, E.; Uno, K.; Hirai, T.; Yamamoto, T.; Yoneda, Y. J. Cell. Physiol. 2009, 220, 756.

(117) Hashimoto, A.; Kumashiro, S.; Nishikawa, T.; Oka, T.; Takahashi, K.; Mito, T.; Takashima, S.; Doi, N.; Mizutani, Y.; Yamazaki, T.; Kaneko, T.; Ootomo, E. J. Neurochem. 1993, 1,348 .

(118) Hashimoto, A.; Oka, T.; Nishikawa, T. Eur. J. Neurosci. 1995, 7, 1657.

(119) Nagata, Y.; Horiike, K.; Maeda, T. Brain Res. 1994, 634, 291.

(120) Dunlop, D. S.; Neidle, A.; McHale, D.; Dunlop, D. M., Lajtha, A. Biochem. Biophys. Res. Commun. 1986, 141, 27.

(121) Excitatory Amino Acids and Synaptic Transmission Wheal, H. V.; Thomson A. M./Academic Press: London, 1995. 
Med. Chem. 2000, 43, 2609.

(123) Lipton S. A. J. Alzheimer's Dis. 2004, 6, S61.

(124) Kemp, J. A.; McKernan, R. M. Nat. Neurosci. 2002, 5, 1039.

(125) Hashimoto, K.; Fukushima, T.; Shimizu, E.; Okada, S.; Komatsu, N.; Okamura, N.; Koike, K.; Koizumi, H.; Kumakiri, C.; Imai, K.; Iyo, M. Biol. Psychiatry 2004, 28, 385.

(126) Sasabe, J.; Chiba, T.; Yamada, M.; Okamoto, K.; Nishimoto, I.; Matsuoka, M.; Aiso, S. EMBO J. 2007, 26, 4149.

(127) Kwak, S.; Hideyama, T.; Yamashita, T.; Aizawa,H. Neuropathology, 2010, 30, 182.

(128) Wu, S.; Barger, S. W. Ann. NY Acad. Sci. 2004, 1035, 133.

(129) Labrie, V.; Fukumura, R.; Rastogi, A.; Fick, L. J.; Wang, W.; Boutros, P. C.; Kennedy, J. L.; Semeralul, M. O.; Lee, F. H.; Baker, G. B.; Belsham, D. D.; Barger, S. W.; Gondo, Y.; Wong, A. H. C.; Roder J. C. Hum. Mol. Gen. 2009, 18, 3227.

(130) Bendikov, I.; Nadri, C.; Amar, S.; Panizzutti, R.; De Miranda, J.; Wolosker, H.; Agam, G. Schizophr. Res. 2007, 90, 41 .

(131) Hashimoto, K.; Fukushima, T.; Shimizu, E.; Komatsu, N.; Watanabe, H.; Shinoda, N.; Nakazato, M.; Kumakiri, C.; Okada, S.; Hasegawa, H.; Kazuhiro, I.; Masaomi, I. Arch. Gen. Psychiatry 2003, 60, 572.

(132) Morita, Y.; Ujike, H.; Tanaka, Y.; Otani, K.; Kishimoto, M.; Morio, A.; Kotaka, T.; Okahisa, Y.; Matsushita, M.; Morikawa, A.; Hamase, K.; Zaitsu, K.; Kuroda, S. Biol. Psychiatry 2007, 61, 1200.

(133) Chumakov, I.; Blumenfeld, M.; Guerassimenko, O.; Cavarec, L.; Palicio, M.; Abderrahim, H. Bougueleret, L.; Barry, C.; Tanaka, H.; La Rosa, P.; Puech, A.; Tahri, N.; Cohen-Akenine, A.; Delabrosse, S.; Lissarrague, S.; Picard, F.-P.; Maurice, K.; Essioux, L.; Millasseau, P.; Grel, P.; Debailleul, V.; Simon, A.-M.; Caterina, D.; Dufaure, I.; Malekzadeh, 
K.; Belova, M.; Luan, J.-J.; Bouillot, M.; Sambucy, J.-L.; Primas, G.; Saumier, M.; Boubkiri,

N.; Martin-Saumier, S.; Nasroune, M.; Peixoto, H.; Delaye, A.; Pinchot, V.; Bastucci, M.;

Guillou, S.; Chevillon, M.; Sainz-Fuertes, R.; Meguenni, S.; Aurich-Costa, J.; Cherif, D.;

Gimalac, A.; Van Duijn, C.; Gauvreau, D.; Ouelette, G.; Fortier, I.; Realson, J.; Sherbatich, T.;

Riazanskaia, N.; Rogaev, E.; Raeymaekers, P.; Aerssens, J.; Konings, F.; Luyten, W.;

Macciardi, F.; Sham, P. C.; Straub, R. E.; Weinberger, D. R.; Cohen, N.; Cohen, D. Proc. Natl. Acad. Sci.U.S.A. 2002, 99, 13675.

(134) Mori, H.; Inoue, R. Chem. Biodiv. 2010, 7, 1573.

(135) Goto, M.; Yamauchi, T.; Kamiya, N.; Miyahara, I.; Yoshimura, T.; Mihara, H.; Kurihara, T.; Hirotsu, K.; Esaki, N. J Biol Chem. 2009, 284, 25944.

(136) Smith, M. A.; Mack, V.; Ebneth, A.; Moraes, I.; Felicetti, B.; Wood, M.; Schonfeld, D.; Mather, O.; Cesura, A.; Barker, J. J. Biol. Chem. 2010, 285, 12873.

(137) Foltyn, V. N.; Bendikov, I.; De Miranda, J.; Panizzutti, R.; Dumin, E.; Shleper, M.; Li, P.; Toney, M. D.; Kartvelishvily, E.; Wolosker, H. J Biol Chem. 2005, 280,1754.

(138) Hoffman, H. E.; Jiraskova, J.; Zvelebil, M.; Konvalinka, J. Collect. Czech. Chem. Comm. 2010, 75, 59 .

(139) Baumgart, F.; Mancheno, J. M.; Rodriguez-Crespo, I. FEBS J. 2007, 274, 4561.

(140) De Miranda, J.; Panizzutti, R.; Foltyn, V. N.; Wolosker, H. Proc. Natl. Acad. Sci. U.S.A. 2002, 99, 14542.

(141) Peracchi, A.; Mozzarelli, A; Rossi, G. L. Biochemistry 1995, 34, 9459.

(142) Raboni, S.; Bettati, S.; Mozzarelli, A. Cellular and Molecular Life Science, 2009, 66, 2391.

(143) Boehning, D.; Snyder, S. H. Annu. Rev. Neurosci. 2003, 26, 105. 
(144) Kim, P. M.; Aizawa, H.; Kim, P. S.; Huang, A. S.; Wickramasinghe, S. R.; Kashani, A. H.; Barrow, R. K.; Huganir, R. L.; Ghosh, A.; Snyder, S. H. Proc. Natl. Acad. Sci. U.S.A. 2005, 102, 2105.

(145) Fujii, K.; Maeda, K.; Hikida, T.; Mustafa, A. K.; Balkissoon, R.; Xia, J.; Yamada, T.; Ozeki, Y.; Kawahara, R.; Okawa, M.; Huganir, R. L.; Ujike, H.; Snyder, S. H.; Sawa, A. Mol. Psychiatry 2006, 11, 150 .

(146) Dumin, E.; Bendikov, I.; Foltyn, V. N.; Misumi, Y.; Ikehara, Y.; Kartvelishvily, E.; Wolosker, H. J. Biol. Chem. 2006, 281, 20291.

(147) Vargas-Lopes, C.; Madeira, C.; Kahn, S. A.; Albino do Couto, I.; Bado, P.; Houzel, J. C.; De Miranda, J.; de Freitas, M. S.; Ferreira, S. T.; Panizzutti, R. J. Neurochem. 2011 116, 281.

(148) Mustafa, A. K.; van Rossum D. B.; Patterson, R. L.; Maag, D.; Ehmsen, J. T.; Gazi, S. K.; Chakraborty, A.; Barrow, R. K.; Amzel, L. M.; Snyder, S. H. Proc. Natl. Acad. Sci. U.S.A. 2009, 106, 2921.

(149) Mustafa A. K.; Kumar, M.; Selvakumar, B.; Ho, G. P.; Ehmsen, J. T.; Barrow, R. K.; Amzel, L. M.; Snyder, S. H. Proc. Natl. Acad. Sci. U.S.A. 2007, 104, 2950.

(150) Arias, C. A.; Martin-Martinez, M.; Blundell, T. L.; Arthur, M.; Courvalin, P.; Reynolds, P. E. Mol. Microbiol. 1999, 31, 1653.

(151) Strisovsky, K.; Jiraskova, J.; Mikulova, A.; Rulisek, L.; Konvalinka, J. Biochem. 2005, $44,13091$.

(152) Hoffman, H. E.; Jirásková, J.; Cígler, P.; Šanda, M.; Schraml, J.; Konvalinka, J. J. Med. Chem. 2009, 52, 6032.

(153) Bruno, A.; Amori, L.; Costantino, G. Molecular Informatics 2011, 30, 317.

(154) Baroni, M.; Cruciani, G.; Sciabola, S.; Perruccio, F.; Mason, J. S. J. Chem. Inf. Model. 2007, 47, 279.

(155) Jones, G.; Willett, P.; Glen, R. C.J. Mol. Biol. 1995, 245, 43. 

Med. Chem. 2002, 45, 2469. Spyrakis, F.; Amadasi, A.; Fornabaio, M.; Abraham, D. J.; Mozzarelli, A.; Kellogg, G. E.; Cozzini, P. Eur. J. Med. Chem. 2007, 42, 921. Spyrakis, F.; Dellafiora, L.; Cozzini. P.; Singh, R.; Salsi, E.; Benedetti, P.; Cruciani, G.; Carosati, E.; Campanini, B.; Cellini, B.; Mozzarelli, A. $2^{\text {nd }}$ Workshop in New Trends in Computational Chemsitry for Industry Applications; Barcelona, 2011

(160) Salsi, E.; Bayden, A.; Spyrakis, F.; Amadasi, A.; Campanini, B.; Bettati, S.; Cozzini, P.; Kellogg, G. E.; Cook, P. F.; Dodatko, T.; Roderick, S. L.; Mozzarelli, A. J. Med. Chem. 2010, 53,345 .

(161) Yorifuji, T.; Misono, H.; Soda, K. J. Biol. Chem. 1971, 246, 5093.

(162) Matsui, D.; Oikawa, T.; Arakawa, N.; Osumi, S.; Lausberg, F.; Stäbler, N.; Freudl, R.; Eggeling, L. Appl. Microbiol. Biotechnol. 2009, 83, 1045.

(163) Matsui, D.; Oikawa, T. Chem Biodivers. 2010, 7, 1591.

(164) Jann, A.; Matsumoto, H.; Haas, D. J. Gen. Microbiol. 1988, 134, 1043.

(165) Haas, D.; Matsumoto, H.; Moretti, P.; Stalon, V.; Mercenier, A. Mol. Gen. Genet. 1984, $193,437$.

(166) Dunlop, D. S.; Neidle, A.; McHale, D.; Dunlop, D. M.; Lajtha, A. 1986. Biochem Biophys Res Commun. 1996, 141, 27.

(167) Hashimoto, A. Nishikawa, T.; Konno, R.; Niwa, A.; Yasumura, Y.; Oka, T.; Takahashi, K. Neurosci. Lett. 1993, 152, 33. 
(168) D'Aniello, A.; Di Cosmo, A.; Di Cristo, C.; Annunziato, L.; Petrucelli, L.; Fisher, G.; D’Aniello, A. Life Sci. 1996, 59, 97.

(169) D'Aniello, S.; Somorjai, I.; Garcia-Fernàndez, J; Topo, E.; D'Aniello, A. FASEB J. 2011, 25,1014 .

(170) Erreger, K.; Geballe, M. T.; Kristensen, A.; Chen, P. E.; Hansen, K. B.; Lee, C. J.; Yuan, H.; Le, P.; Lyuboslavsky, P. N.; Micale, N.; Jorgensen, L.; Clausen, R. P.; Wyllie, D. J. A.; Snyder, J. P.; Traynelis, S. F. Mol. Pharmacol. 2007, 72, 907.

(171) Skerritt, J. H.; Johnston, G. A. J. Neurochem. 1981, 36, 881.

(172) D’Aniello, A.; Di Fiore, M. M.; Fisher, G. H.; Milone, A.; Seleni, A.; D’Aniello, S.; Perna, A. F.; Ingrosso, D. FASEB J. 2000, 14, 699.

(173) Wang, H.; Wolosker, H.; Pevsner, J.; Snyder, S. H.; Selkoe, D. J. J. Endocrinol. 2000, $167,247$.

(174) Topo, E.; Soricelli, A.; D'Aniello, A.; Ronsini, S.; D'Aniello, G. Reprod. Biol. End. 2009, 7, 120 .

(175) Schell, M. J.; Cooper, O. B.; Snyder, S. H. Proc. Natl. Acad. Sci. U.S.A. 1997, 94, 2013.

(176) Imai, K.; Fukushima, T.; Hagiwara, K.; Santa, T. Biomed. Chromatogr. 1995, 9, 106.

(177) Ishio, S.; Yamada, H.; Hayashi. M.; Yatsushiro, S.; Noumi, T.; Yamaguchi, A.; Moriyama, Y. Neurosci. Lett. 1998, 249, 143.

(178) Pampillo, M.; Scimonelli, T.; Bottin, M. C.; Duvilanski, B. H.; Rettori, V.; Seilicovich, A.; Lasaga, M. Neuroreport 2002, 13, 2341.

(179) Wolosker, H.; D’Aniello, A.; Snyder, S. H. Neurosci. 2000, 100, 183.

(180) Ming G. L.; Song, H. Annu. Rev. Neurosci. 2005, 28, 223.

(181) Zhao, C.; Deng, W; Gage, F. H. Cell 2008, 132, 645.

(182) Lee, J. A.; Homma H.; Tashiro, K.; Iwatsubo, T.; Imai, K. Brain Res. 1999, 838, 193. 
Sakai, K; Homma, H.; Lee, J. A.; Fukushima, T. Santa, T.; Tashiro, K.; Iwatsubo, T.; Imai, K. Arch. Biochem. Biophys. 1998, 351, 96.

(184) Shibata, K.; Watanabe, T.; Yoshikawa, H.; Abe, K.; Takahashi, S.; Kera, Y.; Yamada, R.-h. Comp. Biochem. Physiol. 2003, Part B 134, 307.

(185) Shibata, K.; Watanabe, T.; Yoshikawa, H.; Abea, K.; Takahashia, S.; Kera, Y.; Yamada R.-h. Comp. Biochem. Physiol. 2003, Part B 134, 713.

(186) Reina-San-Martín, B.; Degrave, W.; Rougeot, C.; Cosson, A.; Chamond, N.; CordeiroDa-Silva, A.; Arala-Chaves, M.; Coutinho, A.; Minoprio, P. Nature Medicine 2000, 6, 890.

(187) Minoprio, P.; Itohara, S.; Heusser, C.; Tonegawa, S.; Coutinho, A. Immunol. Rev. 1989, $112,183$.

(188) Reina-San-Martin, B.; Cosson, A.; Minoprio, P. Parasitol. Today 2000, 16, 62.

(189) Chamond, N.; Grégoire, C.; Coatnoan, N.; Rougeot, C.; Holanda Freitas-Junior, L.; Franco da Silveira, J.; Degrave, W. M.; Minoprio, P. J. Biol. Chem. 2003, 278, 15484.

(190) Buschiazzo, A.; Goytia, M.; Schaeffer, F.; Degrave, W.; Shepard, W.; Grégoire, C.; Chamond, N.; Cosson, A.; Berneman, A.; Coatnoan, N.; Alzari, P. M.; Minoprio, P. Proc. Nat. Acad.Sci. U.S.A. 2006, 103, 1705.

(191) Chamond, N.; Cosson, A.; Coatnoan, N.; Minoprio, P. Mol. Biochem. Parasitology 2009, $165,170$.

(192) Chamond, N.; Goytia, M.; Coatnoan, N.; Barale, J.-C.; Cosson, A.; Degrave, W. M.; Minoprio, P. Mol. Microbiol. 2005, 58, 46.

(193) Coatnoan, N.; Berneman, A.; Chamond, N.; Minoprio P. Mem. Inst. Oswaldo Cruz, Rio de Janeiro, 2009, 104, 295.

(194) Sela, M.; Zisman, E. FASEB J. 1997, 11, 449. 
(195) Working to overcome the global impact of neglected tropical diseases. First WHO report on neglected tropical diseases, World Health Organization, David W.T. Crompton, Ed. , 2010, p. 75 .

(196) Kirchhoff, L. V.; Weiss, L. M.; Wittner, M.; Tanowitz, H. B. Front. Biosci. 2004, 9, 706.

(197) Gutierrez, F. R. S.; Guedes, P. M. M.; Gazzinelli, R. T.; Silva, J. S. Parasite Immunology 2009, 31,673 .

(198) Coura, J. R.; Pinto Dias, J. C. Mem. Inst. Oswaldo Cruz, Rio de Janeiro, 2009, 104, 31.

(199) Silber, A.M.; Tonelli, R.R.; Martinelli, M; Colli, W.; Alves, M.J. J. Eukaryot. Microbiol. $\mathbf{2 0 0 2}, 49,441$.

(200) Sylvester, D.; Krassner, S. M. Comp. Biochem. Physiol. 1976, 55, 443.

(201) Coutinho, L.; Alves Ferreira, M.; Cosson, A.; Meuser Batista, M.; da Gama Jaén Batista, D.; Minoprio, P.; Degrave, W. M.; Berneman, A.; de Nazaré Correia Soeiro M. Mem. Inst. Oswaldo Cruz, Rio de Janeiro, 2009, 104, 1055.

(202) Berneman, A.; Alves-Ferreira, M.; Coatnoan, N.; Chamond, N.; Minoprio, P. J. Microbial. Biochem. Technol. 2010, 2, 139.

(203) Blondel, A.; Renaud, J. P.; Fischer, S.; Moras, D.; Karplus, M. J. Mol. Biol. 1999, 291, 101.

(204) Laine, E.; Goncalves, C.; Karst, J. C.; Lesnard, A.; Rault, S.; Tang, W. J.; Malliavin, T. E.; Ladant, D.; Blondel, A. Proc. Natl. Acad. Sci. U.S.A. 2010, 107, 11277.

(205) Chamond, N.; Coatnoan, N.; Minoprio, P. Curr. Drug Targets Immune Endocr. Metabol. Disord. 2002, 2, 247.

(206) Bryan, M. A.; Norris, K. A. Infect. Imm. 2010, 78, 810.

(207) Ayengar, P.; Roberts, E. J. Biol. Chem. 1952, 197, 453.

(208) Narrod, S. A.; Wood, W. A. Arch. Biochem. Biophys. 1952, 35, 462. 
(209) Tanner, M. E.; Gallo, K. A.; Knowles, J. R. Biochemistry 1993, 32, 3998.

(210) Doublet, P.; van Heijenoort, J.; Mengin-Lecreulx, D. Microb. Drug Resist. 1996, 2, 43.

(211) Ho, H.-T.; Falk, P. J.; Ervin, K. M.; Krishnan, B. S.; Discotto, L. F.; Dougherty, T. J.; Pucci, M. J. Biochem. 1995, 34, 2464.

(212) Glavas, S.; Tanner, M. E. Biochemistry 2001, 40, 6199.

(213) Hwang, K. Y.; Cho, C. S.; Kim, S. S.; Sung, H. C.; Yu, Y. G.; Cho, Y. Nature Struct. Biol. 1999, 6, 422 .

(214) Lee, K.-S.; Park, S.-M.; Yeon Hwang, K.; Chi, Y.-M. Acta Cryst. 2005, F61, 199.

(215) Mehboob, S.; Guo, L.; Fu, W.; Mittal, A.; Yau, T.; Truong, K.; Johlfs, M.; Long, F.; Fung, L. W.-M.; Johnson, M. E. Biochemistry 2009, 48, 7045.

(216) Fisher, S. L.; Kern, G.; Newton, T.; Lundqvist, T.; Folmer, R.; Xue, Y.: 45th Annual ICAAC, American Society for Microbiology: Washington, DC, 2005.

(217) Klevens, R. M.; Morrison, M. A.; Nadle, J.; Petit, S.; Gershman, K.; Ray, S.; Harrison, L. H; Lynfield, R.; Dumyati, G.; Townes, J. M.; Craig, A. S.; Zell, E. R.; Fosheim, G. E.; McDougal, L. K.; Carey, R. B.; Fridkin, S. K. J. Am. Med. Assoc. 2007, 98, 1763.

(218) Spellberg, B.; Powers, J. H.; Brass, E. P.; Miller, L. G.; Edwards, J. E. Jr Clin. Infect. Dis. 2004, 38, 1279.

(219) Ashiuchi, M.; Yoshimura, T.; Esaki, N.; Ueno, H.; Soda, K. Biosci. Biotech. Biochem. 1993, 57, 1978 .

(220) Tanner, M. E.; Miao, S. Tetrahedron Lett. 1994, 35, 4073.

(221) Glavas, S.; Tanner, M. E. Bioorg. Med. Chem. Lett. 1997, 7, 2265.

(222) de Dios, A.; Prieto, L.; Martín, J. A.; Rubio, A.; Ezquerra, J.; Tebbe, M.; López de Uralde, B.; Martín, J.; Sánchez, A.; LeTourneau, D. L.; McGee, J. E.; Boylan, C.; Parr, T. R. Jr.; Smith, M. C. J. Med. Chem. 2002, 45, 4559. 
(223) Breault, G. A.; Comita-Prevoir, J.; Eyermann, C. J.; Geng, B.; Petrichko, R.; Doig, P.; Gorseth, E.; Noonan, B. Bioorg. Med. Chem. Lett. 2008, 18, 6100.

(224) Basarab, G. S.; Hill, P. J.; Rastagar, A.; Webborn, P. J. H. Bioorg. Med. Chem. Lett. 2008, 18,4716 .

(225) Megraud, F. Cell 2005, 123, 975.

(226) Peek, R. M. Jr. Springer Semin. Immunopathol. 2005, 2, 197.

(227) Nomura, A. M. Y.; Lee, J.; Stemmermann, G. N.; Nomura, Y.; Perez-Perez, G. I.; Blaser, M. J. J. Infect. Dis. 2002, 186, 1138.

(228) Suerbaum, S.; Michetti, P. New Engl. J. Med. 2002, 347, 1175.

(229) Lundqvist, T.; Fisher, S. L.; Kern, G.; Folmer, R. H. A.; Xue, Y.; Newton, D. T.; Keating, T. A.; Alm, R.A.; de Jonge, B. L. M. Nature 2007, 447, 817.

(230) Geng, B.; Basarab, G.; Comita-Prevoir, J.; Gowravaram, M.; Hill, P.; Kiely, A.; Loch, J.; MacPherson, L.; Morningstar, M.; Mullen, G.; Osimboni, E.; Satz, A.; Eyermann, C.; Lundqvist, T. Med. Chem. Lett. 2009, 19, 930.

(231) Newman, J. V.; Rooney, M. T.; Cederberg, C. 46th ICAAC Meeting, San Francisco, CA, USA, 2006, Abs: A-1106.

(232) Whalen, K. L.; Pankow, K. L.; Blanke, S. R.; Spies, M. A. ACS Med. Chem. Lett. 2010, 1,9 .

(233) Choi, S.-Y.; Esaki, N.; Ashiuchi, M.; Yoshimura, T.; Soda, K. Proc. Natl. Acad. Sci. U.S.A. 1994, 91, 10144.

(234) Kim, W.-C.; Rhee, H.-I.; Park, B.-K.; Suk, K.-H.; Cha, S.-H. J. Biomol. Screening 2000, 5,435 .

(235) Lamont, H. C.; Staudenbauer, W. L.; Strominger, J. L. J. Biol. Chem. 1972, 247, 5103. 
(236) Okada, H.; Yohda, M.; Giga-Haama, Y.; Ueno, Y.; Ohdo, S.; Kumagai, H. Biochim. Biophys. Acta 1991, 1078, 377.

(237) Yohda, M.; Okada, H.; Kumagal, H. Biochem. Biophys. Acta 1991, 1089, 234.

(238) Liu, L.; Iwata, K.; Kita, A.; Kawarabayasi, Y.; Yohda, M.; Miki, K. J. Mol. Biol. 2002, $319,479$.

(239) Yoshida, T.; Seko, T.; Okada, O.; Iwata, K.; Liu, L.; Miki, K.; Yohda, M. Proteins Struct., Funct. Bioinfo. 2006, 64, 502.

(240) Ohtaki, A.; Nakano, Y.; Iizuka, R.; Arakawa, T.; Yamada, K.; Odaka, M.; Yohda, M. Proteins Struct., Funct. Bioinfo 2008, 70, 1167.

(241) Ashiuchi, M.; Tani, K.; Soda, K.; Risono, H. J. Biochem. 1998, 123, 1156.

(242) Hutton, C. A.; Perugini, M. A.; Gerrard, J. A. Mol. Biosyst. 2007, 3, 458.

(243) Hutton, C. A.; Southwood, T. J.; Turner, J. J. Mini Rev. Med. Chem. 2003, 3, 115.

(244) Antia, M.; Hoare, D. S.; Work, E. J. Biochem. 1957, 65, 448.

(245) Wiseman, J. S.; Nichols, J. S. J. Biol. Chem. 1984, 259, 8907.

(246) Stenta, M.; Calvaresi, M.; Altoè, P.; Spinelli, D.; Garavelli, M.; Galeazzi, R.; Bottoni, A. J. Chem. Theory Comput. 2009, 5, 1915.

(247) Cirilli, M.; Zheng, R.; Scapin, G.; Blanchard, J. S. Biochemistry 1998, 37, 16452.

(248) Usha, V.; Dover, L. G.; Roper, D. I.; Fütterer, K.; Besra, G. S. Acta Cryst. 2009, D65, 383.

(249) Hor, L.; Dobson, R. C. J.; Dogovski, C.; Huttona, C. A.; Perugini, M. A. Acta Cryst. $\mathbf{2 0 1 0}, F 66,37$. 
(250) Pillai, B.; Moorthie, V. A.; van Belkum, M. J.; Marcus, S. L.; Cherney, M. M.; Diaper,

C. M.; Vederas, J. C.; James, M. N. G. J. Mol. Biol. 2009, 385, 580.

(251) Schleifer, K. H.; Kandler, O. Bacteriol. Rev. 1972, 36, 407.

(252) Wietzerbin, J.; Das, B. C.; Petit, J. F.; Lederer, E.; Leyh-Bouille, M.; Ghuysen, J. M. Biochemistry 1974, 13, 3471.

(253) Goffin, C.; Ghuysen, J. M. Microbiol. Mol. Biol.Rev. 2002, 66, 702.

(254) Dye, C.; Scheele, S.; Dolin, P.; Pathania, V.; Raviglione, M. C. J. Am. Med. Assoc. 1999, 282,677 .

(255) Girodeau, J.-M.; Agouridas, C.; Masson, M.; Pineau, R.; Le Goffict, F. J. Med. Chem. 1986, 29, 1023.

(256) Baumann, R. J.; Bohme, E. H.; Wiseman, J. S.; Vaal, M.; Nichols, J. S. Antimicrob. Agents Chemot. 1988, 32, 1119.

(257) Gelb, M. H.; Lin, Y.; Pickard, M. A.; Song, Y.; Vederas J. C. J. Am. Chem. Soc. 1990, $112,4932$.

(258) Lam, L. K. P.; Arnold, L. D.; Kalantar, T. H.; Kelland, J. G.; Lane-Bell, P. M.; Palcic, M. M.; Pickard, M. A.; Vederas, J. C. J. Biol. Chem. 1988, 263, 11814.

(259) Gerhart, F.; Higgins, W.; Tardif, C.; Ducep, J. B. J. Med. Chem. 1990, 33, 2157.

(260) Higgins, W.; Tardif, C.; Richaud, C.; Krivanek; M.; Cardin, A. Eur. J. Biochem. 1989, $186,137$.

(261) Diaper, C. M.; Sutherland, A.; Pillai, B.; James, M. N. G.; Semchuk, P.; Blanchard, J. S.; Vederas, J. C. Org. Biomol. Chem. 2005, 3, 4402.

(262) Williams, R. M.; Fegley, G. J.; Gallegos, R.; Schaefert, F.; Pruess, D. L. Tetrahedron 1996, 52, 1149 . 


\section{LIST OF CAPTIONS}

Scheme 1. Racemization of an amino acid.

Scheme 2. Role of PLP in the racemization of amino acids.

Scheme 3. Two-base mechanism for PLP-independent racemases.

Scheme 7. Mechanism of action of ProR.

Figure 2. A) Three-dimensional structure of the dimeric AlaR from B. stearothermophilus complexed with propionate (PDB code $2 \mathrm{sfp}^{57}$ ). B) Close up of the binding pocket. The PLP is coloured in yellow and the propionate in black. The residues involved in PLP and ligand binding, and participating to the catalytic processes are represented in capped sticks. The water molecule located in the binding pocket and likely involved in the stabilization of the complex is also highlighted.

Figure 5. Least-squares superposition, reported by LeMagueres et al. ${ }^{8}$ of $M t b A l a R$ (blue), PaoAlaR (green), and BstAlaR (red) of (a) the N-terminal domain and (b) the C-terminal domain. Reprinted with permission from ref 98, Copyright 2005 American Chemical Society.

Figure 6. A) Three-dimensional structure of human SerR complexed with malonate (PDB code $316 b^{136}$ ). B) Close up view of the binding pocket. The PLP is coloured in yellow, the malonate in black, and the manganese ion is represented as a red sphere. The nucleotide analogue phosphomethylphosphonic acid adenylate ester (AMP-PCP) molecules located at the dimer interface were extracted from the crystallographic structure of mammalian SerR from Schizosaccharomyces pombe (PDB code 1wtc ${ }^{135}$ ) and superposed to the human structure. ${ }^{136}$ The residues involved in the ligand binding and in the catalytic processes are highlighted in capped sticks.

Figure 8. Ribbon diagram of the ProR (PDB: 1W61) in complex with two PYC molecules, displayed as sticks. (a) a global view of the enzyme, (b) a close view of the catalytic site. The catalytic Cys 300 and Cys 130, are displayed below and above, respectively. A broken line shows the distances (in $\AA$ ) between the two catalytic sulfur atoms and the Pro $\alpha$ carbon.

Figure 9. Active-site interactions of ProR with proline in the transition state (see Scheme 7).

Figure 14. A) Three-dimensional structure of GluR from $H$. pylori complexed with D-Glu (PDB code $\left.2 \mathrm{jfy}^{229}\right)$. B) Close up view of the enzyme active site in the presence of the substrate and C) in the 
presence of the substrate and an inhibitor (PDB code $2 \mathrm{jfz}$ ). The catalytic cysteines are coloured in yellow, D-Glu in black and the pyrazolopyrimidinedione-based inhibitor in magenta. The residues lining the binding pocket are represented in capped sticks. The pocket vacated by the indole ring movement of Trp252 is filled with the naphthyl moiety of the inhibitor and further stabilized by interactions with Val10, Gly11 (not shown), His183, Leu186, and Trp244 (not shown). Additional interactions are formed between the isobutyl moiety and the Phe13, Ser14 (not shown), Lys17, Leu253 (not shown) residues, while the pyridyl ring substituent makes contacts with the main-chain atoms of residues Glu150 and Ser152.

Figure 16. A) Three-dimensional structure of AspR from P. horikoshii OT3 (PDB code 1jfl ${ }^{238}$ ). B) Close up view of the binding pocket. The catalytic cysteines are coloured in yellow, the residues lining the binding pocket are represented in capped sticks. 